\title{
Learning from Experience \\ -The use of structured video-assisted debriefing among nursing students
}

\section{Hui Zhang}
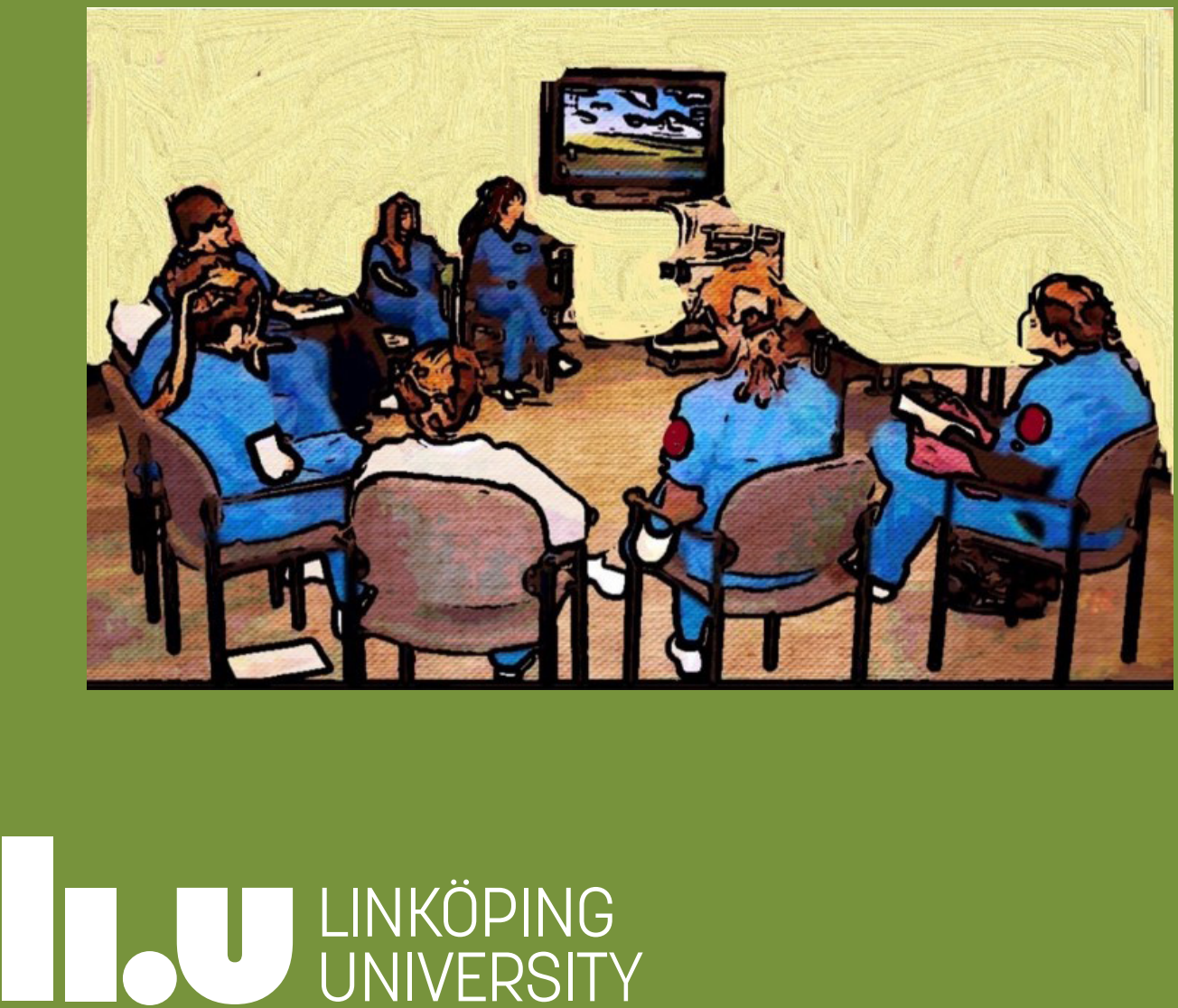


\section{Learning from Experience: The Use of Structured Video-Assisted Debriefing Among Nursing Students}

Hui Zhang

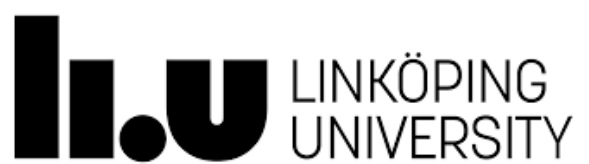

Division of Nursing Sciences and Reproductive Health, Department of Health, Medicine and Caring Sciences, Faculty of Medicine and Health Sciences, Linköping University,

Sweden 2020 
(cc) EY-NC NonCommercial 4.0 International License.

https://creativecommons.org/licenses/by-nc/4.0/

(CHui Zhang, 2020

Cover design: Hui Zhang

Published article has been reprinted with permissions.

Printed in Sweden by LiU-Tryck, Linköping, Sweden, 2020

ISBN: 978-91-7929-778-7

ISSN 0345-0082 
"Truth is not manifest in experience; it must be inferred by a process of learning that questions preconceptions of direct experience, tempers the vividness and emotion of experience with critical reflection, and extracts the correct lessons from the consequences of action."

David A. Kolb 



\section{TABLE OF CONTENTS}

ABSTRACT

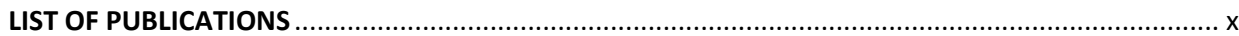

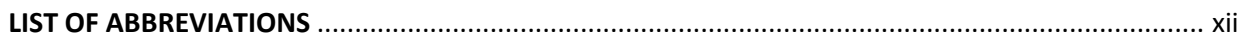

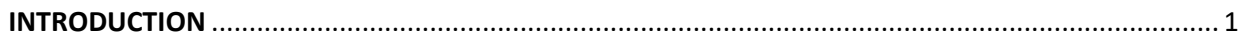

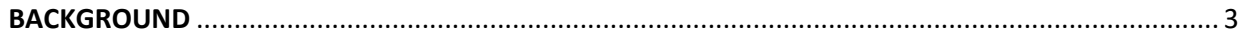

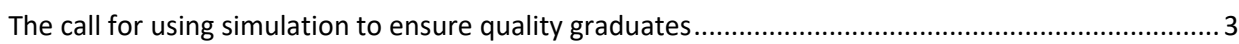

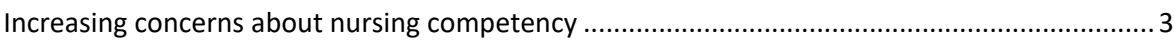

The use of simulation to enhance clinical learning experience ........................................................ 4

The call for using debriefing to enhance experiential learning ......................................................... 5

The concern about learning from experience …………………….................................... 5

The use of debriefing to transform experience into knowledge ................................................ 5

The call for establishing a best practice for video-assisted debriefing .................................................

The concern about the educational effects of video-assisted debriefing ...................................... 7

The need of a framework to enhance video-assisted debriefing .................................................. 7

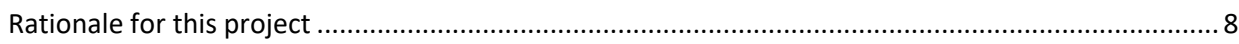

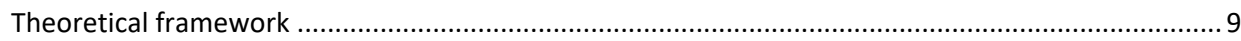

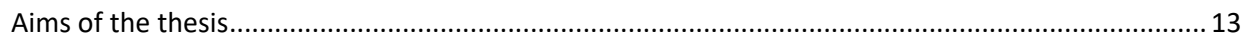

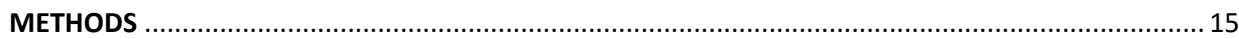

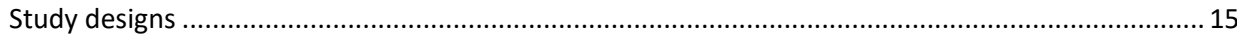

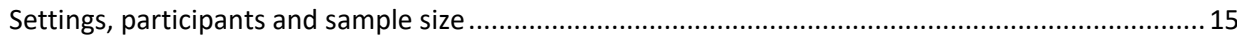

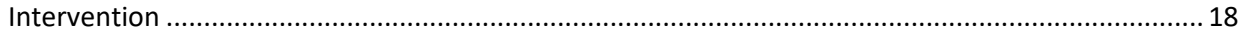

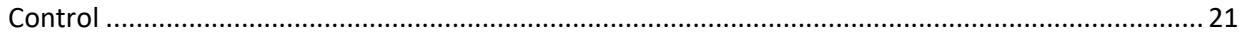

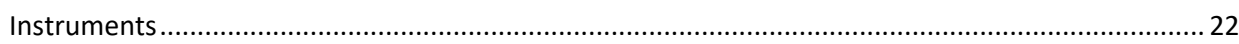

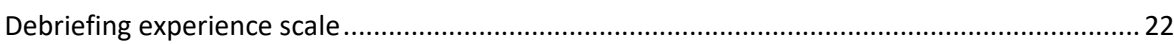

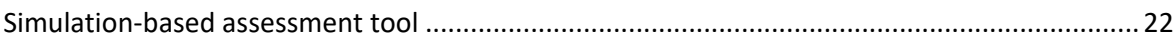

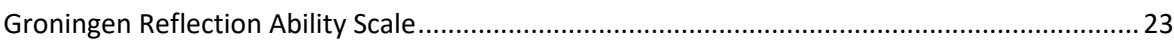

Debriefing Assessment for Simulation in Healthcare ............................................................... 23

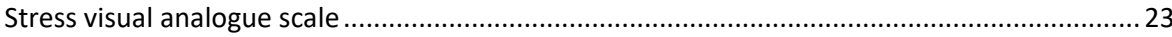

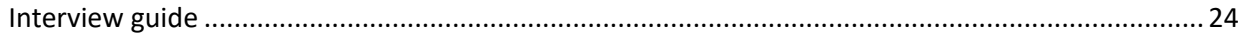

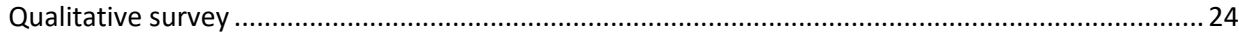

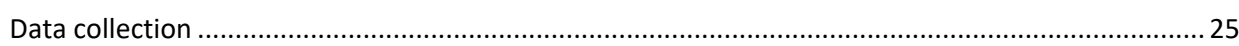

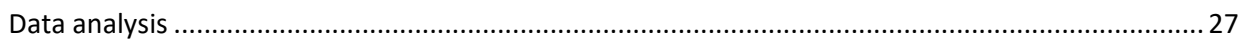

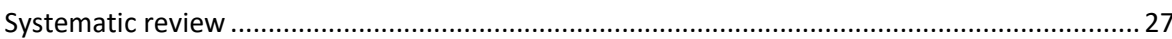




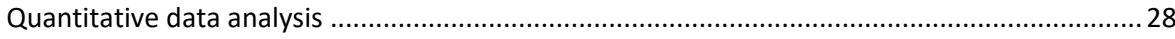

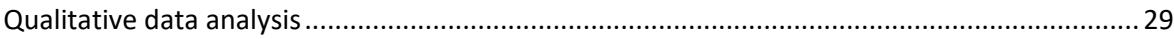

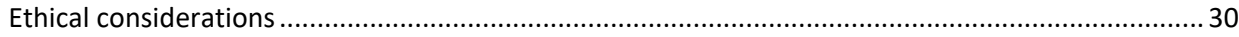

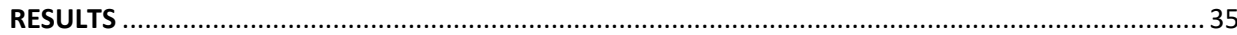

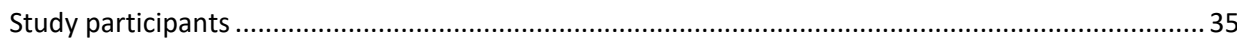

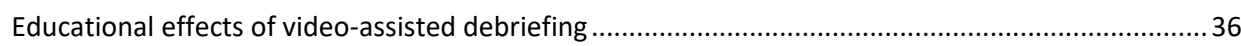

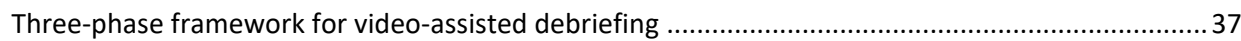

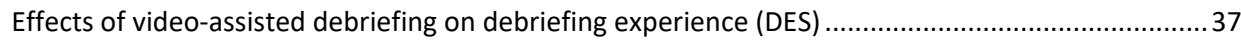

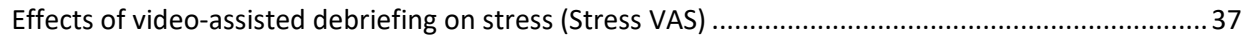

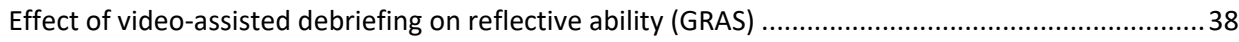

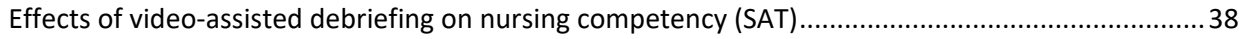

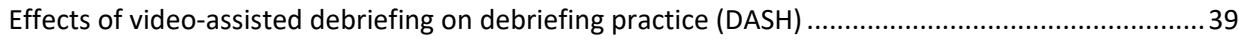

Student perspectives and facilitator perceptions of video-assisted debriefing ...............................40

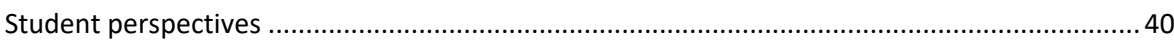

Journey from verbal debriefing to video-assisted debriefing ..............................................40

Praise and criticism of video-assisted debriefing .......................................................... 40

The road to successful video-assisted debriefing ..................................................... 41

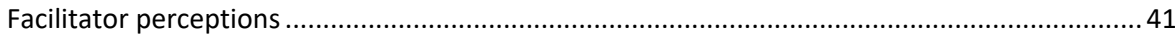

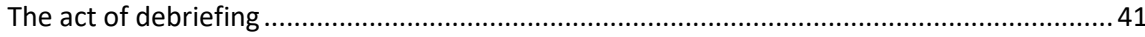

The crux of video-assisted debriefing ........................................................................ 41

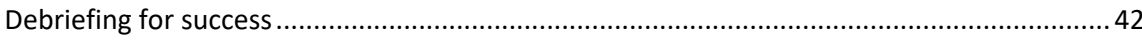

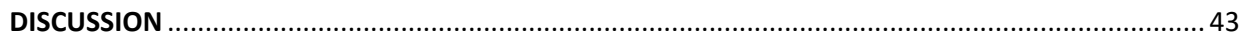

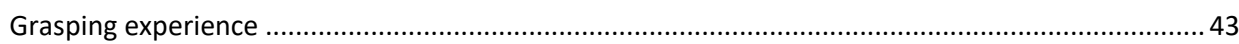

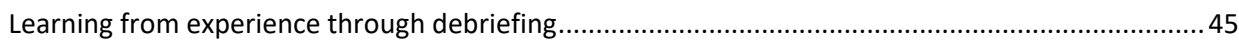

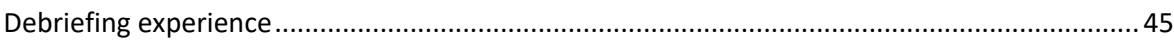

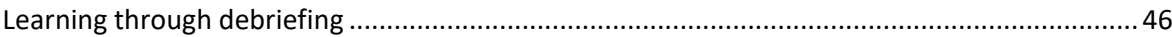

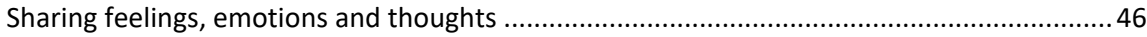

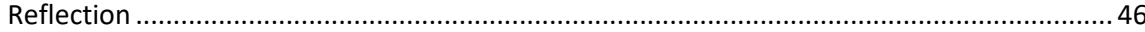

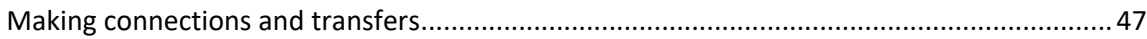

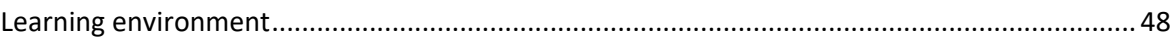

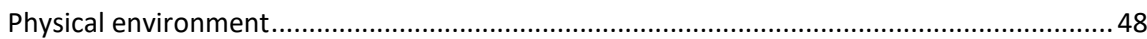

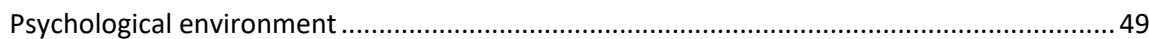

Facilitators' debriefing practices ................................................................................ 51

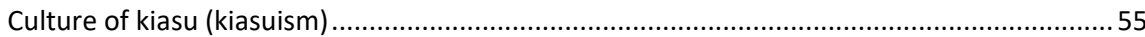

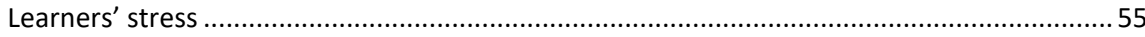




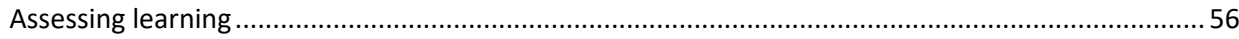

Challenges associated with video-assisted debriefing.......................................................56

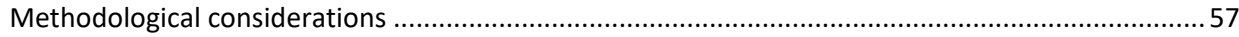

Internal and external validity of quantitative studies......................................................... 57

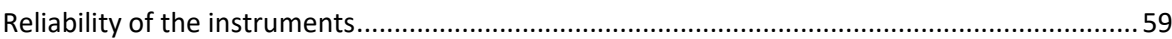

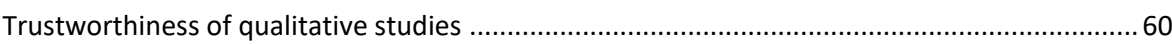

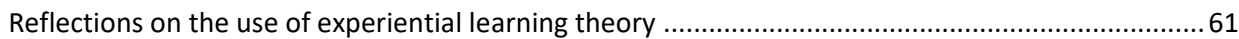

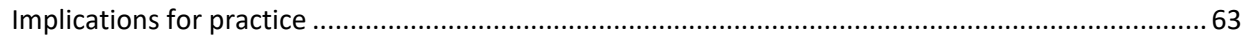

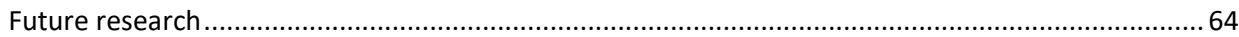

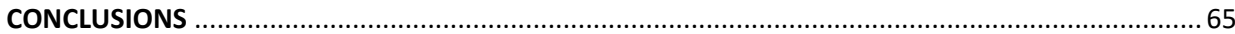

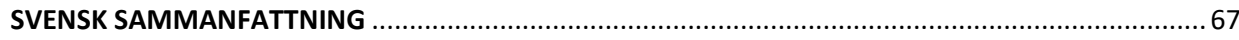

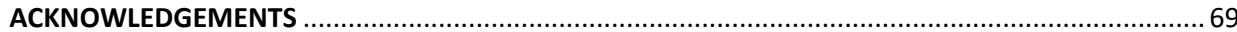

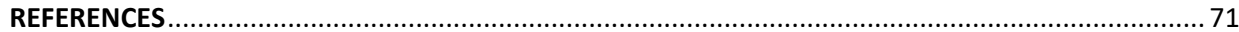

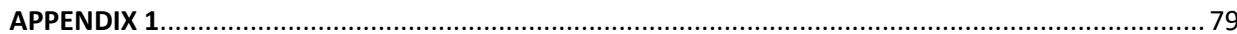

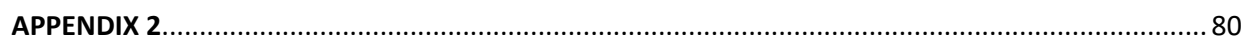

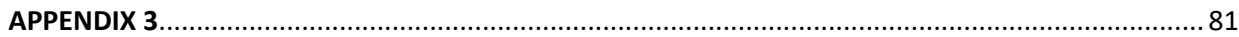

APPENDIX 4

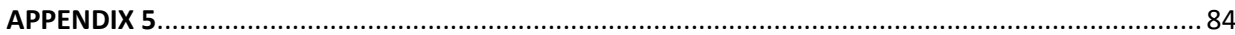

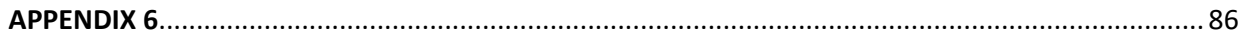

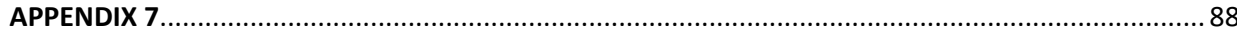




\section{LIST OF FIGURES}

Figure 1: Experiential learning theory

10

Figure 2: Three-phase video-assisted debriefing integrated with experiential learning theory

\section{LIST OF TABLES}

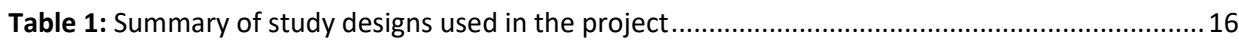

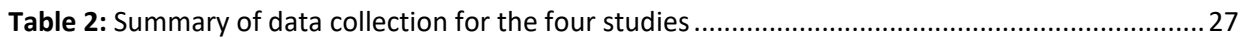

Table 3: Example of data analysis in Study III using thematic analysis................................................ 30

Table 4: Example of data analysis in Study IV using qualitative content analysis .................................. 30

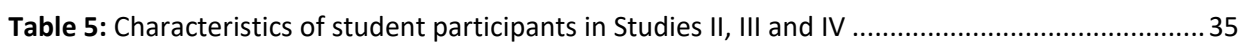

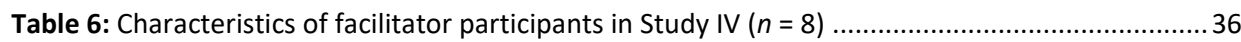

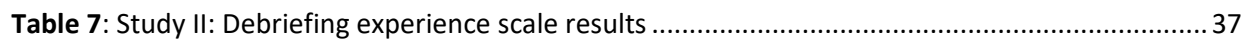

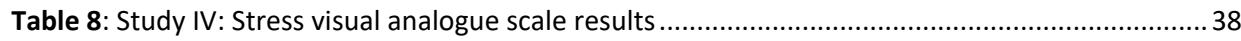

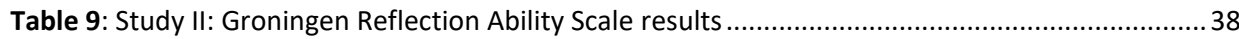

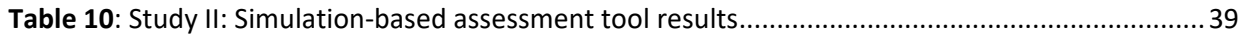

Table 11: Overview of themes and categories emerging from Studies III and IV ...............................42 


\section{ABSTRACT}

Background: Simulation, which enhances experiential learning by creating learning experiences, has been recognised as an effective pedagogy in current health professional education. As an integral element of simulation, debriefing contributes to transforming simulated experiences to new knowledge. Video-assisted debriefing (VAD) refers to the addition of audiovisual capture and review to traditional verbal debriefing (VD). However, despite VAD being considered the gold standard of simulation, the evidence for its educational outcomes is mixed and its best-practice use remains unclear.

Aims: The aims of this thesis are to develop a VAD framework; to test its effects on prelicensure nursing students' experiences, reflective abilities and nursing competencies following high-fidelity simulation in comparison with $\mathrm{VD}$; and to explore facilitator perceptions and practices of VAD.

Design and methods: Four studies using different research designs were conducted for this thesis. Study I was a systematic review in which the characteristics of existing VAD practices in health professional education were synthesised and their effectiveness on learners' responses, learning and behaviours were evaluated. Study II was a proof-of-concept study in which a three-phase framework for VAD was developed and its effects on nursing students' debriefing experiences, reflective abilities and nursing competencies were tested using a pretest-posttest design. Study III adopted a qualitative design, using focus groups and thematic analysis to explore nursing students' experiences and perspectives of structured VAD. Study IV employed a mixed methods research design to investigate the effects of a three-phase VAD on nursing students' debriefing experiences and perceived stress as well as facilitators' perceptions and debriefing practices.

Results: Study I showed that the outcomes of existing VAD practices are comparable with those of VD in terms of learners' experiences, attitudes and performance, but not knowledge acquisition. There is currently mixed evidence for the benefits of using videos in debriefing, explaining the absence of best practice. Preliminary results from Study II show that the threephase VAD significantly improved students' debriefing experiences $(p<0.001)$, reflective abilities $(p<0.01)$ and nursing competencies $(p<0.001)$. Study III revealed the emotional rollercoaster experienced by nursing students undergoing VAD, ranging from unwillingness and the fear of being judged, followed by stress and defensiveness to appreciation and 
satisfaction. Most students agreed that VAD provided a desirable learning experience, with few preferring not to receive peer feedback following the video review. Study IV demonstrated that VAD improved nursing students' debriefing experiences $(p=0.01)$ but caused stress comparable to that caused by VD. Repeated exposure to VAD significantly reduced stress levels. The use of VAD also enhanced facilitators' perceptions and debriefing practices.

Conclusions: In this thesis, a three-phase framework for VAD was developed. Its educational outcomes in terms of improving nursing students' debriefing experiences, reflective abilities and competencies following high-fidelity simulation were confirmed. The stress experienced by nursing students was comparable to that of VD. The emotional rollercoaster experienced by students participating in VAD was in contrast to the negative emotions reported in other studies, providing some clarity to the inconsistent evidence regarding learners' experiences of VAD and contributing to its best practice. This thesis also demonstrates that the three-phase VAD has the potential to enhance facilitators' debriefing practices in student-centred learning.

Keywords: simulation, video-assisted debriefing, nursing students, debriefing experience, reflective ability, debriefing practice. 


\section{LIST OF PUBLICATIONS}

This thesis is based on the following papers, which are referred to by their Roman numerals in the text.

I. Zhang, H., Mörelius, E., Goh, S. H. L., \& Wang, W. (2018). Effectiveness of VideoAssisted Debriefing in Simulation-Based Health Professions Education: A Systematic Review of Quantitative Evidence. Nurse Educator, 44(3), E1-E6. doi:10.1097/nne.0000000000000562

II. Zhang, H., Mörelius, E., Goh, S. H. L., \& Wang, W. (2020). Developing a structured three-phase video-assisted debriefing to enhance prelicensure nursing students' debriefing experience, reflective ability and professional competency: a proof-ofconcept study. Nurse Education in Practice, 44, 102740.

doi:10.1016/j.nepr.2020.102740

III. Zhang, H., Goh, S., Wu, X., Wang, W., \& Mörelius, E. (2019). Prelicensure nursing students' perspectives on video-assisted debriefing following high fidelity simulation: A qualitative study. Nurse Education Today, 79, 1-7. doi:10.1016/j.nedt.2019.05.001

IV. Zhang, H., Wang, W., Goh, S. H. L., Wu, X. V., \& Mörelius, E. (2020). The impact of a three-phase video-assisted debriefing on nursing students' debriefing experiences, perceived stress and facilitators' practices: A mixed methods study. Nurse Education Today, 90, 104460.

doi:10.1016/j.nedt.2020.104460 


\section{LIST OF ABBREVIATIONS}

CVI Content validity index

DASH Debriefing Assessment for Simulation in Healthcare

DASH-IV Debriefing Assessment for Simulation in Healthcare-Instructor Version

DASH-SV Debriefing Assessment for Simulation in Healthcare-Student Version

DES Debriefing experience scale

ELT Experiential learning theory

GAS Gather-analyse-summarise

GRAS Groningen Reflection Ability Scale

HFS High-fidelity simulation

ICC Intraclass correlation coefficient

JBI Joanna Briggs Institute

NUS National University of Singapore

PRISMA Preferred Reporting Items for Systematic Reviews and Meta-Analyses

SAT Simulation-based assessment tool

SBL Simulation-based learning

VAD Video-assisted debriefing

VAS Visual analogue scale

VD Verbal debriefing 


\section{INTRODUCTION}

With advances in technology and increasing concerns for patient safety, the use of simulation in health professional education has become prevalent. Simulation has three main components: prebriefing, the simulated scenario and debriefing. Simulated scenarios provide realistic clinical experiences, while debriefing aids in transforming that experience into knowledge. There is emerging interest in how to maximise learning from simulation, attracting attention to the educational outcomes of various debriefing approaches. In an effort to improve the practice of video-assisted debriefing (VAD) in simulation-based learning (SBL), this thesis aims to develop a framework for VAD, examine its effects on nursing students' learning and explore how it may contribute to best practice.

My research interest in debriefing, specifically in VAD, has grown since 2014, when I first began my teaching career as a nursing tutor at the Alice Lee Centre for Nursing Studies at the National University of Singapore (NUS). Throughout my time in laboratory teaching and simulation facilitation, I have had the opportunity to interact with nursing students and experts in the areas of pedagogy, technology and simulation. Nursing students are often required to attend simulation in place of certain parts of their clinical placements, a practice that is not exclusive to Singapore. In a society that accentuates the value of meritocracy and elitism, nursing students are greatly influenced by the local kiasu culture and are more likely to embrace technology-enhanced learning experiences to fulfil their ambitions for academic success. These unique contexts, valuable experiences and interactions made me excited and curious about how to incorporate videos into debriefing practice to further enhance students' learning experiences and outcomes. Since then, I have been searching for an opportunity to advance my knowledge and practice.

In 2017, Linköping University received the ASPIRE award from the Association for Medical Education in Europe in recognition of its international excellence in medical education and simulation. In the same year, I was honoured and gratified to become a $\mathrm{PhD}$ student at Linköping University, which offered me the opportunity to satisfy my curiosity and ambition to contribute to VAD best practice in nursing education by building a theoretical foundation, conducting empirical research and disseminating the findings via publications and international conferences. 


\section{BACKGROUND}

\section{The call for using simulation to ensure quality graduates}

\section{Increasing concerns about nursing competency}

Emerging trends in global health care have highlighted the necessity of professional competency in patient safety and quality care. Nursing competency refers to the set of attributes demonstrated by nurses when fulfilling their roles and responsibilities in patient care, including their values, knowledge, attitudes and skills (Takase \& Teraoka, 2011) as well as their ability to make sound decisions (Karami et al., 2017). Given the high prevalence of clinical incidents, decreases in nursing competency, which are associated with undesirable consequences such as adverse patient outcomes, prolonged hospital stays and nurses' frustration and attrition, has caused great public concern (Heydari et al., 2016).

The increased demand for quality nursing care has put nurses under enormous pressure. This is especially so for new graduates, who have had insufficient exposure to direct patient care (Heydari et al., 2016). Educational institutions have made efforts to increase nursing students' exposure to clinical environments and real patients by scheduling clinical placements each semester to develop students' knowledge, skills and perceptions of their future roles as registered nurses. Nonetheless, the evidence shows that the quality of clinical placements is compromised by a vicious cycle of nursing shortages, expanded student recruitments and scarce placement sites in many countries (Karami et al., 2017). The shortage of nurses at clinical sites has required more graduates to join the nursing workforce, leading to expanded student recruitment and an increased demand for more clinical sites and nurses for student supervision. However, adding student supervision to routine nursing care has dramatically increased nurses' workloads and stress levels, compromising the quality of patient care and student education in terms of theory-practice gaps, skills acquisition and clinical reasoning (Roberts et al., 2019). Further, an increasing awareness of ethical practice and patient rights has also hindered nursing students from directly engaging in patient care (Takase \& Teraoka, 2011). Consequently, these obstacles have affected the quality of clinical learning and students' competence levels. However, it is possible to enhance nursing competency by improving clinical learning experience. 


\section{The use of simulation to enhance clinical learning experience}

The challenges facing the nursing profession in the current complex healthcare context have required nursing education to shift towards competency-based, student-centred learning. To fulfil the triad of satisfactory clinical learning, adequate clinical sites and quality patient care, healthcare providers, faculty and researchers have been working together for decades to seek solutions. Technological advancements have reformed teaching modalities and provided some solutions for the challenges in health professional education, including the use of simulation (Rosen, 2013). Since then, simulation has flourished in health professional education, as shown by the exponential rise in its design, application and research. The most powerful impetus for integrating simulation into nursing curricula has come from the National League for Nursing (Rizzolo et al., 2015), with the goal of preparing nursing students and graduates for practice in a complex healthcare environment.

Simulation is a teaching strategy used to 'replace or amplify real experiences with guided experiences, often immersive in nature, that evoke or replicate substantial aspects of the real world in a fully interactive fashion' (Gaba, 2004, p. i2). With its unique feature of bringing learning experiences with real-world counterparts into the classroom, simulation is currently being used as an alternative to clinical placement because, to a certain extent, it fulfils the triad by allowing students to make decisions and practise their skills in simulated clinical situations without the risk of harming actual patients (Bland \& Tobbell, 2016). The evidence shows that in health professional education, replacing part of clinical placement with simulation not only ensures the quality of and standardises clinical learning, it also provides opportunities to experience rare clinical situations (Roberts et al., 2019). Similarly, in nursing education, simulation has been widely accepted as an alternative to a certain number of clinical hours to produce well-rounded graduates, overcome the shortage of nurses and clinical sites and respond to the call for a safe learning environment (Armstrong et al., 2009; Hall \& Tori, 2017). To summarise, simulation enables students to understand predefined concepts, practise critical thinking and build confidence in decision-making in a less threatening environment.

Nevertheless, simulation has inherent limitations because it cannot fully represent real-world clinical settings (Lederman, 1984). Currently, evidence for the effects of simulation on patient safety and clinical outcomes is lacking. Thus, a review of the learning process in simulation and its components of prebriefing, scenario and debriefing is called for (Rosen, 2013). 


\section{The call for using debriefing to enhance experiential learning}

\section{The concern about learning from experience}

Learning has been described as 'an enduring change in one's behaviour or capability to behave, which must result from some sort of practice or experience' (Shuell, 1986, p. 412). Experiential learning refers to learning from experience in which people learn about reality by directly sensing and touching it rather than hearing or reading about it (Kolb, 2015). Experience is described as the full response to a situation or event, involving what the individual believes, feels, perceives, decides and does in that moment and immediately afterwards (Boud et al., 2013). In experiential learning theory (ELT), experience is viewed as the basis of learning. However, learning does not occur automatically with experience as experience provides limited information from which to learn and may include subjectivity, bias and errors (Kolb, 2015).

In appraising this situation, Kolb (2015) suggests that to obtain the appropriate lessons from experience, learners should be subject to a series of learning activities, including questioning their own perceptions of the direct experience, mitigating their emotions with critical reflection and deriving objective knowledge from the outcomes of their behaviours. Reflecting on the experience is thought to be essential in learning from experience and is the cornerstone of experiential learning (Lavoie et al., 2017). Reflection is an important cognitive process that requires the learner to return to the experience (e.g. replaying the experience in the mind), diffuse their feelings (e.g. being motivated by positive feelings and removing negative feelings) and ponder the experience (e.g. integrating new concepts to recreate their frame and validating and internalising the new frame) (Boud et al., 2013). Although the task of reflection may appear straightforward, not everyone can spontaneously transform experience into knowledge. The key feature of experiential learning is to examine the experience individually or collectively through reflection, discussion and reframing, which has facilitated the evolution of debriefing.

\section{The use of debriefing to transform experience into knowledge}

Debriefing is 'a facilitated or guided reflection in the cycle of experiential learning' (Fanning \& Gaba, 2007, p. 116). Historically, debriefing originates from military campaigns and war games in the 1940s (where it was known as 'after-action reviews') and the aviation industry in the 1970s (where it was known as 'crew resource management') (Gardner, 2013). Debriefing originally functioned as a performance critique, with judgemental comments used to address 
problems and errors, leading to resentment and poor acceptance. Debriefing has also been used in experimental psychology following the deception of participants for the purpose of dehoaxing to eliminate the negative consequences of deception (Fanning \& Gaba, 2007). Since then, the concept of debriefing has evolved, and it has subsequently been developed as a teaching strategy in the educational setting to enable students to process information and provide an educational experience to facilitate learning.

Evidence supports the central role of debriefing in simulation by demonstrating that new knowledge is only constructed in the process of debriefing (Bland \& Tobbell, 2016) and that it is unethical to conduct simulation without debriefing (Kriz, 2010). Dieckmann et al. (2009) conclude that regardless of the type of simulator used, post-simulation debriefing remains the key for transforming experience into learning. Although abundant simulation literature focuses on debriefing, research concerning undergraduate nursing students' full experiences of VAD is limited, warranting studies to explore learners' debriefing experiences by analysing their thoughts, feelings, learning outcomes, and connection-making in learning as well as the facilitator's guidance throughout the debriefing (Reed, 2012).

Debriefing goes beyond merely having a simple chat or receiving general feedback about what took place during an experience. Feedback refers to the comments provided by an agent (e.g. faculty or peer) to individuals regarding certain aspects of their performance or perceptions (Hattie \& Timperley, 2007). In contrast, debriefing involves a guided dialogue between learners and the facilitator to analyse the experience and what could be learned from that experience. It distinguishes itself from one-sided evaluative feedback by requiring two-way communication between the facilitator and learners to collectively make sense of the experience. In other words, it is kind of 'social practice', which requires people to purposely interact with others and their surroundings to create change (Phrampus \& O’Donnell, 2013). There is debate about VAD regarding who should facilitate it, how to facilitate it and what outcomes should be assessed (Hall \& Tori, 2017). Moreover, reflective debriefing has not been fully explored because previous studies have merely reported the outcomes of debriefing rather than examining the process itself. Reflective debriefing requires learners to deliberately analyse the problematic situations in the experience, critically reflect on their thoughts and actions and engage in a collective discourse to gain insights and improve their future practice (Lavoie et al., 2017). Reflection is the hallmark of debriefing, and the ability to critically reflect enables nurses and students to adapt to professional functioning in clinical settings. Hence, it is 
imperative to enhance learners' reflective abilities from three dimensions: self-reflection, empathetic reflection (thinking about the position of others) and reflective communication (expressing when receiving feedback) (Aukes et al., 2007).

\section{The call for establishing a best practice for video-assisted debriefing}

\section{The concern about the educational effects of video-assisted debriefing}

Advances in technology have made audiovisual capture and replay possible, contributing to the advent of VAD. VAD refers to the addition of a video review to support learning in debriefing. Learners are able to view their performance and listen to their conversations to enhance reflection and change (Krogh et al., 2015). Modes of VAD vary from basic (smartphone or camcorder) to advanced (pan-tilt-zoom camera system with microphones and a wall-mounted monitor). Compared with VD, VAD is more resource intensive because it needs cameras, video recorders and data storage; thus, it is important to evaluate its educational effects.

Although VAD is viewed as the gold standard for simulation (Levett-Jones \& Lapkin, 2014), there is insufficient evidence to substantiate this assumption. Studies showing positive outcomes for VAD have reported that it is more effective than VD in improving technical and non-technical skills, attitudes, performance and response times (Oseni et al., 2017; Ruesseler et al., 2017). Other studies have found that VAD offers similar benefits to VD in terms of performance, behaviours and processing skills (Beaird et al., 2017; Coolen et al., 2012). In contrast, several studies have found that VAD is less effective than VD in terms of knowledge retention (Boet et al., 2011) but can induce stress, anxiety and intimidation (Chronister \& Brown, 2012; Ha, 2014). Several reviews on the overall effects of VAD have concluded that both VAD and VD are effective and comparable in terms of learning outcomes (Cheng et al., 2014; Hall \& Tori, 2017; Levett-Jones \& Lapkin, 2014). The diversity of VAD structures, the heterogeneity of outcome measures and the mixed findings make it difficult to draw conclusions on its best practice, warranting future research.

\section{The need of a framework to enhance video-assisted debriefing}

There is more than one way of conducting debriefing, and various approaches are reported in the simulation literature. Given the vast range of debriefing methods and the inconclusive findings of VAD studies, scholars have called for a VAD framework based on the argument that structured debriefing may serve as an empirical referent for best educational practice to 
promote higher-order thinking and meaningful learning (Dreifuerst, 2009; Waznonis, 2016). Numerous debriefing frameworks have been published in the literature, but limited studies have been conducted specifically on VAD because of the broad consensus that video is merely an adjunct to debriefing (Yeun et al., 2019). There is a need to improve video use in debriefing, calling for a more sophisticated framework to guide the process of VAD to aid learners in obtaining a true picture of their performance prior to change.

\section{Rationale for this project}

Globally, simulation has been widely accepted as an indispensable teaching modality in the educational preparation of health professionals, including nurses, at the tertiary level. As an essential component, debriefing helps learners to transform experience into knowledge. Conventionally, debriefing takes place through group discussions and facilitator feedback, without reference to audiovisual records. With technological advancements, video reviews of recorded activities have been added to traditional VD to form a contemporary debriefing approach VAD to facilitate experiential learning.

Current evidence shows that the extensive use of simulation has not shown significant effects on patient safety and clinical outcomes, attracting attention towards reviewing the learning process in simulation and debriefing. Moreover, the literature reveals that reflective debriefing has not been fully explored because previous studies have only focused on its outcomes rather than the process. It is known that learning does not occur automatically from experience without reflection, and VAD provides learners the opportunity to directly reflect on their performance and observe their thoughts behind action. Nevertheless, negative emotions (e.g. anxiety, stress and intimidation) invoked by video use have mitigated the positive effects of $\mathrm{VAD}$ on learning and informed the absence of its best practice.

Despite the numerous published debriefing models and frameworks, those developed specifically for VAD to optimise the use of video or its internal structure (e.g. how to select video clips or how to elicit information or questions) are limited. The treatment of video as an adjunct to debriefing coupled with a lack of a proper guiding framework have made it difficult to ascertain the educational effects of $\mathrm{VAD}$, warranting research to improve and refine this practice in SBL. 


\section{Theoretical framework}

Learning refers to the acquisition and modification of values, knowledge, skills, attitudes, behaviours and strategies, and its hallmark is behavioural change or the capacity to change a certain behaviour (Schunk, 2012). Given its dynamic and changing nature, learning is perceived differently in terms of its causes, processes and outcomes, which are reflected in theories of learning.

This research project adopted Kolb's (2015) ELT, a holistic theory of learning that is extensively used across diverse disciplines, including nursing, relating to teaching strategies, educational activities and learning outcomes. ELT is deeply rooted in the previous experiential works of Dewey, Lewin and Piaget, and its operational adequacy and pragmatic utility in simulation has been well established in the literature (Poore et al., 2014). ELT integrates two types of grasping experience (concrete experience and abstract conceptualisation) and two types of transforming experience (reflective observation and active experimentation). According to ELT, for effective learning to occur, the learner must travel through the four learning modes of concrete experience (via apprehension), reflective observation (via intention), abstract conceptualisation (via comprehension) and active experimentation (via extension) (see Figure 1). Apprehension refers to one's grasp of experience through sensory perception (feeling) and direct experience with the world (doing), while comprehension requires one to gather knowledge and experience through conceptual interpretation (e.g. to break down experience into meaningful events) and symbolic representations (e.g. to place the meaningful events within a symbolic system of culture and society) (Kayes, 2002). Transformation via intention requires one to reflect internally on one's knowledge, while extension involves manipulation of the external world (p. 66-67).

Learning is perceived as a continuous process in ELT. In this project, I propose that through simulated scenarios, students are able to grasp experience and examine knowledge by responding to patients and peers in a simulated clinical situation. Subsequently, through VAD, students are able to visualise and reflect on their thoughts and actions, understand the context related to the simulated scenario, comprehend general principles and consequently form a new frame for future practice. In applying ELT, the simulation forms the basis of learning (concrete experience), while the video review allows for revisiting the scenario and reflecting on one's actual performance (reflective observation). Through peer feedback and the guidance of the 
facilitator, students are able to make sense of that experience and create new knowledge (abstract conceptualisation) and ultimately devise an action plan for change (active experimentation).

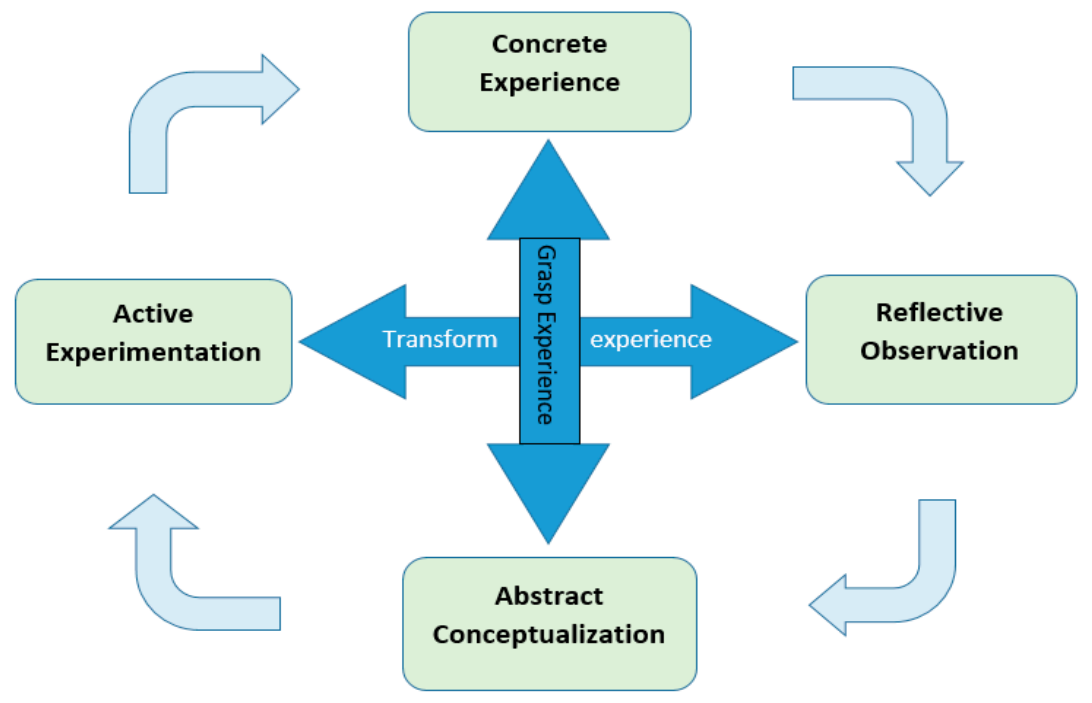

Figure 1: Experiential learning theory (adapted from Kolb, 2015).

In contrast to ELT, behavioural theories view learning merely as a response to stimuli, and learners are portrayed as passive recipients of information, reacting to stimuli and executing commands rather than taking an active role in exploring the environment (Winn, 1990). Although competency-based learning is best explained by behaviourism (Hean et al., 2009), researchers have raised concerns about the use of a single behavioural aspect to explain the complex phenomenon of learning. For example, Aliakbari et al. (2015) explain that behaviourists focus strongly on the physical aspect without consideration of learners' knowledge levels and mental processes; and Schunk (2012) warns that behavioural theories negate learners' personal influences (e.g. subjective feelings and emotions) and interactions with the environment (e.g. self-regulation and motivation) in the learning process.

Unlike behavioural theories, cognitive theories tend to emphasise human functioning over external stimuli by describing learning as a purposive mental process of understanding, information processing, concept formatting and assimilating. Cognitive theorists believe that learning is not only an outcome of behavioural change - it also reflects the change in capacity to respond and react appropriately (Aliakbari et al., 2015). According to Bandura (1986), 
learning can occur vicariously through observing others' behaviours, which challenges the beliefs of behavioural theorists. Although social cognitive theory shares some prominent postulations about learning (e.g. the dynamic interplay between people, behaviours and environments), the philosophical assumption underlying this theory is primarily objectivism, and it calls for a more constructivist method to understand learning (Ertmer \& Newby, 2013). Constructivism supports the claim that an understanding of reality depends on the interpretation of one's own experiences rather than the transference of knowledge from the external world into memory (Ertmer \& Newby, 2013). However, constructivist theories have also been criticised because of their ambiguity in explaining how and when knowledge construction occurs (Schunk, 2012).

In contrast to cognitive theories, which focus on personal functioning over the social environment, or behavioural theories, which negate cognition and subjective feelings in the learning process, ELT offers a more holistic and structured view of learning by integrating experience, perception, cognition and behaviour (Kolb, 2015). Hence, ELT was appropriate to use in this research project. Although ELT has been criticised for focusing too much on individual learning and downplaying the effects of the social environment in cognition (Mughal \& Zafar, 2011), I believe that the social nature of debriefing practice may help to mitigate the drawbacks of this model, and I have reflected on the use of ELT and its pros and cons after completion of this project. 


\section{Aims of the thesis}

The goal of this project was to enhance student learning by improving the practice of VAD. The overall aims were to develop a framework for VAD, to test and compare its effects on prelicensure nursing students' debriefing experiences, reflective abilities and nursing competencies with VD (without video), and to explore its potential impact on facilitators' perceptions and practices following high-fidelity simulation (HFS).

The specific aims of the four studies are as follows:

I. To synthesise the characteristics of existing VAD practices within health professions education, evaluate the effect of VAD on learners' reactions, learning and behaviours compared with VD (where possible), and identify the effective elements of VAD associated with desired outcomes.

II. To develop a three-phase VAD framework and test its preliminary effects on prelicensure nursing students' debriefing experiences, reflective abilities and professional competencies following HFS.

III. To explore prelicensure nursing students' experiences and perspectives of VAD following HFS.

IV. To evaluate the effects of the three-phase VAD on nursing students' debriefing experiences and perceived stress and facilitators' perceptions and debriefing practices following HFS. 


\section{METHODS}

\section{Study designs}

This thesis includes four studies using different research designs: a systematic review (Study I), a quantitative study (Study II), a qualitative study (Study III) and a mixed methods study (Study IV) (see Table 1). The selection of research design and methods was guided by the research questions. With respect to the current project, the main problem was to understand the nature and status quo of contemporary VAD practices in health professions education. This goal was accomplished by carrying out a systematic review (Study I), which built the foundation for the following studies. Based on the findings of Study I, a three-phase framework was developed for the facilitation of VAD in Study II, and its preliminary effects on predefined learning outcomes were pilot tested on a group of nursing students using a pretest-posttest design. Subsequently, in an effort to further explore the effects of this developed three-phase framework, a qualitative design using focus groups was adopted in Study III to obtain an indepth understanding of nursing students' experiences and perceptions of VAD. In Study IV, a multilevel mixed methods research design was used to examine the effects of the three-phase VAD on nursing students' debriefing experiences and perceived stress and facilitators' debriefing practices and perceptions.

\section{Settings, participants and sample size}

This research was conducted at the Centre of Healthcare Simulation, which is part of the medical teaching facility at a local university in Singapore. The centre includes a simulated operating theatre, intensive care unit, emergency room, acute paediatrics ward, labour ward, eight clinical wards, two procedural rooms and 60 consultation rooms. With a suite of highfidelity simulators and task trainers and a pool of trained standardised patients, the Centre of Healthcare Simulation aims to provide a safe learning environment for both medical and nursing students in which to learn and practise clinical skills and procedures and receive interprofessional training. The university offers a 3-year bachelor's degree in nursing. Hence, all third-year nursing students were considered prelicensure nursing students in this project. Nursing simulation was mainly conducted in the simulated clinical wards, which were fully equipped with computer-programmed high-fidelity simulators, pan-tilt-zoom cameras and wall-mounted televisions. 


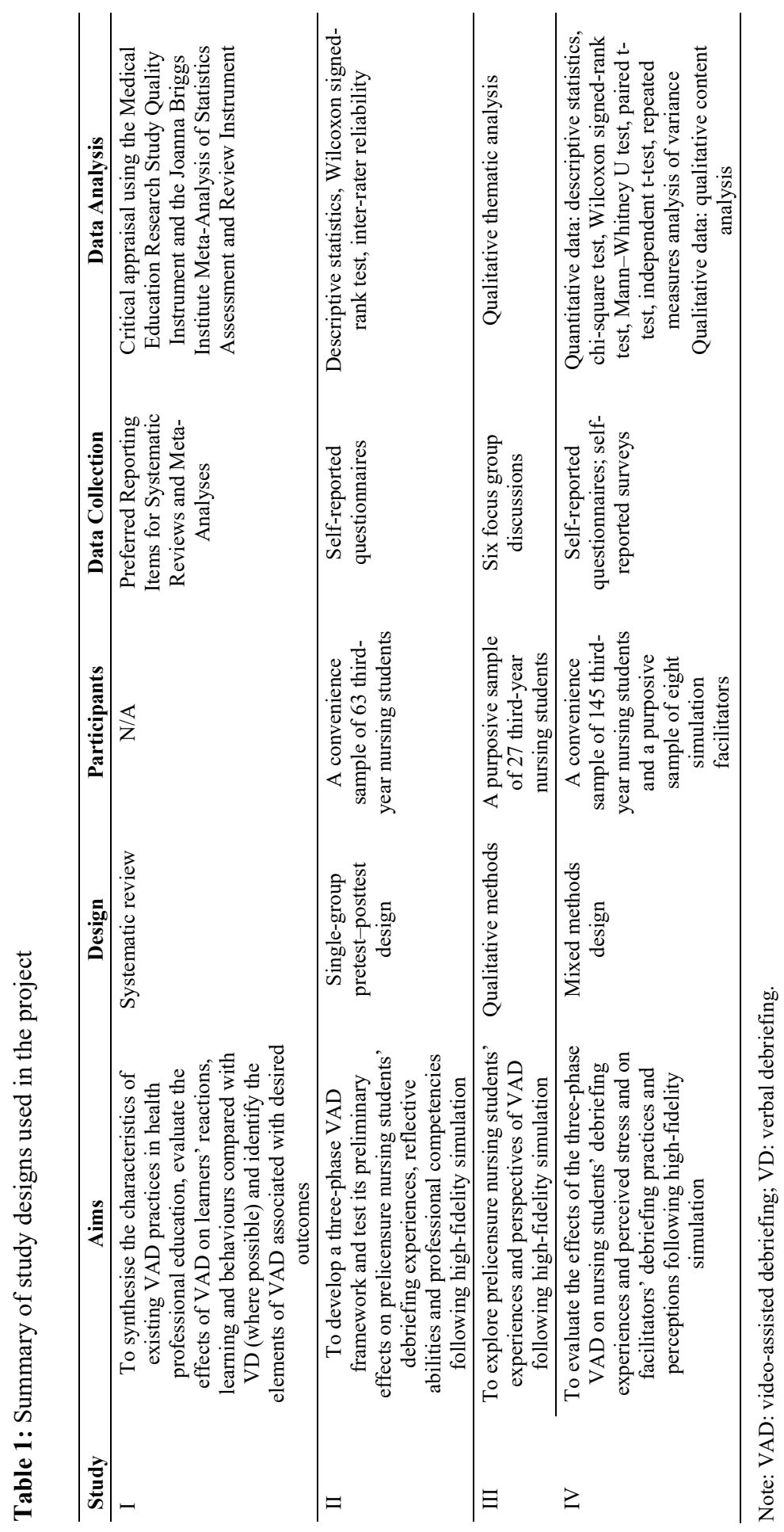


Study I was a systematic review, so no participants were required. In Study II (a pilot quantitative study), 63 third-year nursing students were recruited using convenience sampling through the dissemination of pamphlets in classrooms. Although convenience sampling may cause self-selection bias, it is the most commonly used method in research (Polit \& Beck, 2018). The sample size of 63 was estimated based on previous pilot studies (Chronister \& Brown, 2012; Grant et al., 2010) and Sim and Lewis's (2012) recommendation that a sample size of at least 50 for a pilot study provides a high level of confidence. Eligibility criteria for Study II included: (1) third-year undergraduate nursing students in the academic year 2017/2018; (2) aged above 21 years; (3) first-time enrolment in the module Medical-Surgical Nursing III (NUR3113); and (4) previous experience of VD. The NUR3113 module is conducted in the first semester of each academic year for third-year nursing students (see Appendix 1). Students who declined to consent to video recording were excluded, as were those who were repeating the module to reduce the threat to internal validity arising from prior exposure to the same simulation activities, which may have caused a diffusion effect. Prior to participation in the study (in Week 8 of semester), students had learned neurological assessment, airways management, cardiopulmonary resuscitation, defibrillation using an automated external defibrillator, emergency intravenous drug administration and communication skills using the SBAR (Situation-Background-Assessment-Recommendations) tool in the NUR3113 module through lectures, tutorials and laboratory practice (Weeks 1 to 7 ).

In Study III, a purposive sample of 27 third-year nursing students in the academic year 2017/2018 who had participated in Study II were invited to participate in focus group discussions, which consisted of 24 female and three male students with a mean age of 22.6 years. Purposive sampling is an informant selection method widely used in qualitative studies (Tongco, 2007). As contended by Polit and Beck (2018), it is advantageous to use a purposive sample of heterogeneous people with particular knowledge about the subject when pretesting or evaluating novel interventions.

In Study IV, data were collected from two groups (students and facilitators). A convenience sample of 148 third-year nursing students was recruited through pamphlet dissemination in classrooms. Two students declined to consent to video recording, and one student withdrew because of personal reasons unrelated to the study, resulting in a final sample of 145 . The required sample size for this study was 140 , which was calculated based on an a priori power analysis, giving an alpha of .05 , a power of .80 , a median effect size of .5 and an estimated 
attrition rate of $10 \%$. The outcome variables from the debriefing experience scale (DES) were used for the a priori power analysis. Thus, a sample size of 145 was sufficient to achieve the main objective of the study. The eligibility criteria for student participants included: (1) thirdyear undergraduate nursing student in the academic year 2018/2019; (2) aged above 21 years; (3) first-time enrolment in a 2-week HFS program, which is part of the module Consolidated Clinical Simulation Nursing Practice (NUR3118) conducted in the second semester of each academic year; and (4) previous experience of VD. Prior to the study, students had received training in routine nursing skills, physical assessment, management of clinical deterioration, drug administration and communication skills. Students who declined to consent to video recording and those who were repeating the aforementioned module were excluded. The latter group was excluded to reduce the threat to internal validity arising from prior exposure to the same simulation activities, which may have caused a diffusion effect. Students with previous experience in simulation related to other topics were eligible. The 2-week HFS program comprised one 2-hour simulation session per week, involving medication administration in the first session and patient deterioration in the second session. With respect to facilitator participants, a purposive sample of eight trained simulation facilitators with debriefing experience, who formed the entire teaching team for this program, was selected for the study.

\section{Intervention}

A three-phase VAD framework was developed and used as the intervention in this project (see Figure 2).

\section{Phase 1: Preparation (20 minutes)}

This phase was aimed at creating a safe learning environment and providing a concrete learning experience. It included a 5-minute prebriefing on what to expect in the simulation, the learning objectives and the ground rules for confidentiality and mutual respect during the simulation. Next, students were invited to attend a 15-minute simulated activity with video recordings (performers). Those who did not wish to participate in the scenario observed the performers and provided feedback with observation tool (observers).

\section{Phase 2: Transformation (35 minutes)}

This phase was aimed at transforming the concrete experience into knowledge (abstract conceptualisation) through a cognitive process of reflection, contextualisation, 
decontextualisation and recontextualisation. Immediately following the 15-minute simulated activity, the facilitator provided a 5-minute interlude to allow performers to calm down and detach from the simulated role, while observers discussed their peers' performances using the Plus/Delta tool and jotted comments on a whiteboard. Plus/Delta is a simple tool that allows observers to differentiate effective behaviours $(+)$ from subpar behaviours $(\Delta)$ (Phrampus \& O'Donnell, 2013). Following the interlude, performers were invited to 'unload' any emotional burdens by sharing their emotions and interpretations of the simulated encounter (e.g. 'How did you feel...', 'What happened to the patient and how did you know that...?'). The purpose of this was to allow them to think or objectively reflect in the next phase. Following the emotional outlet, the facilitator shared his or her personal experiences relevant to the scenario and invited other students to share.

Subsequently, three to four video clips selected by the facilitator were played in the debriefing room to highlight certain learning gaps based on three criteria: (1) actions related to patient safety (e.g. if a student failed to perform an identity check before medication administration); (2) actions relevant to learning objectives (e.g. if a student was unable to set up a venturi mask); and (3) actions related to real-world relevance (e.g. if a student did not prepare the suctioning apparatus when assisting in intubating the mannequin). The length of each video clip was $2-$ 3 minutes. Following each review, performers were asked to discuss and reflect on their own actions, with the aim of developing their capabilities for on-the-spot corrections. For students who were not able to reflect critically, the facilitator used the advocacy-inquiry technique to elicit the thought processes behind their actions to help them discover their own gaps and gain insights. Advocacy-inquiry is a commonly used facilitation technique comprising a facilitator's objective observation (e.g. 'I saw...'), a subjective judgement of the action (e.g. 'I think...') and a genuine inquiry (e.g. 'I wonder...') to elicit the aetiology of actions without causing anxiety for students (Rudolph et al., 2006). For example, a facilitator may state, 'I saw that you changed the intravenous infusion without performing a patency check for the intravenous cannula. I think this could make fluid challenge become less effective if the cannula is blocked. I wonder what your thought is behind that'.

Next, the facilitator used the video to guide students to link the simulated scenario to a real-life situation. Students were encouraged to share their past experiences related to similar situations by answering questions such as, 'Please describe your own experience in assisting or observing patient resuscitation with ventricular fibrillation in the clinical setting' or 'How do resuscitation 
in the laboratory setting and the hospital setting differ?'. By contextualising their experiences, the facilitator aimed to detect discrepancies between students' perceived situations and actual situations to examine their mental assimilation (Kolb, 2015; Rivière et al., 2019). Following the gap identified, the facilitator used cognitive aid materials such as clinical guidelines or algorithms to fill students' learning gaps by calibrating the accuracy of their perceptions and extracting general principles for future similar situations (decontextualisation).

Once the general principles had been learned, students' new frames were tested hypothetically using analogical questions beginning with 'What if...?'. Analogical reasoning involves comparing two situations that are structurally similar and using those similarities to draw conclusions and form structural connections between two situations or experiences (Zigmont et al., 2011). For instance, the facilitator may play a video relating to the management of patient collapse caused by ventricular tachycardia and invite students to compare the recorded scenario with similar situations (e.g. comparing the management of ventricular tachycardia with that of ventricular fibrillation or asystole) to arrive at conclusions about managing patients with shockable or non-shockable rhythms. Through this, students can adapt to new frames and be prepared for future similar situations.

\section{Phase 3: Consolidation (5 minutes)}

This phase examined new knowledge through active participation. The facilitator summarised the learning points of the simulation and then invited students to share two to three take-home messages and their plans to improve their performance (e.g. new simulations or clinical practicum). 


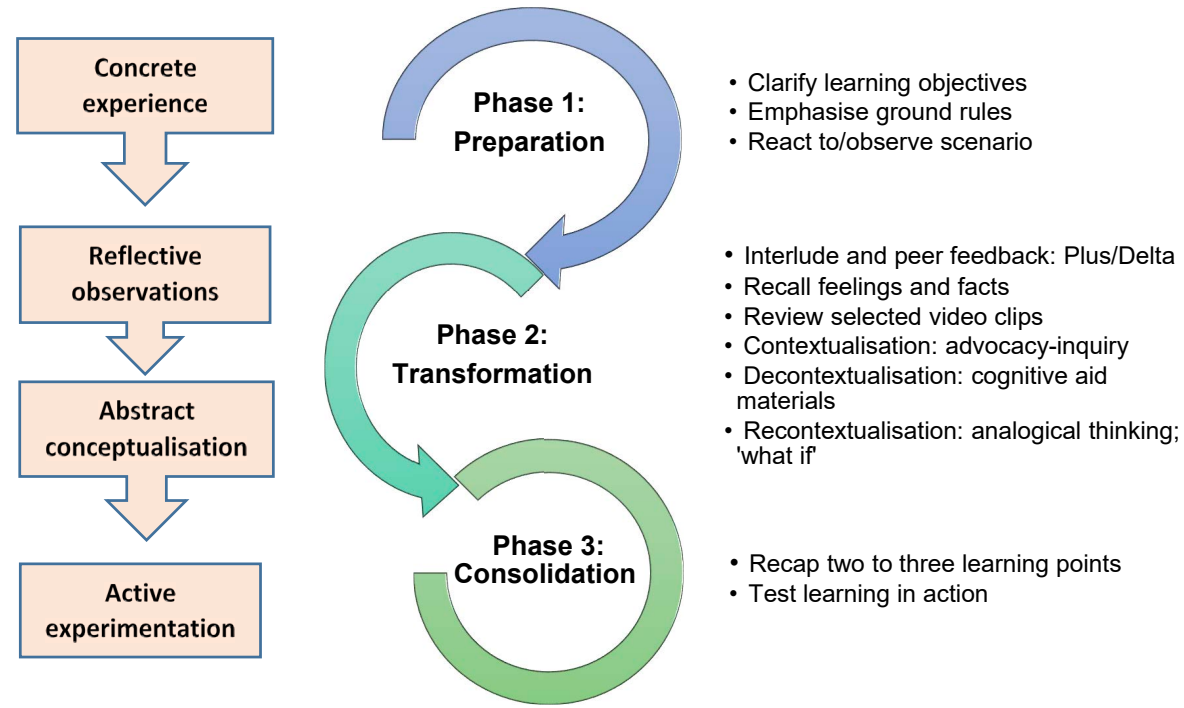

Figure 2: Three-phase video-assisted debriefing integrated with experiential learning theory (modified from Paper IV)

\section{Control}

VD has been adopted as a common practice in SBL worldwide, with various debriefing structures used (Sawyer et al., 2016). Fourteen years ago, leading SBL experts at the Centre for Medical Simulation in Cambridge, Massachusetts, developed a debriefing model involving three steps: reaction, analysis and summary (Rudolph et al., 2006). Since then, this model has been widely accepted and modified to various forms with similar key components, including the gather-analyse-summarise (GAS) model (Fanning \& Gaba, 2007; Phrampus \& O'Donnell, 2013). The gather step allows the facilitator to gather information to understand students' thoughts and feelings to prepare for next two steps; the analyse step aims to facilitate students' reflection and analysis of their performances; and the summarise step helps students to recap the lesson learned.

The control used in this project was VD conducted using the GAS model. Following the 15minute simulation scenario, VD facilitators gathered information by inviting students to share their thoughts about the scenario. Open-ended questions were used to facilitate the process, such as 'What do you think had happened to the patient...?', 'How do you know that...?' and 
'What did you aim to achieve...?'. Next, the VD facilitators assisted students to reflect on and analyse their own performance, including correct and incorrect steps, using questions such as, 'Tell me more about how...', 'Tell me more about why...' and 'How can you improve that...?'. Subsequently, feedback about the performance was invited from peers. Finally, the VD facilitators summarised the lesson and offered general comments to the class before asking them to share two to three take-home messages.

\section{Instruments}

Self-reported questionnaires were used in Studies II and IV for collecting quantitative data because this is the most widely used method for data collection in nursing research and offers the possibility of complete anonymity (Polit \& Beck, 2018). A semi-structured interview guide was developed for Study III to facilitate the focus groups, and open-ended questions were used to obtain written responses in the narrative fashion for Study IV.

\section{Debriefing experience scale}

Nursing students' debriefing experiences were measured using the 20-item self-reported DES, which is based on a 5 -point Likert scale ( $1=$ strongly disagree to $5=$ strongly agree) (Reed, 2012) (see Appendix 4). The DES assessed learners' experiences of debriefing in four domains: analysing thoughts and feelings, learning and making connections, facilitator's debriefing skills and appropriateness of facilitator's guidance during the debriefing (Roberts, 2015). It achieved a content validity index (CVI) score of over 80\% (Almeida et al., 2016) and high internal consistency, with a Cronbach's alpha of 0.93 for the experience scale and 0.91 for the importance scale (Reed, 2012). In light of our research aims, the scale related to learning experience was used in this project.

\section{Simulation-based assessment tool}

Nursing students' competencies were assessed using a simulation-based assessment tool (SAT), which covers six core dimensions: critical thinking, communication, technical skills, management of care, professionalism and safe practice (Tan et al., 2016). It includes a global rating scale of 1 to 9 to rate each competency (1-3= unsatisfactory, 4-6= satisfactory, $7-$ $9=$ outstanding), with a total score of 54 (see Appendix 2). It achieved an item CVI ranging from 0.80 to 1.0 , a scale CVI of 0.97 and high inter-rater reliability, with an intraclass 
correlation coefficient (ICC) of 0.90 (Tan et al., 2016). This instrument is used as a nursing skills assessment tool in the study university.

\section{Groningen Reflection Ability Scale}

Nursing students' reflective abilities were examined using the 23-item Groningen Reflection Ability Scale (GRAS) (Aukes et al., 2007). This instrument is used to measure health professionals' and trainees' personal reflective abilities across three important aspects: selfreflection, empathetic reflection and reflective communication (Rostami et al., 2019). The scale achieved an acceptable internal consistency, with a Cronbach's alpha of 0.74-0.83 (Aukes et al., 2007). Participants were required to read each statement and self-rate it on a 5-point Likert scale ( 1 = totally disagree to 5 = totally agree) (see Appendix 5). Its concurrent validity was established by comparing it with Korthagen's reflection scale, with a reported correlation ranging from 0.67 to 0.32 (Aukes, 2008).

\section{Debriefing Assessment for Simulation in Healthcare}

Facilitators' debriefing practices were assessed using the Debriefing Assessment for Simulation in Healthcare (DASH), which is based on a 7-point scale ( 1 = extremely ineffective to 7 = extremely effective) to differentiate levels of effectiveness across six elements: setting the stage, engaging learners, structuring debriefing, provoking discussions, identifying gaps and achieving learning objectives. A student version of DASH (DASH-SV) was used by students to rate their impressions of facilitators' debriefing effectiveness (Simon, Raemer, \& Rudolph, 2010) (see Appendix 6), while an instructor version (DASH-IV) was used by facilitators to evaluate their own debriefing practices (Simon et al., 2012) (see Appendix 3). The tool achieved high internal reliability, with a Cronbach's alpha of 0.89 , and satisfactory inter-rater reliability, with an ICC of 0.74 (Brett-Fleegler et al., 2012).

\section{Stress visual analogue scale}

Nursing students' stress levels during debriefing were assessed using a stress visual analogue scale (VAS), which is a simple and time-efficient tool (Dutheil et al., 2017). Nursing students were asked to self-rate their perceived stress on an 11-point Likert scale $(0=n o t$ stressed to $10=$ extremely stressed $)$. The inter-rater reliability and stability of the stress VAS have been validated in prior studies, with high concordance with the perceived stress scale $(r=0.66)$ (Lesage et al., 2012). Given its short time intervals, it was appropriate for this study to use a 
VAS instrument to measure students' perceived stress at three time points in each simulation session (prescenario and pre- and post-debriefing).

\section{Interview guide}

An interview guide was used to facilitate the semi-structured focus groups in Study III. The guide was initially developed based on the literature review and several rounds of discussions among research team members. Subsequently, a panel of simulation experts comprising three senior lecturers and three lecturers from the nursing department of the study university were invited via email or in person to review and validate the developed interview guide. Each simulation expert received two items via email: one copy of the developed interview guide and one set of validation tools. The guide was vetted according to several criteria, including whether the questions covered the range of issues to be discussed, were clear, precise and relevant and enabled participants to agree or disagree with each other. A total of six sets of completed validation tools were collected after 2 weeks. Written inputs were meticulously analysed and discussed among research team members. Changes were made to the original version based on the written comments and agreements reached among research team members. For instance, closed questions were rephrased as open-ended questions. A final version of the interview guide was developed, covering five dimensions relating to VAD: participants' understanding, personal experience, possible impetus and barriers, suggestions for future improvement and direction.

\section{Qualitative survey}

Qualitative surveys are an inexpensive, time-efficient and less daunting way to collect data and offer privacy and anonymity to participants (Braun \& Clarke, 2013). Hence, a self-reported qualitative survey consisting of seven open-ended questions was used in Study IV to collect information relating to facilitators' perceptions of debriefing practices. This survey was developed based on simulation experts' opinions and several rounds of discussions among research team members. Content validation refers to the process of collecting logical evidence to support the use of a test through expert judgements about the test content of a defined domain of knowledge (Krippendorff, 2019). This was performed by a group of simulation experts from the nursing department of the study university, including four senior lecturers and three lecturers. Experts were invited via email or in person, and each received the survey together with the validation tool. The survey was vetted in detail, including whether the questions were 
focused on the topic or stated in a succinct and easy to understand manner to avoid question fatigue. A total of seven sets of completed validation tools were collected after 2 weeks. The written inputs were analysed and discussed among research team members. Minor amendments were made based on the comments. For instance, three experts pointed out that the fifth question was redundant and suggested removing it. A final version of the qualitative survey was developed, with a total of seven open-ended questions aimed at exploring facilitators' perceptions of debriefing practices.

\section{Data collection}

A summary of the data collection for Studies I, II, III and IV is shown in Table 2. Study I was aimed at evaluating the effectiveness of VAD on learners' outcomes in health professions education. A search of the literature was conducted in seven electronic databases from October 2016 to December 2017. This review was limited to experimental studies (e.g. quasiexperimental or randomised controlled trials) conducted since the year 2000 to evaluate the educational effects of VAD in a laboratory setting. The reason for this was that papers published earlier were less likely to reflect current debriefing practices in intermediate-fidelity simulation and HFS. A standardised three-step search was performed for potential articles. The first search was conducted in three electronic databases - PubMed, Medline and CINAHL — to identify relevant keywords. The second search involved using all identified keywords to continue searching for articles in four other electronic databases-ScienceDirect, Scopus, Web of Science and PsycINFO. The third search was carried out by looking through the references of included articles and review papers to search for relevant articles not found by the electronic database search. Dissertation Abstracts International and GreyNet were searched for unpublished studies to avoid publication bias. Subsequently, the titles and abstracts of selected articles were read to check for relevance. The Preferred Reporting Items for Systematic Reviews and Meta-Analyses checklist was used to guide and record the decision-making process and search results at each step. A librarian was consulted on keyword searching, and the final keywords used for the literature search included video-assisted, debriefing, video review, video playback, feedback, effect, effectiveness, simulation, health professions and health care. Studies were excluded if they were conducted in clinical or other settings (e.g. aviation, music or military), recruited non-healthcare participants (e.g. police students), evaluated the effects of other components of simulation (e.g. simulated patients) or were written in non-English language. 
Study II aimed to test the preliminary effects of the developed three-phase VAD on nursing students' debriefing experiences, reflective abilities and nursing competencies. Data were collected immediately before and 1 week after the VAD using a self-reported questionnaire comprising DES, GRAS and sociodemographic data. There was no attrition from the pilot study. A total of 29 students volunteered as performers for code blue scenarios, and their nursing competencies were evaluated by two independent researchers (HZ and SG) using the SAT. The remaining 34 students were observers who watched but did not participate in the simulated scenario. To promote directed observation, observers were provided with a digital copy of the SAT as an observation tool with which to evaluate the specific learning objectives and their peers' performance.

It has been well established that SBL emphasises experiential learning, through which participants explore their learning gaps independently and collectively through planned activities to facilitate the process of trial and error ( $\mathrm{Ng}$ et al., 2019). Constructivist epistemology emphasises the learner's active role in knowledge construction from both individual and social experience (Dennick, 2016). Constructivism aligned well with the aims of Study III, with its epistemological assumption of learners actively creating their own knowledge from experience. Focus groups were conducted to collect information related to students' experiences and perspectives regarding VAD. Braun and Clarke (2013) argue that the use of focus groups is an excellent data collection method that aims to explore, clarify or confirm views or knowledge about a predefined topic of interest from multiple participants simultaneously. A semi-structured interview guide was used to facilitate the discussions, focusing on participants' understanding, personal experiences, perceived motivations and barriers, strategies for improvement and future directions. Six focus groups, which were both video and audio recorded, were independently conducted by two researchers (HZ and SG) in quiet tutorial rooms at the study university. Each focus group was attended by three to six students and had an average duration of 55 minutes (ranging from 45 to 65 minutes). To produce a rich and in-depth discussion, the two researchers (HZ and SG) made an effort to ensure the discussions were open and supportive. The recorded videos served as field notes and were used to facilitate data transcription and analysis. The data saturation concept was applied in the data collection of this study. More details are provided in the section 'Methodological considerations'. 
Study IV aimed to evaluate the effects of VAD practice. Thus, a pragmatic epistemology was more appropriate because the knowledge generated from this study was intended to improve the practice of debriefing in SBL. The choice of outcome measures was based mainly on the findings of Studies II and III. Quantitative data were collected from the nursing students immediately before VAD and 1 week after the 2-week program using a self-reported questionnaire comprising demographic information, the DES and the DASH-SV. All nursing students $(n=145)$ were required to rate their acute stress scores using the stress VAS at three time points for each simulation session: prescenario, pre-debriefing and post-debriefing. The attrition rate of student participants of this study was $0.6 \%$ (one student withdrew due to person issue unrelated to this study). Quantitative data were collected from facilitators $(n=8)$ using the DASH-IV, and qualitative data were collected using the open-ended question survey after the simulation program.

Table 2: Summary of data collection for the four studies

\begin{tabular}{|c|c|c|c|c|}
\hline \multirow{2}{*}{ Study } & & \multicolumn{3}{|c|}{ Data collection } \\
\hline & & Before intervention & During intervention & After intervention \\
\hline I & & $\begin{array}{l}\text { Literature review guided } \\
\text { by PRISMA checklist }\end{array}$ & & \\
\hline II & & DES, GRAS, SAT & N/A & DES, GRAS, SAT \\
\hline III & & N/A & N/A & Focus groups \\
\hline \multirow{2}{*}{ IV } & $\begin{array}{l}\text { Student } \\
\text { participants }\end{array}$ & $\begin{array}{c}\text { DES, DASH-SV, stress } \\
\text { VAS }\end{array}$ & Stress VAS & $\begin{array}{c}\text { DES, DASH-SV, stress } \\
\text { VAS }\end{array}$ \\
\hline & $\begin{array}{l}\text { Facilitator } \\
\text { participants }\end{array}$ & & & $\begin{array}{c}\text { DASH-IV, open-ended } \\
\text { questions }\end{array}$ \\
\hline
\end{tabular}

Note: PRISMA: Preferred Reporting Items for Systematic Reviews and Meta-Analyses; DES: debriefing experience scale; GRAS: Groningen Reflective Ability Scale; SAT: Simulation-based assessment tool; VAS: visual analogue scale; DASH-SV: Debriefing Assessment for Simulation in Healthcare-Student Version; DASH-IV: Debriefing Assessment for Simulation in Healthcare-Instructor Version.

\section{Data analysis}

\section{Systematic review}

The study protocol for Study I was registered in Joanna Briggs Institute (JBI) Evidence Synthesis. Quality appraisal of the identified articles was performed independently by two reviewers (HZ and SG) using the Medical Education Research Quality Instrument, a tool for evaluating the methodological quality of medical education articles with high inter-rater reliability ( $\mathrm{ICC}=0.72$ to 0.98$)$ and intra-rater reliability ( $\mathrm{ICC}=0.78$ to 0.998$)$ (Cook \& Reed, 2015). Two reviewers (HZ and SG) independently extracted and organised the data using 
summary tables. The first data extraction was performed to elicit information related to study design, participants, sample size, study intervention, outcome measures and results. This process was guided by a modified data extraction instrument from the JBI Meta-Analysis of Statistics Assessment and Review Instrument. The second data extraction was conducted using a format modified from Lederman's (1992) seven elements of the debriefing process to obtain details about the characteristics of existing VADs. Any doubts that arose during analysis phase were resolved through discussion between the two reviewers or with the involvement of a third reviewer until consensus was reached.

\section{Quantitative data analysis}

Data analysis was performed using SPSS Statistics 23.0. Descriptive statistics were used to analyse the demographic data. In Study II, because most data were not normally distributed, the Wilcoxon signed-rank test was used to compare within-group differences for the DES, GRAS and SAT scores before and after VAD. Inter-rater reliability was also performed using ICC. With respect to the DES, subgroup comparisons were carried out between performers $(n=29)$ and observers $(n=34)$.

In Study IV, the chi-square test was also performed to compare the demographic characteristics of the intervention and control clusters for student participants. The Wilcoxon signed-rank test and Mann-Whitney $U$ test were performed to compare within-cluster and between-cluster differences, respectively, in the scores of the DES (data were not normally distributed). A paired t-test and independent t-test were used to compare within-cluster and between-cluster differences, respectively, in the scores of the DASH-SV (data were normally distributed). In addition, repeated measures analysis of variance was conducted to detect whether there was a statistical significance in student stress levels between the two clusters for the three different observations because this was robust to violation of normality (Plichta, Kelvin, \& Munro, 2013). Given the small facilitator sample size $(n=8)$, the study was not adequately powered to detect significant differences in DASH-IV scores between VAD and VD facilitators. Hence, only descriptive statistics were performed. As advocated by Morse (2012), the results of DASH-IV in this study were calculated based on rating scores of 5 and above $(5=$ mostly effective to $7=$ extremely effective) to ensure adequate competency in debriefing practices. 


\section{Qualitative data analysis}

Using focus groups, Study III explored nursing students' experiences and perspectives of VAD following HFS. Student interactions and articulations during the group discussions were recorded. Recorded audiotapes were then transcribed verbatim and analysed using a six-step thematic analysis. Braun and Clarke (2013) argue that thematic analysis can be used to analyse almost any kind of data because it only offers a method for analysing data without stipulated certain criteria. The six steps are: familiarisation with the data set, initial coding, searching for themes, reviewing themes, defining themes and generating the report. Hence, the transcripts were repeatedly read by the researchers and recorded videos were watched multiple times to become familiar with the data set and gain a sense of wholeness. In this phase, our initial concepts and impressions of the data were jotted down. Next, initial coding was independently conducted by two researchers (HZ and SG) to mark the features of interest by highlighting the parts of the text with same meanings. These highlighted codes were then extracted and collated into potential themes based on their similarities and overlapping concepts. These potential themes were then reviewed by three researchers (HZ, SG and VW) to assess their relevance to the initial codes and the entire data set by creating a thematic map. Subsequently, the researchers validated these themes by assessing the core of each theme and the aspects of the data that each theme covered. Each theme was then further refined by linking it back to the initial codes to ensure that the data within the defined theme connected coherently with the subthemes. Last, the findings were related back to the research questions and a report was produced to describe the emerging themes with embedded narratives (see Table 3 for a sample of data analysis in Study III).

Study IV aimed to explore facilitators' perceptions of debriefing practices using an open-ended survey. Qualitative content analysis was used because it is recommended for analysing text data obtained from open-ended survey questions (Graneheim \& Lundman, 2004). Written comments on the surveys were transcribed into Word documents to facilitate the analysis process, which focused more on manifest content. The text was independently and repeatedly read by two researchers ( $\mathrm{HZ}$ and $\mathrm{SG}$ ) to obtain a full picture of the data before identifying meaning units, which were then condensed and assigned codes. Subsequently, all codes were compared according to their similarities and differences and grouped into potential categories. The categories were then reviewed and revised by the researchers through discussions until 
consensus was reached (see Table 4 for an example of data analysis in Study IV). More details are discussed in the section 'Methodological considerations' below.

Table 3: Example of data analysis in Study III using thematic analysis

\begin{tabular}{|c|c|c|c|c|}
\hline Data extract & Initial coding & Categories & Subthemes & Themes \\
\hline $\begin{array}{l}\text { 'I get to see what [the] whole scenario } \\
\text { is like. Because when I am in the } \\
\text { situation, like what she has said, there } \\
\text { are a lot of blind spots, and also when } \\
\text { you step out of the situation you can } \\
\text { actually evaluate what you have done. } \\
\text { When you are in the situation it feels } \\
\text { because you are too into the actions, } \\
\text { you are so called, like, blinded from } \\
\text { the critical thinking, and then also, } \\
\text { like, it helps others to learn as well } \\
\text { because when you play back, you can } \\
\text { actually see. So that's why I think it is } \\
\text { beneficial for learning' (G1P1P2L25) }\end{array}$ & $\begin{array}{l}\text { See whole scenario; } \\
\text { blind spots; notice } \\
\text { things previously did } \\
\text { not notice; blinded } \\
\text { from critical thinking } \\
\text { Step out of the } \\
\text { situation; can evaluate } \\
\text { what you have done; } \\
\text { helps others to learn } \\
\text { when playing back }\end{array}$ & $\begin{array}{l}\text { Third-person } \\
\text { perspective }\end{array}$ & $\begin{array}{l}\text { Advantages } \\
\text { of video- } \\
\text { assisted } \\
\text { debriefing }\end{array}$ & $\begin{array}{c}\text { Praise and } \\
\text { criticism of } \\
\text { video- } \\
\text { assisted } \\
\text { debriefing }\end{array}$ \\
\hline
\end{tabular}

Table 4: Example of data analysis in Study IV using qualitative content analysis

\begin{tabular}{lccc}
\hline Data extract & Meaning units & Codes & Categories \\
\hline $\begin{array}{l}\text { 'Structured debriefing: It helps to } \\
\text { organise the debriefing session in a } \\
\text { systematic way that allow[s] the } \\
\text { exploration [of] students' thought [on] }\end{array}$ & $\begin{array}{c}\text { Structured, systematic } \\
\text { and organised; } \\
\text { exploring students' } \\
\text { thoughts at a deeper } \\
\text { level allows student to } \\
\text { students to anticipate what is expected } \\
\text { from them during the introduction. } \\
\begin{array}{l}\text { The summary before ending the } \\
\text { session helps to consolidate their }\end{array}\end{array}$ & $\begin{array}{c}\text { Benefits of } \\
\text { conducting } \\
\text { structured } \\
\text { debriefing }\end{array}$ & $\begin{array}{c}\text { The act of } \\
\text { debriefing }\end{array}$ \\
learning' (Q1I3) & $\begin{array}{c} \\
\text { consolidates students' } \\
\text { learning }\end{array}$ & \\
\end{tabular}

\section{Ethical considerations}

Ethical approval for this project was sought from the NUS Institutional Review Board (NUSIRB: S-17-217). Permission to use the validated instruments was obtained from the respective authors prior to the project. According to Beauchamp and Childress (2013), research studies should be fair (principle of justice) and transparent (principle of respect for autonomy) for participants, and anticipated benefits should always outweigh potential risks (principle of beneficence/ non-maleficence).

In compliance with the principle of respect for autonomy, all participants in this project were given a participant information sheet, which provided detailed information about the research aims, possible risks and benefits, expected involvement and participant rights. Participants 
were also informed that participation was voluntary and that they had the right to withdraw from the study without reason at any point by informing the principle investigator (HZ). Prior to consent, potential participants for Study II were informed that their performances in code blue simulation would be video recorded. Similarly, potential participants for Study III were informed that the entire group discussion would be both video and audio recorded. Unlike Studies II and III, potential participants for Study IV were informed that they may or may not be video recorded during the simulation because it would depend on their cluster randomisation. If they were allocated to the intervention cluster, their performance would be video recorded; otherwise, their performance would not be recorded. Notifications of allocation were provided by the research team in person or via SMS 1 day before the 2-week simulation period. Facilitator participants in Study IV were also randomised to either VAD or VD groups, and their allocations were disclosed 1 week before the 2-week simulation period to ensure sufficient time for VAD facilitators to receive VAD training. All questions raised by participants were answered by the research team to ensure their decisions to volunteer were fully informed. Declining to participate or withdrawing after agreeing to participate would not result in penalties or affect their academic grades. Participants were also assured that their performance during simulation and their responses to the survey would not affect their academic grades because the questionnaires and focus group discussions were not part of the existing curriculum. Participant confidentiality was assured by making the survey anonymous and not collecting identifiers. Only mobile phone numbers were collected, and pseudo names were assigned to all participants during data transcription.

The principle of justice emphasises a fair, equitable and appropriate distribution of benefits and burdens. In other words, it is a duty to provide others with that which they deserve. In educational research, this principle can be applied to the equality of learning resources, privileges and opportunities. In this project, although participation in the scenarios was on a voluntary first-come, first-served basis because of logistical and human resource constraints, researchers attempted to equalise the learning resources by engaging participants in either active participation (performers) or direct observation (observers) to achieve the learning objectives. Moreover, to ensure equity of opportunity in research participation, participants with diverse ethnic backgrounds were invited, including those from ethnic minorities.

The principle of beneficence/non-maleficence highlights the obligation to do no harm to others. Evidence supports the benefits of VD and VAD in improving learner outcomes. Hence, 
participants in this project were expected to receive similar benefits. Given the use of video in VAD, breaches of confidentiality could be a major concern. To minimise this risk, the performers were permitted to wear surgical face masks to cover their faces during recording, and masks were made available in all simulated wards. Meanwhile, observer students were reminded not to record simulations using personal devices (e.g. phones, tablets or laptops). Given that video use may induce certain psychological burdens (e.g. embarrassment, stress or intimidation), all students were advised not to disclose the debriefing content to others outside the group and were assured that recorded videos would be used for learning purposes only and would not be shared with others. To minimise the risk of misuse, recorded videos were deleted 1 week following completion of the simulation by the laboratory technician involved in video recording for this project, witnessed by the principle investigator (HZ).

Teacher-student relationships between the researcher and participants was a potential source of concern about access, power and confidentiality in this project (Ferguson et al., 2004). For example, a student's ability to consent voluntarily may be compromised or limited by their subordinate position to the researchers. With this in mind, the researchers emphasised to students that participation in the project was entirely voluntary, the process of data collection would remain anonymous, and data collected would be kept confidential and only accessed by the research team. Students were also reassured that the simulation would be in the form of a formative assessment to facilitate their learning, and their performance in the scenarios would not be graded or affect their academic results. Most importantly, the researchers would not be involved in any summative assessment of third-year nursing students during the study semester.

In accordance with NUS's research data management policy and information technology guidelines, prior to project completion, data collected in paper format (e.g. written consents and completed questionnaires and surveys) were kept in a locked cabinet in the study department, with only the research team having access to the key. Data collected in paper format were then converted into digital copies (e.g. Excel and SPSS) and electronically stored in an encrypted and password-protected computer. The original audio and videos files of focus groups were transferred to the same password-protected computer before being deleted from the audio recorders and camera by the principal investigator (HZ) and a witness (SG). All digital transcripts of audio files were kept in the same password-protected computer. Only members of the research team had access to the data. Backup copies of data were saved in a password-protected hard drive in case of data loss arising from electronic failure or damage to 
hard copies (e.g. fire). The backup hard drive was locked in a cabinet in the principal investigator's office. All published data were anonymised to ensure no participants were identifiable.

According to the NUS Institutional Review Board's latest update in relation to the retention of research records, upon completion of the project, data in paper format (hard copies) need to be submitted to the board for safekeeping for a minimum period of 10 years. Electronic data (soft copies) will be stored in one of the NUS repositories (e.g. nBox, SharePoint or ScholarBank@NUS) for archival storage. The deadline of data submission for this project is 30 September 2022. 


\section{RESULTS}

\section{Study participants}

Student participants were homogeneous in Studies II and IV. The majority were young females with a mean age of 22.6 years and limited clinical working experience (see Table 5).

Table 5: Characteristics of student participants in Studies II, III and IV

\begin{tabular}{llccc}
\hline Characteristics & & Study II $(\boldsymbol{n}=\mathbf{6 3})$ & Study III $(\boldsymbol{n}=\mathbf{2 7})$ & Study IV $(\boldsymbol{n}=\mathbf{1 4 5})$ \\
\hline \multirow{4}{*}{ Age (years) } & All $(M \pm S D)$ & $22.6 \pm 3.34$ & $22.6 \pm 2.78)$ & $(22.6 \pm 2.12)$ \\
& $21-25$ & $57(90.5 \%)$ & $22(81.5 \%)$ & $140(96.6 \%)$ \\
& $26-45$ & $6(9.5 \%)$ & $5(18.5 \%)$ & $5(3.4 \%)$ \\
\hline \multirow{2}{*}{ Gender } & Female & $56(88.9 \%)$ & $24(88.9 \%)$ & $128(88.3 \%)$ \\
& Male & $7(11.1 \%)$ & $3(11.1 \%)$ & $17(11.7 \%)$ \\
\hline \multirow{2}{*}{ Clinical working } & Yes & $13(20.7 \%)$ & $9(33.3 \%)$ & $17(11.7 \%)$ \\
& No & $50(79.3 \%)$ & $18(66.7 \%)$ & $128(88.3 \%)$ \\
\hline \multirow{2}{*}{ Education level } & Junior college & $42(66.7 \%)$ & $22(81.5 \%)$ & $101(69.7 \%)$ \\
& Polytechnic & $21(33.3 \%)$ & $5(18.5 \%)$ & $44(30.3 \%)$ \\
\hline
\end{tabular}

Some data for Study IV were collected from facilitators $(n=8)$, all of whom were registered nurses with a minimum bachelor's qualification $(n=8)$. Seven of the facilitators were female, the mean age was 40.8 years $(S D=13.17$, ranging from 25 to 60$)$ and experience in facilitating debriefing ranged widely from $<1$ year to $>10$ years (see Table 6 ). 
Table 6: Characteristics of facilitator participants in Study IV $(n=8)$

\begin{tabular}{|c|c|c|c|}
\hline Characteristics & & VAD facilitators $(n=4)$ & VD facilitators $(n=4)$ \\
\hline \multirow{3}{*}{ Age (years) } & $21-25$ & 1 & 0 \\
\hline & $26-30$ & 0 & 2 \\
\hline & $40-60$ & 3 & 2 \\
\hline \multirow{2}{*}{ Gender } & Female & 3 & 4 \\
\hline & Male & 1 & 0 \\
\hline Ethnicity & Chinese & 4 & 4 \\
\hline \multirow{4}{*}{ Education level } & Bachelor's degree & 1 & 0 \\
\hline & Master’s degree & 2 & 0 \\
\hline & Doctoral candidate & 1 & 2 \\
\hline & Doctorate & 0 & 2 \\
\hline Profession & Registered nurse & 4 & 4 \\
\hline \multirow{2}{*}{$\begin{array}{l}\text { Debriefing } \\
\text { experience }\end{array}$} & $\mathrm{VD}$ & 2 & 2 \\
\hline & $\mathrm{VD}+\mathrm{VAD}$ & 2 & 2 \\
\hline \multirow{4}{*}{$\begin{array}{l}\text { Years of } \\
\text { debriefing } \\
\text { experience }\end{array}$} & $<1$ & 1 & 1 \\
\hline & 3 to 5 & 2 & 1 \\
\hline & 5 to 10 & 1 & 0 \\
\hline & $>10$ & 0 & 2 \\
\hline
\end{tabular}

Note: VAD: video-assisted debriefing; VD: verbal debriefing.

\section{Educational effects of video-assisted debriefing}

Study I confirmed the positive effects of VAD for healthcare professionals and students in terms of learner satisfaction, learning experience and performance. However, there is little evidence for its advantage over VD in terms of knowledge acquisition. The review revealed that the benefits of VAD include enabling learners to make connections between knowledge and real life, visualise their own actions and clarify areas of uncertainty. The review also disclosed some disadvantages of VAD, including mental fatigue, stress and distraction. In addition, several elements for the success of VAD were identified, including appointing clinical experts or faculty members with debriefing experience as facilitators, using structured VAD for procedural skills training, controlling VAD time to 2-3 times the scenario time and watching video clips in class to ensure sufficient time for information processing. Importantly, the review revealed a lack of understanding of VAD best practice and the need for future research. 


\section{Three-phase framework for video-assisted debriefing}

A three-phase framework for VAD was developed based on Kolb's ELT (see Figure 2). Phase 1 was aimed at creating a concrete experience for learners through simulated scenarios. Phase 2 was aimed at helping learners transform their experience into learning through video reviews, reflection and discussion. Phase 3 was aimed at consolidating learning through assessing thoughts and skills.

\section{Effects of video-assisted debriefing on debriefing experience (DES)}

The findings of Studies II and IV showed that VAD significantly improved nursing students' overall DES scores. In Study II, VAD students significantly improved their scores in nine of the 20 DES items, and no significant differences were found between performers and observers before and after VAD (see Table 7). The internal consistency of the DES achieved a Cronbach's alpha of 0.916 in Study II. Study IV showed that VAD significantly improved students' scores in 12 of 20 DES items (see Appendix 4). The internal reliability of the DES achieved a Cronbach's alpha of 0.94 in Study IV.

Table 7: Study II: Debriefing experience scale results

\begin{tabular}{|c|c|c|c|c|c|c|}
\hline \multirow{2}{*}{ Variables } & \multicolumn{2}{|c|}{ Performers $(n=29)$} & \multicolumn{2}{|c|}{ Observers $(n=34)$} & \multicolumn{2}{|c|}{$p$} \\
\hline & Pretest & Posttest & Pretest & Posttest & Pre & Post \\
\hline $\mathrm{DES}: M( \pm S D)$ & $77.97( \pm 7.45)$ & $88.69( \pm 8.17)$ & $78.71( \pm 7.23)$ & $87.21( \pm 8.28)$ & & \\
\hline Minimum & 60 & 66 & 60 & 68 & & \\
\hline Maximum & 98 & 98 & 100 & 100 & $.69^{\mathrm{a}}$ & $.46^{\mathrm{b}}$ \\
\hline Median & 79.00 & 91.00 & 79.00 & 87.00 & & \\
\hline Interquartile range & 8 & 15 & 7 & 15 & & \\
\hline
\end{tabular}

Note: ${ }^{*}$ Significance at $p<0.05$; ${ }^{\mathrm{a}}$ Independent $\mathrm{t}$-test; ${ }^{\mathrm{b}}$ Mann-Whitney U test.

\section{Effects of video-assisted debriefing on stress (Stress VAS)}

Findings of Study IV showed that VAD was comparable with VD in causing stress. Students in the VAD cluster significantly reduced their stress scores at three time points after repeated exposure, while no significant difference was observed in VD students' stress scores at three time points after repeated exposure. Between clusters, VAD students had significantly lower stress scores after debriefing compared with VD students after repeated exposure (see Table 8). Time had a significant effect on stress, with a large effect size of 0.6 , while allocation had no significant effect. The reliability of the stress VAS achieved a Cronbach's alpha of 0.76 . 
Table 8: Study IV: Stress visual analogue scale results

\begin{tabular}{lccccccccc}
\hline \multirow{2}{*}{$\begin{array}{l}\text { Stress VAS } \\
\text { Mean } \pm \boldsymbol{S D})\end{array}$} & \multicolumn{3}{c}{ VAD $(\boldsymbol{n}=\mathbf{7 2})$} & \multicolumn{3}{c}{ VD $(\boldsymbol{n}=\mathbf{7 3})$} & \multicolumn{2}{c}{ 1st } & 2nd \\
\cline { 2 - 8 } & 1st & 2nd & $\boldsymbol{p}$ & 1st & 2nd & $\boldsymbol{p}$ & $\boldsymbol{p}$ & $\boldsymbol{p}$ \\
\hline Prescenario & $7.60 \pm 1.31$ & $7.04 \pm 1.49$ & $<.001^{\mathrm{a}^{*}}$ & $7.71 \pm 1.64$ & $7.45 \pm 1.63$ & $.201^{\mathrm{a}}$ & $.64^{\mathrm{b}}$ & $.12^{\mathrm{b}}$ \\
Pre-debriefing & $6.74 \pm 1.43$ & $6.31 \pm 1.63$ & $.007^{\mathrm{a}^{*}}$ & $6.59 \pm 1.88$ & $6.38 \pm 1.87$ & $.305^{\mathrm{a}}$ & $.60^{\mathrm{b}}$ & $.79^{\mathrm{b}}$ \\
Post-debriefing & $4.42 \pm 2.07$ & $3.74 \pm 1.89$ & $.001^{\mathrm{a}}$ & $4.93 \pm 2.45$ & $4.71 \pm 2.54$ & $.337^{\mathrm{a}}$ & $.17^{\mathrm{b}}$ & $.01^{\mathrm{b}^{*}}$ \\
\hline
\end{tabular}

Note: VAD: video-assisted debriefing; VD: verbal debriefing; ${ }^{*}$ Significance at $p<0.05$; ${ }^{\text {a }}$ Paired sample t-test; ${ }^{\text {b }}$ Independent sample t-test.

\section{Effect of video-assisted debriefing on reflective ability (GRAS)}

Findings of Study II demonstrated that VAD improved nursing students' reflective abilities. Significant differences were observed in 17 of 23 GRAS items (see Appendix 5). No significant differences were found between performers and the observers before and after VAD (see Table 9). The reliability of the GRAS achieved a Cronbach's alpha of 0.71 .

Table 9: Study II: Groningen Reflection Ability Scale results

\begin{tabular}{lcccccc}
\hline \multirow{2}{*}{ Variables } & \multicolumn{2}{c}{ Performer $(\boldsymbol{n}=\mathbf{2 9})$} & \multicolumn{2}{c}{ Observer $(\boldsymbol{n}=\mathbf{3 4})$} & Pre & Post \\
\cline { 2 - 6 } & Pretest & Posttest & Pretest & Posttest & $\boldsymbol{p}$ & $\boldsymbol{p}$ \\
\hline GRAS: $M( \pm S D)$ & $85.59( \pm 5.28)$ & $87.31( \pm 5.22)$ & $85.71( \pm 7.00)$ & $88.76( \pm 6.47)$ & \\
Minimum & 79 & 75 & 75 & 78 & $.895^{\mathrm{b}}$ & $.336^{\mathrm{a}}$ \\
Maximum & 103 & 100 & 103 & 102 & \\
Median & 84.00 & 86.00 & 83.00 & 88.50 & \\
Interquartile range & 8 & 6 & 10 & 10 & \\
\hline
\end{tabular}

Note: ${ }^{*}$ Significance at $p<0.05 ;{ }^{\mathrm{a}}$ Independent t-test; ${ }^{\mathrm{b}}$ Mann-Whitney U test.

\section{Effects of video-assisted debriefing on nursing competency (SAT)}

Findings of Study II showed that VAD significantly improved nursing students' competencies in all six domains of the SAT (see Table 10). Estimation of inter-rater reliability of the SAT gave an ICC of 0.983 . 
Table 10: Study II: Simulation-based assessment tool results

\begin{tabular}{|c|c|c|c|c|}
\hline Variables & & Pretest $(n=29)$ & Posttest $(n=29)$ & $p$ \\
\hline \multirow{3}{*}{$\begin{array}{l}\text { Simulation-based } \\
\text { assessment tool } \\
\text { overall scores }\end{array}$} & Median & 19.0 & 38.0 & \multirow{3}{*}{$<.001^{*}$} \\
\hline & Q1 & 15.0 & 36.3 & \\
\hline & Q3 & 24.5 & 41.8 & \\
\hline \multirow{3}{*}{ Critical thinking } & Median & 3.0 & 6.5 & \multirow{3}{*}{$<.001^{*}$} \\
\hline & Q1 & 2.5 & 5.5 & \\
\hline & Q3 & 4.5 & 7.0 & \\
\hline \multirow{3}{*}{ Communication } & Median & 3.0 & 7.0 & \multirow{3}{*}{$<.001^{*}$} \\
\hline & Q1 & 2.5 & 6.5 & \\
\hline & Q3 & 4.0 & 7.5 & \\
\hline \multirow{2}{*}{ Technical skills } & Mean $(S D)$ & $3.3(1.4)$ & $5.9(1.4)$ & \multirow{2}{*}{$<.001^{* \mathrm{aa}}$} \\
\hline & SEM & .3 & .3 & \\
\hline \multirow{3}{*}{ Management of care } & Median & 3.0 & 6.5 & \multirow{3}{*}{$<.001^{*}$} \\
\hline & Q1 & 2.3 & 5.5 & \\
\hline & Q3 & 4.0 & 7.0 & \\
\hline \multirow{3}{*}{ Safe practice } & Median & 3.0 & 6.5 & \multirow{3}{*}{$<.001^{*}$} \\
\hline & Q1 & 2.5 & 5.5 & \\
\hline & Q3 & 4.3 & 7.0 & \\
\hline \multirow{3}{*}{$\begin{array}{l}\text { Professionalism \& } \\
\text { ethical practice }\end{array}$} & Median & 3.0 & 6.5 & \multirow{3}{*}{$<.001^{*}$} \\
\hline & Q1 & 2.8 & 6.0 & \\
\hline & Q3 & 4.0 & 7.5 & \\
\hline
\end{tabular}

Note: * Significance at $p<0.05$; Wilcoxon signed-rank test; Q1: first quartile; Q3: third quartile; $S D$ : standard deviation; SEM: Standard error of mean; ${ }^{\text {a }}$ paired t-test.

\section{Effects of video-assisted debriefing on debriefing practice (DASH)}

Study IV found that VAD facilitators received significantly higher scores than did VD facilitators, and significant differences were found in 10 of 23 DASH-SV items (see Appendix 6). The reliability of DASH-SV achieved a Cronbach's alpha of 0.93. Compared with VD facilitators, VAD facilitators perceived themselves to be more effective in five of the six DASH elements: maintaining an engaging context, structuring the debriefings, provoking discussion and reflection, identifying learning gaps and improving performance. The only element that VAD facilitators did not perceive as more effective was setting the stage for engaging learning. In contrast, students scored VAD facilitators higher in terms of setting the stage for engaging learning, provoking discussion and reflection and identifying learning gaps, but scored similarly to VD facilitators in maintaining an engaging context, structuring the debriefings and improving performance. 


\section{Student perspectives and facilitator perceptions of video-assisted debriefing}

\section{Student perspectives}

Perspective refers to a point of view and is often viewed as one dimension of perception (Colman, 2015). Study III identified three themes related to nursing students' perspectives and experiences of VAD following HFS.

\section{Journey from verbal debriefing to video-assisted debriefing}

Nursing students disclosed unfulfilled learning needs emerging from VD. Without solid evidence, different observers may perceive the same action differently or miss certain observations and gave biased comments, leading to confusion, frustration or unresolved feelings, which were not beneficial for learning. VAD overcame these drawbacks by providing accurate event records for reflection and discussion, making comments more specific and judicious. However, students revealed that they experienced an emotional rollercoaster when participating in VAD. They were initially reluctant to participate VAD because of being filmed, but most were able to acclimatise themselves to being video recorded after taking part in the scenarios. Prior to the video reviews, performers struggled with ambivalent feelings arising from their ambition to improve and the fear of criticism. During the video reviews, they were able to evaluate and discuss their performance objectively, thus became more receptive to comments and criticism. Overall, students agreed that their learning experiences from VAD were desirable.

\section{Praise and criticism of video-assisted debriefing}

Nursing students recognised the benefits of VAD, including the video reviews to verify comments, minimise biases and ensure consistency. They believed that VAD not only improved their reflective practice, learning attitudes and behaviours in the classroom but also helped them relate the current situation to future practice through mental assimilation. Nonetheless, students raised concerns about the consequential behaviours of learning because some fully relied on the video review and facilitator's comments. In addition, some criticisms were associated with less time for skills practice, unsatisfactory video quality and the risk of video misuse. Although students were uncertain about the appropriate time frame for video reviews, they agreed that the time should be decided by the context and learning needs. 


\section{The road to successful video-assisted debriefing}

Nursing students reflected that they should be more motivated and responsible for their own learning and become more resilient to stress and criticism. Moreover, they also suggested that they should be desensitised to filming early, and VAD should be conducted in small groups with onsite information technology support. They preferred to have tutor-led VAD for new lessons and peer-led VAD for consolidation. Students believed that facilitators should be competent in engaging learners and using video to maximise their learning and sensitive to learners' emotions. Last, they disclosed that their attitudes towards VAD were highly influenced by the directives of the institution and the local kiasu culture, and they were keen to try various strategies to improve their academic grades.

\section{Facilitator perceptions}

Perception is defined as a cognitive process of understanding how things are in the world, and it informs one of how things are in the world from one's perspective (Bruno \& Pavani, 2018). Study IV reported three categories related to facilitators' perceptions of debriefing practices.

\section{The act of debriefing}

The VAD facilitators recognised the benefits of VAD and favoured the structure of the threephase VAD because it enabled them to lead and students to anticipate and think deeply. In contrast, the VD facilitators tended to be less structured when facilitating group discussions because they intended to cover all learning points with general comments.

\section{The crux of video-assisted debriefing}

Although both VAD and VD facilitators encountered similar challenges in terms of student engagement, questioning techniques and time, VAD facilitators appeared to be more stressed because they perceived that VAD required additional skills, technical support and time. They were also concerned about the adverse effects of video use, such as video reliance, passive learning and psychological consequences. Hence, VAD facilitators rated themselves as less effective in setting the stage for engaging learning, which was different from the students' perspectives. On the contrary, VD facilitators appeared to be more positive towards VAD by expressing that they would use VAD for more complex simulated scenarios. 
All facilitators felt the need to improve their debriefing practices. The VD facilitators verbalised that they would use effective questioning to engage students, allocate sufficient time to address student questions and engage in lesson planning to improve their debriefing. In contrast, the VAD facilitators tended to structure the debriefing, use videos to solve disputes, provide specific feedback and share personal experiences to facilitate learning transfer. Table 11 shows an overview of themes and categories that emerged from Studies III and IV.

Table 11: Overview of themes and categories emerging from Studies III and IV

\begin{tabular}{lll}
\hline Three themes of Study III & \multicolumn{2}{c}{ Three categories of Study IV } \\
\hline 1. Journey from VD to VAD & $\begin{array}{l}\text { Unfulfilled learning needs from VD } \\
\text { Emotional rollercoaster with VAD }\end{array}$ & \\
\hline 2. Praise and criticism of VAD & $\begin{array}{l}\text { Exclusive benefits of VAD } \\
\text { Challenges of VAD }\end{array}$ & 1. The crux of VAD \\
\hline & $\begin{array}{l}\text { Laying the groundwork for VAD } \\
\text { Role as a motivated learner } \\
\text { Role as an effective facilitator } \\
\text { Influence of educational context }\end{array}$ & $\begin{array}{l}\text { 2. The act of debriefing } \\
\text { 3. Debriefing for success }\end{array}$ \\
\hline
\end{tabular}

Note: VD: verbal debriefing; VAD: video-assisted debriefing. 


\section{DISCUSSION}

Kolb's ELT was used as the primary theoretical framework in this project, including underpinning intervention development and the selection of outcome measures. To foster learning from simulated experience, a three-phase VAD was developed and conducted after simulated scenarios to promote reflection, construct new concepts, refine mental frames and facilitate transfer in the form of purposive group discussions. A mind map was created to illustrate how ELT was used to guide the development of this project (see Appendix 7).

\section{Grasping experience}

According to ELT, concrete experience, regardless of its origin (real life or simulated), forms the basis of experiential learning, and the most effective educational experiences are often filled with strong emotions, challenges and manageable stress (Zigmont et al., 2011). On this basis, the (concrete) educational experience created in this project was entirely simulated. This involved a group of third-year undergraduate nursing students responding to a 15-minute HFS in simulated wards equipped with real medical equipment and computerised mannequins as part of their curriculum. Students were given the choice to 'grasp' the experience through either active participation (performer role) or direct observation (observer role). Based on the findings of Study I, which support VAD for procedural skills training, the created scenarios mimicked clinical situations and procedures related to patient deterioration or code blue resuscitation.

In this project, nursing students grasped the simulated experience by playing different roles (either as performers or observers) during the simulation. There were no significant differences found in debriefing experiences or reflective abilities between performers and observers before and after VAD, which is consistent with findings that role assignments do not affect learners' overall learning outcomes when direct observation is used (Blanié et al., 2018; Delisle et al., 2019). This may be attributable to the different learning styles of students. For example, the role of performer was favoured by students who identified as hands-on learners - those who learned from thinking on their feet, experiencing emotions and practising skills through recall of prior experience and knowledge. Indeed, Thidemann and Söderhamn (2013) highlight that interactions between thinking, feeling and acting are the essence of drama pedagogy, which is important for insights into the encounter. From this perspective, ELT was appropriate to illustrate how performers learn from experience by showing that after a physical interaction with other people and the environment, one reflects on that experience to derive new 
knowledge and integrate it into one's existing frame. This learning approach is described as the 'experiencing style' in Kolb Learning Style Inventory 4.0 (Kolb, 2015, p. 145).

In contrast, the role of observer involves watching but not participating in the scenario, with guided observations on specific learning objectives, behaviours and activities (Delisle et al., 2019). This learning approach is described as the 'imaging style' in Kolb Learning Style Inventory 4.0 (Kolb, 2015, p. 145). This role was chosen by learners who preferred to observe without the pressure of being critiqued by faculty or peers. Although the observer role has received criticism because of its passive involvement in learning (Stroben et al., 2016), the literature supports the observer role by demonstrating that it represents a different learning style that involves actively observing others' actions and consequences on a vicarious basis (Roberts, 2010). In other words, observers are not passive recipients of learning if they are fully engaged in direct observation and analyse what they have observed using their knowledge, skills and imagination (Thidemann \& Söderhamn, 2013). To embrace vicarious learning in this project, observer students were required to use an SAT tool to change passive watching to active observation to immerse themselves through mental rehearsal. Through direct observation, students were able to learn skills without engaging in trial and error, experience emotions and fears by watching and empathising with others and learn from others' experiences through reflection and group discussion.

Our findings support the claim made by Bethards (2014) that all learners in SBL, regardless of their roles, have the same opportunity to achieve the learning objectives via different paths. Observers benefit from practising critical thinking and decision-making, without the pressure of receiving criticism from others, but they miss out on hands-on experience and opportunities to reflect or identify gaps to change their practices (Delisle et al., 2019). In contrast, performers benefit from experiencing a higher sense of realism and an interplay between thinking, feeling and acting to achieve new insights and personal development (Harder et al., 2013; Thidemann \& Söderhamn, 2013). Both roles have their pros and cons. It is argued that observational learning is more suited to the acquisition of new knowledge or skills (e.g. a tutor demonstrating tracheostomy suctioning), in which learners imitate similar behaviours or actions following observation. Overall, this project affirms that both hands-on experience and vicarious learning enhance student learning and reflection, contributing to the body of knowledge regarding learning and reflective practice in SBL. 


\section{Learning from experience through debriefing}

To better understand student learning from experience, the following three aspects are discussed: debriefing experience, learning through debriefing and learning environment.

\section{Debriefing experience}

Experience is simply raw data, and learning from experience requires appropriate strategies to organise information in the perceptual field into salient features to achieve new insights (Johansson et al., 2017). More specifically, it is a process involving the scrutiny of one's preconceptions, tempering of one's emotions, guiding of reflections and development of an alternative frame, following a reverse sequence of frame-actions-results (Kolb, 2015; Rudolph et al., 2007), which may be achieved through debriefing. Moreover, it is vital to understand learners' debriefing experiences as positive because they often enhance one's capacity for thinking, feeling and acting in subsequent events (Novak, 2010).

In this project, Studies II and IV demonstrated that VAD improved students' debriefing experiences following HFS, which is in line with other findings (Soucisse et al., 2017; Yeun et al., 2019). Study III revealed an overall satisfactory experience of VAD, with its pros and cons discussed. Several reasons were attributed to these positive findings. First, the findings of Study I were used to guide the development of a structured VAD and its setting. For instance, VAD was used to train students in procedural skills, and this project was conducted in vivo within the curriculum, helping to directly assess the feasibility of VAD in context and boosting students' intrinsic motivations, as evidenced by the low attrition rate. Second, the use of repeated VAD sessions in Study IV enhanced learning by repeating the cycle of visualisation, imitation and hands-on experience, substantiating findings by Lave and Wenger (1991). More importantly, the developed VAD aligned learning activities with the four learning modes of ELT, supporting the systematic and anticipative flow of debriefing to ensure that learning occurred spontaneously. Third, video was used effectively to support the discussions in debriefing. According to Novak (2010), humans have three types of memory: sensory memory (1 second recall), working memory (1-30 second recall) and long-term memory (lifetime recall). Classroom learning typically involves working memory; however, working memory can only process information less than 30 seconds at a time, leading to limitations in learning fully from experience. In this project, the use of video overcame this limitation by enabling students to relive their words, actions and specific events, minimising subjectivity in the 
appraisal of performance and enabling reflections on actual performance. Fourth, comments from the facilitators and peers substantiated the video clips and generated various perspectives about the performances, enabling performers to reconceive their experiences, co-construct knowledge and develop insights into the relationships between feelings, cognition and outcomes.

\section{Learning through debriefing}

\section{Sharing feelings, emotions and thoughts}

In this project, VAD helped students defuse their emotions, as evidenced by the significant differences observed in Item 4 of the DES (see Appendix 4). I argue that sharing their feelings allowed the performers to vent their emotions, relieve tensions and prepare for discussion, while providing an opportunity for observers to gain insights into their peers' feelings elicited in the simulated nurse role. This step is considered a process of 'empathy before education' (Fey et al., 2014). According to Zigmont et al. (2011), people learn more from experience if it changes their body state or emotions, and the process of sharing assists them in identifying the areas provoking the most intense feelings before efforts are made for improvement. In addition, facilitators and peers had limited access to performers' thoughts and feelings, and they could only rely on what the learners revealed about themselves and what was displayed in the videos to identify, interpret and validate learners' thoughts and non-verbal actions. According to the literature, this step of sharing emotions and thoughts aids in subjective knowledge construction, empathetic reflection and mental frame discovery (Rudolph et al., 2007).

\section{Reflection}

Studies II and IV showed that VAD improved not only students' self-reflection but also their empathetic reflections and reflective communication, as evidenced by the significant differences seen in the DES (e.g. Item 15) (see Appendix 4) and GRAS (e.g. Items 2, 5, 11, 13, and 15) (see Appendix 5). The finding of improved self-reflection supports the use of video, which allowed students to assess their first-hand experiences using a third-person perspective to reconceptualise that experience. As explained by Boud et al. (2013), video aids students in dredging their memories and reconstructing an account of the salient features based on undeniable evidence, ultimately contributing to self-reflection and new insights. With regard to empathetic reflection, which involves thinking about the positions and feelings of others as 
if they were their own (Aukes et al., 2007), I argue that VAD enhances it through emotional engagement and helps to build the basis of vicarious learning. Moreover, improved reflective communication (with respect to feedback) in this project may be attributable to the fact that video reviews provide undeniable evidence, helping students become more receptive when receiving evidence-based comments and more accountable when commenting on others. To summarise, reflection involves a series of intellectual and affective activities in the appraisal of experience to achieve new interpretations. To a certain extent, these findings harmonise with the principle of experiential learning, which advocates for the non-existence of absolute truth and promotes collective thinking (e.g. considering different perspectives to avoid interpretations from one single perspective) through VAD (Kriz, 2010).

\section{Making connections and transfers}

The core of education is to empower learners to create their own meanings from learning to achieve transfer (Novak, 2010). Creating meaning from experiential learning requires learners to comprehend the differences and similarities between created scenarios and their real-life counterparts through generalisation and discrimination (Rivière, et al., 2019). However, it is less likely that learners will make comparisons and draw conclusions on their own. This project shows that VAD can help students make connections in learning and promote transfer, which can be explained by the following points:

Making connections between past, current and future experiences. The developed threephase VAD, which involves a metacognitive process (contextualisation, decontextualisation and recontextualisation), was used to guide students through a series of mental activities, including comparing, generalising, integrating and applying, with the intent to reform their frames for learning transfer. Students contextualised their simulated experiences by describing their cognitive representations of real patients and clinical situations (including their social and cultural aspects) as well as the differences in their cognitive representations between simulated and actual situations. Indeed, the identified similarities between the created and real-life situations reflect the interplay between students' prior experiences and cognitive representations of the simulated situation. Thus, they were able to identify the possible risk of transfer failure and opportunities for rectification (Kolodner, 1997). The students decontextualised their simulated experiences by learning general principles and solutions relevant to the discussed issues, without specific reference to the created scenario, to enable them to manage similar situations in the future. Subsequently, students recontextualised the 
experience using the analogical question, 'What if...?'. According to Zigmont et al. (2011), analogical reasoning supports the process of making structural connections between the problem situation (e.g. current experience) and a familiar situation (e.g. past experience). From the cognitive perspective, analogical reasoning examines learners' developed information network (long-term memory) and its application to the problem situation (working memory) (Schunk, 2012). Recontextualisation relies on verifying how general principles learned during simulation can be translated to real life to strengthen the connection between the action and its relevant context with known limitations (Roth \& Jornet, 2013). Through contextualisation, decontextualisation and recontextualisation, students were able to connect their past, current and future experiences to expand and reform their mental frames with new concepts.

Make connections between theory and real life (transfer). In Studies II and IV, VAD was somewhat effective (although it did not reach significance) in helping students make connection between theory and real-life situations, which is consistent with other findings (Royle, 2014; Alhaj Ali, 2018). The lack of significance may have been attributable to the small sample size used in Study II, meaning it was not sufficiently powered to detect a significant change. Despite the intentions and efforts made, VAD demonstrated comparable effects to VD in making connections in learning. In other words, the use of video did not show any significant advantage in making connections in learning among nursing students, which may be attributed to participants' inadequate professional competence or clinical experience. This finding corroborates that of Fukkink et al. (2011) that professional practitioners who are familiar with clinical settings are more likely to improve their receptive, informative and relational skills by watching their own behaviours on video. Indeed, learning transfer requires learners to possess a certain level of knowledge of the potential context (Johansson et al., 2017). However, in this project, nursing students' knowledge of clinical context was limited, leading to a lack of insight into potential transfer domains and difficulty in capturing important aspects, further decreasing learning connections and transfer.

\section{Learning environment}

\section{Physical environment}

The findings of Studies II and IV show that the physical environments created for both VD and VAD were comparable - no significant difference was found for Item 3 of DES ('The debriefing environment was physically comfortable'). In this project, simulation and debriefing 
were conducted in soundproof rooms with adequate lighting and a temperature of $22-25{ }^{\circ} \mathrm{C}$ to ensure a conducive learning environment. Each simulation room was separated by a curtain into scenario and debriefing zones to disengage students from their simulated roles and defuse any tension. Chairs in the debriefing zone were arranged into a circle for VD and a semi-circle for VAD (facing the monitor) to avoid 'energy gaps' (discontinuities in group discussions) (Fanning \& Gaba, 2007) and minimise power inequalities between students and the facilitator. One whiteboard and three marker pens were placed in the debriefing zone. All equipment, computerised mannequins, recording facilities and monitors were checked prior to simulation. Students were briefly oriented to the equipment (e.g. blood pressure monitoring devices) to familiarise them with it. Upon completion of the project, no complaints were received from students regarding the simulation setting. Hence, it may be confidently concluded that the physical environment created in this project was conducive to an engaging learning experience.

\section{Psychological environment}

Clarifying learning objectives. The findings of Study IV show that VAD students were better prepared with the learning content compared with VD students, as evidenced by the significant differences in responses to Item 1 of DASH-SV ('The instructor introduced him/herself, described the simulation environment, what would be expected during the activity and introduced the learning objectives'). Moreover, students felt that VAD facilitators were more effective in setting the stage for engaging learning, which is in line with the findings of Rudolph et al. (2014) that learners are more likely to engage when they are clear about what is expected of them and what to expect from the facilitator. This finding also implies that the three-phase VAD helped to enhance facilitators' practice of clarifying learning objectives.

Setting the ground rules. Study III revealed that VAD students experienced an emotional rollercoaster, showing that learners are vulnerable to psychological harm in SBL in relation to criticism and anxiety about their academic grades. While psychologically safety is important for learning-oriented behaviours (e.g. asking questions) (Rudolph et al., 2014), this does not mean that learners should totally avoid negative emotions invoked by errors (Zhao, 2011). In this project, learners' psychological safety was preserved by establishing ground rules (e.g. no unauthorised recording) and optimising levels of stress and emotions by titrating the level of facilitator support. 
Study IV show that VAD students had a better response to psychological safety, as evidenced by the significant improvement seen in Item 4 of DASH-SV ('The instructor made me feel stimulated to share my thoughts and questions about the upcoming simulation and debriefing and reassured me that I wouldn't be shamed or humiliated in the process'). To a certain extent, this finding also infers that the VAD facilitators established a positive tone, which concurs with debriefing best practice and demonstrates that the climate established by the facilitators had a significant influence on learner engagement (Rudolph et al., 2014).

Establishing a virtual contract. Although simulation experts endeavour to create realistic simulation environments, some aspects cannot be made completely realistic. Hence, in this project, students were required to treat simulation as if it were real and to perform as if they were in a real ward setting. This process is known as establishing a virtual contract. Study IV showed that students believed that VAD and VD facilitators were comparable in providing information related to the realism of simulation, as evidenced by Item 6 of DASH-SV ('The instructor acknowledged concerns about realism and helped the participants learn, even though the cases were simulated'). This may have been attributable to the same type of computerised mannequins and medical equipment used in both clusters; thus, it was understandable that students received similar information regarding the realism issue.

The intent to use simulation-based learning (formative assessment). In this project, students were informed about the aim of formative assessment in simulation, which refers to the process of identifying learners' deficits or assets based on specific learning objectives, followed by giving personalised feedback to remediate deficits and leverage assets (Rudolph et al., 2008). Students in Study IV perceived that the VAD and VD facilitators were comparable in clarifying the purpose of debriefing, as evidenced by no significant difference observed in Item 5 of DASH-SV ('The instructor clarified the purpose of the debriefing, what was expected of me, and the instructor role in the debriefing'). The reason for this may be that debriefing aims to promote learning and change practice, regardless of the method used (Fanning \& Gaba, 2007). Further, I argue that it was appropriate for this project to use the method of formative assessment for debriefing because it preserved students' psychological safety and mitigated the possible effect of the teacher-student relationship in terms of students being vulnerable to the power of the researchers.

In sum, the findings of this project demonstrate that prebriefing conducted by nursing facilitators prior to HFS enhances student engagement and learning from simulated experience, 
contributing to the body of knowledge on the importance of prebriefing in producing better outcomes. No nursing students were reported to seek medical treatment or counselling because of psychological harm related to this project, indicating that the levels of stress invoked by simulation and debriefing were manageable and this project adhered well to the ethical principles of respect for autonomy and beneficence/non-maleficence. Although there was no standardised template for the content of prebriefing, I agreed that the prebriefing should be customised to suit the context of learners and the learning goals.

\section{Facilitators' debriefing practices}

In this project, the VAD facilitators conducted VAD following the three-phase framework, while the VD facilitators used the GAS model to guide debriefing. In Study IV, nursing students believed that the VAD facilitators were more effective in engaging students, provoking discussion and reflection and identifying gaps but comparable to VD facilitators in keeping students engaged, organising debriefing and sustaining effective performance. These quantitative findings are further complemented by the qualitative findings, which show that VAD facilitators were more likely to provide concrete and constructive feedback and care about students' emotions and psychological safety in debriefing. This may be attributable to the fact that VAD facilitators followed the activities suggested in the three-phase framework, including conducting group discussions in a systematic manner using video clips and effective questioning (e.g. advocacy-inquiry and analogic reasoning) to foster reflective learning. Although the 1-hour VAD training may not have been sufficient to boost facilitators' confidence in facilitating VAD, it helped to increase their awareness of students' emotional changes and use more tact when offering critical comments. Along with their preconceptions of video use causing more stress, VAD facilitators became more sensitive and considerate towards learners' emotions. This point corresponds well with Study III, where students described that an effective VAD facilitator should care about their emotions and adjust their level of facilitation to optimise learning. Indeed, such expectations should not only be limited to VAD facilitators. Given that debriefing is viewed as a stressful activity, all facilitators should take care of participants' psychological safety, regardless of the debriefing method used. To a certain extent, I was confident that the three-phase VAD framework had the potential to shift facilitators' perceptions and practices towards more student-centred learning, making them 'fraternal partners' rather than 'the sage on the stage'. These findings also challenge those of an earlier study, which found that nursing facilitators seldom conduct effective debriefings 
following simulation (Hall \& Tori, 2017), by demonstrating that nursing facilitators are capable of conducting high-quality VAD if they follow an evidence-based debriefing framework with a theoretical basis.

Several similarities and differences in debriefing practices between VAD and VD facilitators were identified in this project. In terms of the process of debriefing, both VAD and VD facilitators used structured debriefing and believed it promoted higher thinking and meaningful learning, which is consistent with claims made by Mariani et al. (2014). With respect to debriefing for success, both VAD and VD facilitators faced similar challenges related to student engagement in terms of finding ways to motivate students who were less active. The strategies proposed by VD facilitators included using effective questioning, promoting reflection and offering collective comments according to predefined learning objectives. Moreover, they preferred to engage less-active students using direct questions (e.g. how, why and what) and improve their own debriefing skills through practice. This aligns with evidence for the GAS model, which focuses on 'what you did', 'how you did' and 'how you can improve' (Sawyer et al., 2016). Unlike the VD facilitators, whose strategies were mainly facilitator focused, VAD facilitators were more student oriented in terms of their debriefing practices, which may have been attributable to the influence of the three-phase framework, which emphasises rapport building, psychological safety and 'crystal clear' comments with good judgement. To a certain extent, the developed VAD framework showed the potential to shift facilitators' awareness and practices towards student-centred learning, which advocates for acknowledging students' voices and experiences in the process of knowledge construction. In addition, the VAD facilitators preferred to give personalised comments with selected clips to engage students.

The aforementioned challenge faced by facilitators also infers that the level of facilitation was considered low to moderate, based on Waznonis's (2015) classification of facilitation levels. This postulation is in line with the findings of Study IV, which reported that facilitators lacked a strong theoretical foundation with which to support their debriefing practices, raising concerns about their understanding of the relationship between learning concepts and their ability to interpret environmental observations and strategize facilitation in SBL (Schunk, 2012). For example, SBL has a long tradition of creating active learning opportunities and embracing various perspectives to co-construct knowledge. If facilitators are not familiar with the key concept of constructivism, they may conduct debriefing with a focus on passive 
knowledge transfer and have limited tolerance to alternative opinions about the nature of reality, hindering the process of co-constructing knowledge. If facilitators are not aware of ELT, they will be less likely to guide students in systemic learning through reflecting on and evaluating cognitive, affective, behavioural and social aspects or foster learning transfer from the simulated setting to real life. If the trend of using simulation to partially replace clinical placement continues, it is imperative that facilitators expand their knowledge of theory and enhance their values to ensure quality learning and outcomes.

Some maybe question whether there would be any difference in outcomes if VD and VAD facilitators received the same debriefing training using the same three-phase framework. There is no direct answer to this at this time because of the lack of empirical studies and this being only an initial attempt at developing a framework for VAD. Nonetheless, based on the current evidence investigating the instructional use of video and its central role in the assessment of performance, I made some assumptions related to student learning. Rather than being a tool for remembering, video was used to engage learners and prompt reflection by enabling them to view their own performance from a distance and obtain a more realistic picture than that which is provided by memory. Memory may be distorted and hinder a true examination of performance (Grant et al., 2010), while video may be used to complement recollections and allow learners to revisit scenarios and access the details of words, behaviours and events across a time sequence (Kong et al. 2010). Similarly, in this project, video was used as solid evidence to encourage students to reconceive their performances in the scenario. In doing so, the thirdperson perspective (the observer view) produced by the video was contrasted with the firstperson experience of the actual situation to facilitate students to discover, understand and interpret the frames behind their actions and their possible perception gaps. Following the video reviews, the facilitators did not simply pose questions in search of correct answers from students. Instead, they used advocacy-inquiry questioning to guide performers to reconceive their performances based on how the situation appeared on the screen, with the intent of bringing old frames to the surface. Through advocacy-inquiry questioning, facilitators assisted those students who failed to properly reflect to explore their thoughts, diffuse their emotions and reorganise and make sense of new constructs. In doing so, the students were more likely to detect unfinished tasks, unresolved questions and incomplete documentations. Additionally, comments from the facilitator and peers substantiated the video review and guided students to compare and contrast their frames, developing insights into the relationships between feelings, cognition and outcomes. Without the video, it would not have been possible for the nursing 
students to evaluate their performance from a third-person perspective (to see their actual performance rather than their perceived performance) to gain new insights. Therefore, it may be difficult for a three-phase VD to achieve similar outcomes as VAD. In fact, the power of video in debriefing has been confirmed in studies by McIlvenny (2011), in which the use of video helped participants to reconceptualise their experiences, and Johansson (2017), in which the use of video enhanced learners' sense of camaraderie. In sum, video plays an important role in the assessment of performance in competence-based nursing education by enabling students to observe their own actions from a third-person perspective, reactualise the scenario and reconceptualise how the performance was seen and assessed. Rather than focusing on their mistakes, students should collaborate with their facilitator, with the aid of video, to explore the frame-actions-results causal sequence in reverse order to develop alternative frames and actions for the future. With respect to the earlier question of, 'If we provide both VD and VAD facilitators with the same debriefing training in the three-phase framework, would there be any differences in outcomes?', I am confident that it is hypothetically possible for VD facilitators to improve their awareness and practices of student-centred learning after the three-phase framework training if they adhere to the suggested learning activities. However, I am uncertain about student outcomes if the important element of video is removed from the process of experience-based knowledge construction, warranting future research to shed light on these assumptions and narrow the gap.

Nevertheless, learners may not be able to innately derive knowledge from simulated experiences or connect the lessons learned with their real-life counterparts. In other words, video is important, but it does not guarantee success. Johansson et al. (2017) caution that without proper guidance, learners tend to use their own appearance as a starting point for comments, distracting their attention from the instructional agenda of highlighting relevant aspects of professional conduct. Likewise, Fukkink et al. (2011) warn that unguided viewing may lead to superficial impressions, requiring instructional efforts to redirect learners' attention to substantial aspects. How the recorded performance is seen, reflected upon and assessed is not provided by the video itself, and it should be tied to the instruction of debriefing. In this project, the focus on the audiovisual aspects of students' performances in the scenarios was established through the facilitator's questions and maintained throughout peer feedback. Facilitators remained central in addressing the intended issues in group discussions to keep students on track and shape their perceptions. As claimed by Johansson et al. (2017), by showing footage of a key part of the scenario, followed by posing the initial question, the 
facilitators set the agenda of the sequence and upgraded the level of assessment from 'clear' to 'crystal clear'.

\section{Culture of kiasu (kiasuism)}

Study III revealed the unique culture of kiasu (kiasuism) in influencing nursing students' attitudes towards VAD. Kiasuism is described as 'an obsessive desire for value for moneyhailed as a national fixation in Singapore' (Ho et al., 1998, p. 359). According to Hwang (2003) and Yap (2013), kiasuism has at least two conflicting facets: a desirable positive attitude in which diligence and hard work are applied to meet the demands of the task (i.e. doing well and being competitive) and an undesirable negative attitude in which efforts are made to prevent others from getting ahead (i.e. the fear of losing out). The kiasu culture is deeply rooted in many aspects of Singaporean students' lives, not only education. In a society that accentuates the value of meritocracy and elitism, success among students is perceived as academic achievement because most believe that academic success will greatly increase their chance of higher positions and better socioeconomic status in the future (Ong \& Cheung, 2016; Barr \& Skrbiš, 2008). This culture has motivated students towards more learning-oriented behaviours and extra efforts in their work (Lim, 2013). Hence, it is not surprising that nursing students were able to quickly adapt to VAD after their initial reluctance. On this basis, the transferability of Study III should be carefully gauged by readers. Although a similar competitive culture exists in other countries or settings, the kiasu culture in Singapore requires consideration of the multifaceted nature of competitiveness when applying the findings to other contexts.

\section{Learners' stress}

The findings of Study III suggest that the stress experienced by nursing students attending VAD needs to be further explored. Study IV responded to this call by disclosing that the stress caused by VAD was comparable to that of VD, and repeated exposure reduced stress, challenging the current criticisms of VAD and substantiating the claim that the addition of video will not cause extra stress for learners (Rossignol, 2017). These findings may be explained by the following. While it is common for learners to experience stress on first exposure, they will be more likely to accept the new strategy after experiencing it because they will perceive that their personal resources are sufficient to meet the demands of the learning situation (Royle \& Hargiss, 2015). Because of the nature of simulation, learners experienced acute short-term stress during the scenarios and debriefing, the reasons for which may be multifactorial (e.g. exposure of 
inadequate knowledge, the presence of faculty and a judgemental environment). However, most simulation studies tend to amplify the negative feelings experienced in VAD, resulting in incomplete conclusions and prejudice against VAD. In fact, stress is a subjective and controllable imbalance between demands and resources, which may be moderated by a learner's personal resources (Goff, 2011), and only high levels of stress negatively affect learning (Beischel, 2013; Turner \& McCarthy, 2017). It was unclear in this project whether the role assignment (observer vs performer) affected students' stress levels. Based on the literature, the observer role tends to elicit lower stress levels (Bethards, 2014).

\section{Assessing learning}

Disparities exist between learners' conceptions and behaviours (Bandura, 1986), and hypothetical assessment is not sufficiently powerful to guarantee performance change. Learning should be physically assessed to resolve the feelings identified by learners in the scenario and examine their new frames refined in the debriefing. Thus, repeated scenarios were used in Study II to assess student learning, both physically (actions) and hypothetically (frames). This was based on MacLean et al. (2019) that providing an opportunity to redo the scenario may be likened to redemption, contributing to the consolidation of learning. The findings of Study II show that VAD significantly improved students' individual and overall scores pertaining to six competencies, which is in line with a previous study (Gamboa et al., 2018). This may have been because video use added some distance for observation and selfreflection and gave a realistic picture of students' proficiency levels. Through aligning perceived performance with actual performance, students were able to evaluate their performance and correctly identify gaps. In this project, the use of video was significant for assessing learning and correcting lessons learned by aiding students to dredge their memories and reconstruct an account of the salient features based on undeniable evidence to reduce the risk of disputes and learning lessons incorrectly. Moreover, the literature confirms that watching videos in groups facilitates the development of a collaborative view and motivation to change (Manojlovich et al., 2019).

\section{Challenges associated with video-assisted debriefing}

Several challenges were identified with the use of VAD. Students were hesitant to engage in VAD because they knew their performance would be recorded. Thus, it was necessary to desensitise students to the fear of cameras prior to VAD. Video use may cause observers to 
feel bored or reliant on footage. In response to this, the facilitators attempted to develop the observer role by offering the SAT as an observation guide to improve their critique and feedback skills. Upon project completion, no observer students were identified by facilitators as being disengaged in the debriefing because of video use; however, the quality of their comments varied (although this was beyond the scope of this project). The quality of the videos was also highlighted, including the fact that important steps were not captured, and certain parts of the footage were not clear because of the absence of a zoom function. Facilitators commented that conducting VAD caused them stress from having to manage technical issues and caused students to be lax because they relied on the video and facilitator for feedback. From the researchers' perspectives, VAD required more groundwork (e.g. permission from management and consent from the students) and effort (e.g. checking the cameras). Given the drawbacks in the video facilities (e.g. video controls and monitors being in different rooms), the VAD facilitators were unable to navigate the video inside the debriefing room and required additional people to control the video. Managing the technical issues was challenging and interrupted the progress of debriefing. Tablet-like devices appear to be more suitable for VAD because of features such as built-in cameras, video stabilisation and sophisticated zoom functions.

\section{Methodological considerations}

Study I (a systematic review) included quantitative studies only, limiting its capacity in providing a comprehensive view of VAD and how video use influences learners' experiences in debriefing. To complement Study I, it would be of value to conduct a review of qualitative studies on VAD to obtain a fuller picture of VAD in health professions education. Given the methodological heterogeneity and differences in outcome measures in the included studies, it was not possible to pool the studies into a meta-analysis because the existence of heterogeneity may affect the interpretation and conclusions drawn from a meta-analysis. Moreover, only studies published in English were included because of limited translation resources, which may have biased results because most of the included studies were conducted in the Western context.

\section{Internal and external validity of quantitative studies}

Study II (a pilot quantitative study) used a single-group, pretest-posttest design to examine the preliminary effects of VAD. This design may not be the best to provide plausible explanations for the changes observed because of potential threats to internal validity. It is possible that there 
were differences between the first and second measurements (e.g. if a participant attended another VAD session during the study period), confounding the effects of VAD. With this in mind, students were reminded not to attend other VAD sessions during the study period. Data were collected from only one site, limiting the generalisability of the study findings. Moreover, the pretest-posttest design required students to complete identical questionnaires twice, which may have caused a testing threat to the observed changes. The existing teacher-student relationship may have affected outcomes and caused social desirability bias. To minimise this bias, students' performances in this study were independent of their academic grades. Being aware of these limitations, a clustered randomised controlled study (Study IV) was conducted to replicate the findings by controlling extraneous factors to strengthen internal validity.

Study IV used a multilevel mixed methods design to explore the effects of VAD in both nursing students and facilitators. This was based on the conclusion of Creswell and Clark (2007) that an experiment may be more meaningful if both 'process' and 'product' data are gathered. Hence, data triangulation was used because quantitative (numerical) data addressed students' learning outcomes, while qualitative (textual) data explored facilitators' perceptions of VAD. This study did not provide a third gender option (such as 'do not want to report') when collecting demographic information because most simulation studies in the context of undergraduate nursing education have reported gender as 'male' or 'female', without providing a third option (Grant et al., 2010; Beaird, et al., 2017). Moreover, this design was aimed at understanding the impact of VAD from different perspectives (that of students and facilitators).

There were some limitations to Study IV. First, the intervention fidelity of the three-phase VAD (i.e. whether the VAD was delivered as planned) was not explicitly assessed. However, prior to the study, the VAD facilitators received training in VAD, including its technical steps, structure, time frame and questioning techniques, which helped to standardise the debriefing practice and strengthen the intervention fidelity of the study (Siedlecki, 2018). Second, using an open-ended question survey to collect qualitative data may have affected the richness of the data. Hence, it will be beneficial for future research to interview facilitators with maximum variation to obtain a full picture of VAD. Third, subgroup comparisons of stress levels between observers and performers were not performed. The reasons for this were as follows: (1) Because of the high student enrolment numbers with limited resources, this project focused on group-based learning by combining both roles to complement each other in one learning unit; (2) I believed that all students were in a safe learning environment, and the step of sharing 
feelings in debriefing helped to alleviate performers' stress, diminishing the differences in stress levels experienced by the two roles; (3) The small differences in stress levels experienced by students in the different roles were less likely to significantly affect learning outcomes; and (4) Continual efforts to reduce students' stress in debriefing were far more important than identifying which role (i.e. performer or observer) experienced more stress in view of its multifactorial causes. While these considerations were applied to this project, it does not minimise the importance of comparing the psychological outcomes of the different roles in SBL, which should be determined by the needs and aims of individual studies. Nevertheless, the validity of mixed methods research remains inconclusive because scholars hold different views on it, making it difficult to assess. In this study, a mixed methods appraised tool (Hong et al., 2018) was used to guide the appraisal of methodological quality. The results showed that the study met all five criteria in the qualitative category and four criteria in the quantitative category, with one unmet criteria pertaining to outcome assessors being blinded to the intervention (because nursing students were the outcome assessors and they were aware of the VAD intervention).

\section{Reliability of the instruments}

Validated and reliable instruments were used in this project, and data analysis and interpretation were guided by the instructions of the respective instruments. Nevertheless, data were collected using self-reported questionnaires, which are subject to biases and limitations. Students may not be fully honest in their answers or attempt to give more socially acceptable answers to protect their confidentiality, leading to potential social desirability bias. To minimise this risk, students were reassured that their confidentiality would be preserved through anonymising the survey process (i.e. no identifiers were collected). The questionnaire statements may also have been interpreted differently or incorrectly by students. In consideration of this, the principle investigator's contact details were provided in case students needed to clarify certain questions. No students contacted the principle investigator during the study. In Study IV, students rated their stress scores retrospectively after debriefing, which may have caused the scored stress levels to deviate slightly from actual levels. Therefore, it would be more valuable to measure salivary amylase or cortisol levels or heartrate variability if research resources permit. In addition, the inter-rater reliabilities of the respective instruments were calculated with adequate values of Cronbach's alpha above .70 (Polit \& Beck, 2012). 


\section{Trustworthiness of qualitative studies}

To ensure the trustworthiness of qualitative studies, the principles of credibility, dependability, confirmability and transferability are applied (Lincoln \& Guba, 1985). Credibility refers to the consistency between participants' views and the researcher's interpretation of them, which may be improved through prolonged engagement, data triangulation and researcher triangulation (Nowell et al., 2017). Hence, member checking was applied in Study III to strengthen credibility because it helped to ensure that the developed themes were based on the evidence and captured that which was concealed in participants' accounts (Vaismoradi \& Snelgrove, 2019). Prolonged engagement was applied in Study IV because most of the researchers knew the facilitator participants and were familiar with the study organisation, helping to establish trust between the two parties. Dependability was maintained in Study III by inviting an external researcher to audit the analysis process and evaluate whether the findings matched the data, while the dependability of Study IV was ensured by describing the research design and its implementation in detail to enable future researchers to repeat the work. Confirmability refers to how conclusions and interpretations are derived from the data (Nowell et al., 2017); hence, analyst triangulation among the three researchers was applied in Studies III and IV to establish confirmability. Transferability in qualitative research refers to case-to-case transferability. Given that it is impossible for researchers to know all the sites to which findings may be transferred, transferability of qualitative findings should be decided by readers rather than researchers (Nowell et al., 2017). To facilitate study transferability in both Studies III and IV, I described the characteristics of participants, the context (e.g. the final year of a 3-year undergraduate nursing program at the tertiary level) and the process of data analysis in detail. Taking into account the influences of meritocracy and kiasuism, the transferability of findings should be carefully considered by readers. The Consolidated Criteria for Reporting Qualitative Research checklist (Tong et al., 2007) was used to guide Study III, with the aim of evaluating the research process and positively influencing theme construction (Boeije et al., 2011).

With regard to data analysis, thematic analysis was used in Study III to analyse the transcribed data, and qualitative content analysis was used in Study IV to analyse the written comments. Qualitative content analysis is commonly used with overt data to easily categorise it (Vaismoradi \& Snelgrove, 2019). These two methods have some differences. Although they use similar analytical strategies, codes and meanings, thematic analysis generates themes (latent content) to achieve interpretation (Braun \& Clarke, 2006), while qualitative content 
analysis generates categories and subcategories (manifest content). The use of thematic analysis or content analysis depends on whether the researcher wishes to achieve interpretive or descriptive levels of analysis (Vaismoradi et al., 2016). Thematic analysis is a purely interpretative approach, which largely depends on the researcher's subjectivity and personal insights to interpret and understand the essence of data through searching for themes. Therefore, it was suitable to use thematic analysis in Study III to understand the meanings of students' experiences in VAD. Qualitative content analysis can be used for both interpretive and descriptive analysis. In Study IV, descriptive analysis of the written comments was performed.

With respect to data saturation, Study III data reached saturation after the fourth focus group because no new codes or themes emerged from the subsequent two groups and most perspectives appeared to have been covered. In Study IV, data saturation occurred after the sixth document because no new information was generated from the subsequent two documents. The rationale for data saturation in this project was based on the fact that (1) no new codes were determined during data collection and from thematic analysis (Braun \& Clarke, 2019) and (2) new data repeated what had been expressed in previous data (Saunders et al., 2017). However, there is no one-size-fits-all method of reaching data saturation because of the heterogeneity of study designs. Hence, Braun and Clarke (2019) argue for more precision in defining the concept of data saturation in thematic analysis and concrete guidance on determining the likely point of data saturation in advance of data collection.

\section{Reflections on the use of experiential learning theory}

Learning from experience involves individual and collective learning, and ELT offers a blueprint that illustrates the harmonious transformational changes in individual learning. It demonstrates how to foster learning from experience using four sequential learning activities and recognises the individuality in learning processes by introducing four basic individual learning styles: convergence, divergence, assimilation and accommodation (Kolb, 2015). The prevalent adoption of ELT across a wide range of situations and disciplines affirms its generalisability to all adult learning, including nursing education. However, this model does not sufficiently explain the process of learning from experience, aligning with Seaman (2008), who argues that defining experiential learning as an orderly series of mechanical steps oversimplifies the process of learning. Moreover, ELT neither provides a clear process of how to reflect nor classifies the expectations of reflection, making it difficult to support the claim that reflection is the key to learning from experience. Kayes (2002) echoes this critique and 
suggests placing more emphasis on reflective practice in experience-based learning. Learning from experience is not a linear activity; hence, I agree with Seaman (2008) that the pattern of experience-reflect-learn embedded in ELT should be considered an ideology of experiential learning rather than a philosophy or a theory. ELT does not highlight social interactions in learning, making it inadequate to explain how knowledge is co-constructed in debriefing. Nevertheless, it may be adapted to various practical applications and support adult training programs that rely on self-direction (Seaman, 2008). In view of the complex process of learning, it would be beneficial to extend ELT in terms of its psychodynamic, social and institutional aspects. 


\section{Implications for practice}

The findings of this project may be used as a reference for researchers who are interested in debriefing practice and VAD. They may also be used to guide novice educators or faculty members who wish to integrate VAD into their simulation programs. For example, the findings of the systematic review suggest the use of a structured VAD for procedural skills training rather than for factual knowledge acquisition in SBL. Watching video clips in class is preferable to watching entire videos because it ensures a more efficient use of time and prevents fatigue.

The three-phase framework developed in this project may serve as a viable tool to assist facilitators in honing their VAD skills. For example, the framework may be used in debriefing workshops to equip novice faculty members with the concept of experiential learning and technical skills in debriefing. This project also has the potential to change the current practice of laboratory teaching by training senior students to conduct peer-led VAD for junior students, which would not only alleviate faculty shortages but also enhance senior students' professional development.

This project provides a better understanding of what learners experience during VAD in the context of nursing education and offers valuable insights into what is beneficial or troubling for learners, contributing to the body of knowledge regarding its best practice. For example, the identified emotional rollercoaster and ambivalent feelings arising from the use of VAD may help increase facilitators' awareness and allow them to put strategies in place to manage the adverse effects of stressors (e.g. desensitising learners prior to VAD or training observers in the use of the observation tool), enhancing learning experiences and outcomes. Concurrently, faculty members, managers and institutions may identify possible causes and modify the design of VAD accordingly to better fit students' learning needs and increase the effectiveness of such a technology-enhanced pedagogy. In addition, this project identified a gap in facilitators' knowledge of theoretical principles, constructs and values in debriefing, demonstrating the need for continuing professional development to enhance the quality and practice of VAD in SBL. 


\section{Future research}

To confirm the educational effects of the three-phase VAD in SBL, it will be beneficial for future research to collect data from multiple sites and different groups of healthcare students to strengthen the generalisability of this research findings. Observational studies could focus on facilitators' onsite debriefing practices (e.g. using checklists or videos) to gather objective data, while individual interviews could offer new insights into the effects and influences of the three-phase VAD on facilitators' perceptions and practices. To better understand the possible stressors or events associated with changes in students' stress levels in SBL, future studies could use saliva (e.g. amylase or cortisol levels) or heartrate variability to monitor physiological changes during the debriefing process.

The effects of the three-phase peer-led VAD or tutor-led VD are uncertain, warranting future research in this area. If applying this framework to peer-led VAD, it would be important to assess its feasibility in a pilot study prior to a full-scale study to ensure its fitness for that setting. Moreover, the actual effects of VAD in learning transfer are unknown, warranting future studies on learners' behaviours and patient outcomes in clinical settings. Considering the heavy investments in equipment, human resources and time for VAD, its cost effectiveness should be determined in future research. 


\section{CONCLUSIONS}

This project evaluated the existing evidence for VAD in health professions education and reported on the inconsistent educational effects when compared with VD, demonstrating the lack of understanding of its best practice and the need for a proper framework to facilitate its use. To fill this gap, a three-phase framework for VAD was developed and tested, confirming its ability to improve nursing students' debriefing experiences, reflective abilities and competencies following HFS, with associated stress comparable to that experienced in VD. Notably, this project reported on the emotional rollercoaster experienced by nursing students during VAD and challenged the snapshot of negative emotions reported in other studies, providing some clarity to the inconsistent evidence regarding learners' experiences of VAD. By adding new knowledge to the current limited qualitative evidence, this project helps to vindicate the criticisms of VAD in health professions education, contributing to its best practice. Kolb's ELT was used to scaffold this project because it provided a theoretical lens for the researchers to gain insights into how learning may be fostered through VAD and how students may learn from experience through different role assignments. Moreover, this project also found that the developed three-phase VAD has the potential to shift facilitators' debriefing practices towards student-centred learning. Technical issues were the main obstacle for the use of VAD in health profession education; thus, a sophisticated video system is essential for VAD success.

Given that debriefing is a stressful activity, the findings of this project echo the importance of creating a safe and supportive environment to ensure that learners feel less threatened and more receptive to critique during $\mathrm{VAD}$, despite the influence of kiasuism, to achieve meaningful learning with optimised experiences. To a certain degree, this project supports the claim that VAD is the gold standard of HFS. Future research is needed to further investigate the effects of using a three-phase VAD in different settings. 


\section{SVENSK SAMMANFATTNING}

Bakgrund: Att simulera olika vårdsituationer är idag en väl använd pedagogisk metod inom hälsoutbildningarna eftersom erfarenheten av att träna simulering kan förbättra inlärningen. Debriefing ingår som en integrerad del i simuleringen och bidrar till att omvandla erfarenheten till kunskap. Video-assisterad debriefing innebär att simuleringssituationen filmas och filmen används sedan i debriefingen. Trots att det är vanligt att använda video-assisterad debriefing är bevisen för att det är bättre än debriefing utan video oklara.

Syfte: Syftet med denna avhandling var att utveckla en strukturerad video-assisterad debriefing att använda i samband med simulering på sjuksköterskeutbildningen. Att sedan testa den på sjuksköterskestudenter för att se om den påverkade deras debriefing erfarenhet, reflektionsförmåga och omvårdnadskompetens jämfört med sjuksköterskestudenter som erhöll debriefing utan video. Syftet var också att utforska handledarnas uppfattning och genomförande av video-assisterad debriefing i samband med simulering.

Design och Metod: Avhandlingen består av fyra studier med olika design. Studie 1 var en systematisk litteraturstudie där 23 artiklar innehållande tidigare erfarenheter av videoassisterad debriefing från hälsoutbildningar granskades och syntetiserades. I studie 2 utvecklades en strukturerad video-assisterad debriefing i tre faser som sedan testades på sjuksköterskestudenternas $\quad(n=63)$ debriefing erfarenhet, reflektionsförmåga och omvårdnadskompetens genom en före-efter design. I studie 3 användes en kvalitativ design för att med hjälp av fokusgrupper utforska sjuksköterskestudenternas $(n=27)$ erfarenheter av att använda video-assisterad debriefing. Studie 4 var en mixed-methods studie som undersökte betydelsen av en strukturerad video-assisterad debriefing jämfört med debriefing utan video på sjuksköterskestudenternas $(n=145)$ debriefing erfarenhet och uppfattning av stress i samband med debriefingen. I studie 4 undersöktes även handledarnas $(n=8)$ uppfattningar och genomförande av video-assisterad debriefing.

Resultat: Studie 1 visade att video-assisterad debriefing var jämförbart med debriefing utan video vad det gäller erfarenheter, attityder och genomförande men var inte bättre vad det gäller förvärvande av ny kunskap. Resultaten från studie 2 visade att den strukturerade videoassisterade debriefingen signifikant förbättrade sjuksköterskestudenternas debriefing erfarenhet $(p<0,001)$, reflektionsförmåga $(p<0,01)$ och omvårdnadskompetens $(p<0,001)$. Studie 3 visade att strukturerad video-assisterad debriefing var som en emotionell bergodalbana 
för sjuksköterskestudenterna, från att inte vara så villiga att delta i videofilmning, rädsla för att bli bedömda följt av upplevelse av stress och motstnd till en känsla av tacksamhet och tillfredställelse. Studie 4 demonstrerade att jämfört med debriefing utan video, kunde strukturerad video-assisterad debriefing förbättra sjuksköterskestudenternas debriefing erfarenhet $(p=0,01)$ men det var ingen skillnad i uppfattningen av stress mellan grupperna. Upprepade tillfällen med strukturerad video-assisterad debriefing minskade däremot stressnivåerna. Strukturerad video-assisterad debriefing kunde även förbättra handledarnas uppfattningar och genomförande.

Konklusion: I denna avhandling utvecklades en strukturerad video-assisterad debriefing för sjuksköterskestudenter. Efterföljande studier påvisade dess utbildningspotential vad det gäller erfarenheter, reflektionsförmåga och omvårdnadskompetens i samband med simulering utan att tillföra mer stress än vid debriefing utan video. Sjuksköterskestudenternas emotionella upplevelse utmanar tidigare studiers resultat och bringar viss klarhet i studenternas erfarenheter. Avhandlingen visar även att en strukturerad video-assisterad debriefing har potential att öka möjligheterna för att handledarnas genomförande av debriefingen ska bli mer student-centrerad. 


\section{ACKNOWLEDGEMENTS}

Embarking on a journey towards gaining a PhD can be exciting, challenging, demoralising and rewarding. Many people have supported me along this journey, in both the research itself and the completion of this thesis. As this journey draws to an end, I would like to take the opportunity to express my gratitude to those who have provided me with guidance, support, care and love in various ways over the years.

First and foremost, I wish to extend my deepest gratitude to my principal supervisor Professor Evalotte Mörelius and co-supervisor Associate Professor Wang Wenru for their patient guidance, words of encouragement, advice in keeping my progress on schedule and valuable critique of the manuscripts and this thesis. They empowered me with much autonomy and trust to build my research foundation and develop my capability in intellectual criticism and debate.

I would also like to thank Professor Emily Ang Neo Kim, head of the Alice Lee Centre for Nursing Studies and my work supervisor, for her support and advice in my pursuit of a $\mathrm{PhD}$ and professional growth. Of course, to my colleagues and friends Dr Sam Goh Hongli and Dr Vivien $\mathrm{Xi} \mathrm{Wu}$, my sincere gratitude for your friendship, encouragement and contributions to the research project. My grateful thanks are also extended to all participants in this research, including our lovely nursing students and colleagues at the Alice Lee Centre for Nursing Studies. Without you all, this research and thesis would not have been possible.

Last but not the least, to my super-lovely and supportive family, especially my father-in-law Andrew Yun and my mother-in-law Amy Chan, who helped to take care of the entire family and my 2-year old daughter Shanisse Yun. Thank you for your support and care, which enabled me to focus on my PhD study and career development. To my husband, Mr Yun Hein Yeong, your unconditional love, humour and companionship have supported me through good times and bad, making this arduous journey pleasant and successful. 


\section{REFERENCES}

1. Alhaj Ali, A. (2018). The impact of high fidelity simulation debriefing modalities on cardiac emergency knowledge \& leadership skills among acute care nurse practitioner students (Order No. 27981025). Available from ProQuest Dissertations \& Theses Global. (2391997964). Retrieved from http://libproxy1.nus.edu.sg/login?url=https://searchproquest-com.libproxy1.nus.edu.sg/docview/2391997964?accountid=13876

2. Aliakbari, F., Parvin, N., Heidari, M., \& Haghani, F. (2015). Learning theories application in nursing education. Journal of Education and Health Promotion, 4. doi:10.4103/22779531.151867

3. Almeida, R. G. d. S., Mazzo, A., Martins, J. C. A., Coutinho, V. R. D., Jorge, B. M., \& Mendes, I. A. C. (2016). Validación para la lengua portuguesa de la Debriefing Experience Scale. Revista brasileira de enfermagem, 69(4), 705-711. doi:10.1590/0034-7167.2016690413i

4. Armstrong, G. E., Spencer, T. S., \& Lenburg, C. B. (2009). Using quality and safety education for nurses to enhance competency outcome performance assessment: a synergistic approach that promotes patient safety and quality outcomes. The Journal of nursing education, 48(12), 686-693. doi:10.3928/01484834-20091113-02

5. Aukes, L. C. (2008). Personal reflection in medical education.

6. Aukes, L. C., Geertsma, J., Cohen-Schotanus, J., Zwierstra, R. P., \& Slaets, J. P. (2007). The development of a scale to measure personal reflection in medical practice and education. Medical teacher, 29(2-3), 177-182.

7. Bandura, A. (1986). Social foundations of thought and action: a social cognitive theory. Englewood Cliffs, N.J: Prentice-Hall.

8. Barr, M. D., \& Skrbiš, Z. (2008). Constructing Singapore: Elitism, ethnicity and the nationbuilding project: Nias Press.

9. Beaird, G., Nye, C., \& Thacker, L. R. (2017). The Use of Video Recording and Standardized Patient Feedback to Improve Communication Performance in Undergraduate Nursing Students. Clinical Simulation in Nursing, 13(4), 176-185. doi:10.1016/j.ecns.2016.12.005

10. Beauchamp, T. L., \& Childress, J. F. (2013). Principles of biomedical ethics (7th ed.). New York: Oxford University Press.

11. Beischel, K. P. (2013). Variables affecting learning in a simulation experience: A mixed methods study. Western Journal of Nursing Research, 35(2), 226-247. doi:10.1177/0193945911408444

12. Bethards, M. L. (2014). Applying social learning theory to the observer role in simulation. Clinical Simulation in Nursing, 10(2), e65-e69. doi:10.1016/j.ecns.2013.08.002

13. Bland, A. J., \& Tobbell, J. (2016). Towards an understanding of the attributes of simulation that enable learning in undergraduate nurse education: A grounded theory study. Nurse Education Today, 44, 8-13. doi:10.1016/j.nedt.2016.05.011

14. Blanié, A., Gorse, S., Roulleau, P., Figueiredo, S., \& Benhamou, D. (2018). Impact of learners' role (active participant-observer or observer only) on learning outcomes during high-fidelity simulation sessions in anaesthesia: A single center, prospective and randomised study. Anaesthesia Critical Care \& Pain Medicine, 37(5), 417-422. doi:10.1016/j.accpm.2017.11.016

15. Boeije, H. R., van Wesel, F., \& Alisic, E. (2011). Making a difference: Towards a method for weighing the evidence in qualitative synthesis. Journal of Evaluation in Clinical Practice, 17(4), 657-663. doi:10.1111/j.1365-2753.2011.01674.x

16. Boet, S., Bould, M. D., Bruppacher, H. R., Desjardins, F., Chandra, D. B., \& Naik, V. N. (2011). Looking in the mirror: self-debriefing versus instructor debriefing for simulated crises. Critical Care Medicine, 39(6), 1377-1381.

17. Boud, D., Keogh, R., \& Walker, D. (2013). Reflection: Turning experience into learning: Routledge. 
18. Braun, V., \& Clarke, V. (2006). Using thematic analysis in psychology. Qualitative research in psychology, 3(2), 77-101. doi:10.1191/1478088706qp063oa

19. Braun, V., \& Clarke, V. (2013). Successful qualitative research: A practical guide for beginners: sage.

20. Braun, V., \& Clarke, V. (2019). To saturate or not to saturate? Questioning data saturation as a useful concept for thematic analysis and sample-size rationales. Qualitative research in sport, exercise and health, 1-16. doi:10.1080/2159676x.2019.1704846

21. Brett-Fleegler, M., Rudolph, J., Eppich, W., Monuteaux, M., Fleegler, E., Cheng, A., \& Simon, R. (2012). Debriefing assessment for simulation in healthcare: development and psychometric properties. Simulation in healthcare : journal of the Society for Simulation in Healthcare, 7(5), 288-294. doi:10.1097/SIH.0b013e3182620228

22. Bruno, N., \& Pavani, F. (2018). Perception: A multisensory perspective (First ed.). Oxford: Oxford University Press.

23. Cheng, A., Eppich, W., Grant, V., Sherbino, J., Zendejas, B., \& Cook, D. A. (2014). Debriefing for technology - enhanced simulation: a systematic review and meta - analysis. Medical Education, 48(7), 657-666. doi:10.1111/medu.12432

24. Chronister, C., \& Brown, D. (2012). Comparison of simulation debriefing methods. Clinical Simulation in Nursing, 8(7), e281-e288. doi:10.1016/j.ecns.2010.12.005

25. Colman, A. M. (2015). A dictionary of psychology (Fourth ed.). Oxford: Oxford University Press.

26. Cook, D. A., \& Reed, D. A. (2015). Appraising the Quality of Medical Education Research Methods: The Medical Education Research Study Quality Instrument and the NewcastleOttawa Scale-Education. Academic Medicine, 90(8), 1067-1076. doi:10.1097/ACM.0000000000000786

27. Coolen, E. H., Draaisma, J. M., Hogeveen, M., Antonius, T. A., Lommen, C. M., \& Loeffen, J. L. (2012). Effectiveness of high fidelity video-assisted real-time simulation: a comparison of three training methods for acute pediatric emergencies. International journal of pediatrics, 2012.

28. Creswell, J. W., \& Plano Clark, V. L. (2007). Designing and conducting mixed methods research. Thousand Oaks, Calif: SAGE Publications.

29. Delisle, M., Ward, M. A. R., Pradarelli, J. C., Panda, N., Howard, J. D., \& Hannenberg, A. A. (2019). Comparing the learning effectiveness of healthcare simulation in the observer versus active role: Systematic review and meta-analysis. Simulation in Healthcare: The Journal of the Society for Simulation in Healthcare, 14(5), 318-332. doi:10.1097/SIH.0000000000000377

30. Dennick, R. (2016). Constructivism: reflections on twenty five years teaching the constructivist approach in medical education. International journal of medical education, 7 , 200. doi: 10.5116/ijme.5763.de11

31. Dieckmann, P., Molin Friis, S., Lippert, A., \& Østergaard, D. (2009). The art and science of debriefing in simulation: Ideal and practice. Medical teacher, 31(7), e287-e294. doi:10.1080/01421590902866218

32. Dreifuerst, K. T. (2009). The essentials of debriefing in simulation learning: A concept analysis. Nursing education perspectives, 30(2), 109-114.

33. Dutheil, F., Pereira, B., Moustafa, F., Naughton, G., Lesage, F.-X., \& Lambert, C. (2017). Atrisk and intervention thresholds of occupational stress using a visual analogue scale. PloS one, 12(6), e0178948. doi:10.1371/journal.pone.0178948

34. Ertmer, P. A., \& Newby, T. J. (2013). Behaviorism, Cognitivism, Constructivism: Comparing Critical Features From an Instructional Design Perspective. Performance Improvement Quarterly, 26(2), 43-71. doi:10.1002/piq.21143 
35. Fanning, R. M., \& Gaba, D. M. (2007). The Role of Debriefing in Simulation-Based Learning. Simulation in Healthcare, 2(2), 115-125. doi:10.1097/SIH.0b013e3180315539

36. Ferguson, L. M., Yonge, O., \& Myrick, F. (2004). Students' involvement in faculty research: Ethical and methodological issues. International Journal of Qualitative Methods, 3(4), 56-68. doi:10.1177/160940690400300405

37. Fey, M. K., Scrandis, D., Daniels, A., \& Haut, C. (2014). Learning Through Debriefing: Students' Perspectives. Clinical Simulation in Nursing, 10(5), e249-e256. doi:10.1016/j.ecns.2013.12.009

38. Fukkink, R. G., Trienekens, N., \& Kramer, L. J. (2011). Video feedback in education and training: Putting learning in the picture. Educational Psychology Review, 23(1), 45-63. doi:10.1007/s10648-010-9144-5

39. Gaba, D. M. (2004). The future vision of simulation in health care. BMJ quality \& safety, 13(suppl 1), i2-i10. doi:10.1136/qshc.2004.009878

40. Gamboa, O. A., Agudelo, S. I., Maldonado, M. J., Leguizamón, D. C., \& Cala, S. M. (2018). Evaluation of two strategies for debriefing simulation in the development of skills for neonatal resuscitation: a randomized clinical trial. BMC Research Notes, 11(1), 739. doi:10.1186/s13104-018-3831-6

41. Gardner, R. (2013). Introduction to debriefing. Seminars in Perinatology, 37(3), 166-174. doi:10.1053/j.semperi.2013.02.008

42. Goff, A.-M. (2011). Stressors, Academic Performance, and Learned Resourcefulness in Baccalaureate Nursing Students. International Journal of Nursing Education Scholarship, 8(1), Article 1. doi:10.2202/1548-923X.2114

43. Graneheim, U. H., \& Lundman, B. (2004). Qualitative content analysis in nursing research: concepts, procedures and measures to achieve trustworthiness. Nurse Education Today, 24(2), 105-112. doi:10.1016/j.nedt.2003.10.001

44. Grant, J. S., Moss, J., Epps, C., \& Watts, P. (2010). Using video-facilitated feedback to improve student performance following high-fidelity simulation. Clinical Simulation in Nursing, 6(5), e177-e184. doi:10.1016/j.ecns.2009.09.001

45. Ha, E.-H. (2014). Attitudes toward Video-Assisted Debriefing after simulation in undergraduate nursing students: An application of Q methodology. Nurse Education Today, 34(6), 978-984. doi:10.1016/j.nedt.2014.01.003

46. Hall, K., \& Tori, K. (2017). Best Practice Recommendations for Debriefing in Simulation-Based Education for Australian Undergraduate Nursing Students: An Integrative Review. Clinical Simulation in Nursing, 13(1), 39-50. doi:10.1016/j.ecns.2016.10.006.

47. Harder, N., Ross, C. J., \& Paul, P. (2013). Student perspective of roles assignment in highfidelity simulation: An ethnographic study. Clinical Simulation in Nursing, 9(9), e329-e334. doi:10.1016/j.ecns.2012.09.003

48. Hattie, J., \& Timperley, H. (2007). The Power of Feedback. Review of Educational Research, 77(1), 81-112. doi:10.3102/003465430298487

49. Hean, S., Craddock, D., \& O'Halloran, C. (2009). Learning theories and interprofessional education: A user's guide. Learning in Health and Social Care, 8(4), 250-262. doi:10.1111/j.1473-6861.2009.00227.x

50. Heydari, A., Kareshki, H., \& Armat, M. R. (2016). Is Nurses' Professional Competence Related to Their Personality and Emotional Intelligence? A Cross-Sectional Study. Journal of caring sciences, 5(2), 121-132. doi:10.15171/jcs.2016.013

51. Ho, J. T. S., Ang, C. E., Loh, J., \& Ng, I. (1998). A preliminary study of kiasu behaviour - is it unique to Singapore? Journal of Managerial Psychology, 13(5/6), 359-370. doi:10.1108/02683949810220015

52. Hong, Q. N., Fàbregues, S., Bartlett, G., Boardman, F., Cargo, M., Dagenais, P., ... Pluye, P. (2018). The Mixed Methods Appraisal Tool (MMAT) version 2018 for information 
professionals and researchers. Education for information, 34(4), 285-291. doi:10.3233/EFI180221

53. Hwang, A. (2003). Adventure learning: Competitive (kiasu) attitudes and teamwork. The Journal of Management Development, 22(7), 562-578.

doi:http://dx.doi.org.libproxy1.nus.edu.sg/10.1108/02621710310484731

54. Johansson, E., Lindwall, O., \& Rystedt, H. (2017). Experiences, appearances, and interprofessional training: The instructional use of video in post-simulation debriefings. International Journal of Computer-Supported Collaborative Learning, 12(1), 91-112. doi:10.1007/s11412-017-9252-z

55. Karami, A., Farokhzadian, J., \& Foroughameri, G. (2017). Nurses' professional competency and organizational commitment: Is it important for human resource management? PloS one, 12(11), e0187863-e0187863. doi:10.1371/journal.pone.0187863

56. Kayes, D. C. (2002). Experiential learning and its critics: Preserving the role of experience in management learning and education. Academy of Management Learning \& Education, 1(2), 137-149. doi:10.5465/AMLE.2002.8509336

57. Kolb, D. A. (2015). Experiential learning: Experience as the source of learning and development: FT press.

58. Kolodner, J. L. (1997). Educational implications of analogy: A view from case-based reasoning. American psychologist, 52(1), 57. doi:10.1037/0003-066X.52.1.57

59. Krippendorff, K. (2019). Content analysis: An introduction to its methodology (Fourth ed.). Los Angeles: SAGE.

60. Kong, S. C. (2010). Using a web-enabled video system to support student-teachers' selfreflection in teaching practice. Computers \& Education, 55(4), 1772-1782. doi:10.1016/j.compedu.2010.07.026

61. Kriz, W. C. (2010). A Systemic-Constructivist Approach to the Facilitation and Debriefing of Simulations and Games. Simulation \& gaming, 41(5), 663-680. doi:10.1177/1046878108319867

62. Krogh, K., Bearman, M., \& Nestel, D. (2015). Expert Practice of Video-Assisted Debriefing: An Australian Qualitative Study. Clinical Simulation in Nursing, 11(3), 180-187. doi:https://doi.org/10.1016/j.ecns.2015.01.003

63. Lave, J., \& Wenger, E. (1991). Situated learning: Legitimate peripheral participation: Cambridge university press.

64. Lavoie, P., Pepin, J., \& Cossette, S. (2017). Contribution of a reflective debriefing to nursing students' clinical judgment in patient deterioration simulations: A mixed-methods study. Nurse Education Today, 50, 51-56. doi:10.1016/j.nedt.2016.12.002

65. Lederman, L. C. (1984). Debriefing: a critical reexamination of the postexperience analytic process with implications for its effective use. Simulation \& Games, 15, 415-431. Retrieved from

http://libproxy1.nus.edu.sg/login?url=http://search.ebscohost.com/login.aspx?direct=true\& $\mathrm{db}=$ ssa\&AN=513115940\&site=ehost-live

66. Lederman, L. C. (1992). Debriefing: Toward a Systematic Assessment of Theory and Practice. Simulation \& gaming, 23(2), 145-160. doi:10.1177/1046878192232003

67. Lesage, F. X., Berjot, S., \& Deschamps, F. (2012). Clinical stress assessment using a visual analogue scale. Occupational medicine (Oxford, England), 62(8), 600-605. doi:10.1093/occmed/kqs140

68. Levett-Jones, T., \& Lapkin, S. (2014). A systematic review of the effectiveness of simulation debriefing in health professional education. Nurse Education Today, 34(6), e58-e63. doi:10.1016/j.nedt.2013.09.020

69. Lim, L. (2013). Meritocracy, elitism, and egalitarianism: a preliminary and provisional assessment of Singapore's primary education review. Asia Pacific Journal of Education, 33(1), 1-14. doi:10.1080/02188791.2012.711294 
70. Lincoln, Y. S., \& Guba, E. G. (1985). Naturalistic inquiry (Vol. 75): Sage.

71. MacLean, H., Janzen, K. J., \& Angus, S. (2019). Lived experience in simulation: Student perspectives of learning from two lenses. Clinical Simulation in Nursing, 31, 1-8. doi:10.1016/j.ecns.2019.03.004

72. Manojlovich, M., Frankel, R. M., Harrod, M., Heshmati, A., Hofer, T., Umberfield, E., \& Krein, S. (2019). Formative evaluation of the video reflexive ethnography method, as applied to the physician-nurse dyad. BMJ quality \& safety, 28(2), 160-166. doi:10.1136/bmjqs-2017-007728

73. Mariani, B., Cantrell, M. A., \& Meakim, C. (2014). Nurse educators' perceptions about structured debriefing in clinical simulation. Nursing education perspectives, 35(5), 330-331. doi:10.5480/13-1190.1

74. Mcllvenny, P. (2011). Video interventions in "everyday life": semiotic and spatial practices of embedded video as a therapeutic tool in reality TV parenting programmes. Social Semiotics, 21(2), 259-288. doi:10.1080/10350330.2011.548648

75. Morse, C. J. (2012). The Effect of Debriefing with Good Judgment on Acute Care Nurse Practitioner Students' Reflective Ability and Perspective Transformation. [Doctoral dissertation]. Villanova, Pennsylvania: Villanova University. Retrieved from http://pqdtopen.proquest.com/pubnum/3552408.html.

76. Mughal, F., \& Zafar, A. (2011). Experiential Learning from a Constructivist Perspective: Reconceptualizing the Kolbian Cycle. International Journal of Learning and Development, 1(2). doi:10.5296/ijld.v1i2.1179

77. Ng, S. L., Kangasjarvi, E., Lorello, G. R., Nemoy, L., \& Brydges, R. (2019). 'There shouldn't be anything wrong with not knowing': Epistemologies in simulation. Medical Education, 53(10), 1049-1059. doi:10.1111/medu.13928

78. Novak, J. D. (2010). Learning, creating, and using knowledge: Concept maps as facilitative tools in schools and corporations (2nd ed.). New York, N.Y: Routledge

79. Nowell, L. S., Norris, J. M., White, D. E., \& Moules, N. J. (2017). Thematic analysis: Striving to meet the trustworthiness criteria. International Journal of Qualitative Methods, 16(1), 160940691773384. doi:10.1177/1609406917733847

80. Ong, X. L., \& Cheung, H. S. (2016). Schools and the class divide: an examination of children's self-concept and aspirations in Singapore: Singapore Children's Society.

81. Oseni, Z., Than, H. H., Kolakowska, E., Chalmers, L., Hanboonkunupakarn, B., \& McGready, R. (2017). Video-based feedback as a method for training rural healthcare workers to manage medical emergencies: a pilot study. BMC Medical Education, 17(1), 149-111. doi:10.1186/s12909-017-0975-3

82. Phrampus, P. E., \& O’Donnell, J. M. (2013). Debriefing Using a Structured and Supported Approach. In A. I. Levine, S. DeMaria, A. D. Schwartz, \& A. J. Sim (Eds.), The Comprehensive Textbook of Healthcare Simulation (pp. 73-84). New York, NY: Springer New York.

83. Plichta, S. B., Kelvin, E. A., \& Munro, B. H. (2013). Munro's statistical methods for health care research (6th ed.). Philadelphia: Wolters Kluwer Health/Lippincott Williams \& Wilkins.

84. Polit, D. F., \& Beck, C. T. (2018). Essentials of nursing research: appraising evidence for nursing practice (9th ed.). Philadelphia: Wolters Kluwer

85. Polit, D. F., \& Beck, C. T. (2012). Nursing research: generating and assessing evidence for nursing practice (9th ed.). Philadelphia: Wolters Kluwer Health/lippincott Williams \& Wilkins.

86. Poore, J. A., Cullen, D. L., \& Schaar, G. L. (2014). Simulation-based interprofessional education guided by Kolb's Experiential Learning Theory. Clinical Simulation in Nursing, 10(5), e241-e247.

87. Reed, S. J. (2012). Debriefing Experience Scale: Development of a Tool to Evaluate the Student Learning Experience in Debriefing. Clinical Simulation in Nursing, 8(6), e211-e217. doi:10.1016/j.ecns.2011.11.002 
88. Rivière, E., Jaffrelot, M., Jouquan, J., \& Chiniara, G. (2019). Debriefing for the Transfer of Learning: The Importance of Context. Academic Medicine, 94(6), 796-803.

doi:10.1097/ACM.0000000000002612

89. Rizzolo, M. A., Kardong-Edgren, S., Oermann, M. H., \& Jeffries, P. R. (2015). The National League for Nursing project to explore the use of simulation for high-stakes assessment: Process, outcomes, and recommendations. Nursing education perspectives, 36(5), 299-303.

90. Roberts, D. (2010). Vicarious learning: A review of the literature. Nurse Education in Practice, 10(1), 13-16. doi:10.1016/j.nepr.2009.01.017

91. Roberts, E., Kaak, V., \& Rolley, J. (2019). Simulation to Replace Clinical Hours in Nursing: A Meta-narrative Review. Clinical Simulation in Nursing, 37, 5-13. doi:10.1016/j.ecns.2019.07.003

92. Roberts, P. K. (2015). Nursing Students' Perception of Post-Simulation Debriefing. ProQuest Dissertations Publishing, Retrieved from http://nus.summon.serialssolutions.com/2.0.0/link/0/eLvHCXMwY2AwNt|zOEUrExLNk4zSzEx AB2olAqtM4zRgrZ1qCqybU00sE81SILe_GQVHGbt6G0dBFxeCtsZAoxtWSoKL7pT8ZNCoub4ha DmHKTC9mtsXFOqC7pECzbdCL9VgZmA1BDZeQIv83JEbRPD-

O7BvZmkCOs7dEnrwE4xvgFEqg6saNwGGdMT4CniNiaFeXinksMPidLRDHClyuyADjwvSZLwQA 1NqnjADO3T4QITBCspSCIYcf1msrhAAXwWjkJ-

mALrnVzc4Mxd6AZgCsOgC9rvTgFpEGZTdXEOcPXRhroqHJtnielSTjMUYWPLy81IIGBQsUxIt05J MU9JMkOCXchgmmlmYJSamGBonJyebGidaSDLI4DNJCrONAMXsP1hChnRkGFgKSkqTZVIYAaGqhw42gAbmawu (Dissertation/Thesis)

93. Rosen, K. (2013). The history of simulation. In The comprehensive textbook of healthcare simulation (pp. 5-49): Springer.

94. Rossignol, M. (2017). Effects of Video-Assisted Debriefing Compared with Standard Oral Debriefing. Clinical Simulation in Nursing, 13(4), 145-153. doi:https://doi.org/10.1016/j.ecns.2016.12.001

95. Rostami, A., Keshmiri, F., Askari, R., Jambarsang, S., \& Shafiei, M. (2019). Validation of Groningen Reflection Ability Scale Questionnaire and Evaluation of Reflection Ability Level of Health Care Management Students. Evidence Based Health Policy, Management \& Economics, 3(4), 293-302. doi:10.18502/jebhpme.v3i4.2071

96. Roth, W. M., \& Jornet, A. (2013). Situated cognition. Wiley Interdisciplinary Reviews: Cognitive Science, 4(5), 463-478. doi:10.1002/wcs.1242

97. Royle, C. (2014). Comparison of baccalaureate nursing students' experience of video-assisted debriefing versus oral debriefing following high-fidelity human simulation (Order No. 3674142). Available from Publicly Available Content Database. (1614431504). Retrieved from http://libproxy1.nus.edu.sg/login?url=https://search-proquestcom.libproxy1.nus.edu.sg/docview/1614431504?accountid=13876

98. Royle, C., \& Hargiss, K. (2015). Comparison of baccalaureate nursing students' experience of video-assisted debriefing versus oral debriefing following high-fidelity human simulation. International Journal of Strategic Information Technology and Applications (IJSITA), 6(2), 4049. doi:10.4018/IJSITA.2015040103

99. Rudolph, J. W., Raemer, D. B., \& Simon, R. (2014). Establishing a safe container for learning in simulation: The role of the presimulation briefing. Simulation in Healthcare: Journal of the Society for Simulation in Healthcare, 9(6), 339-349. doi:10.1097/SIH.0000000000000047

100. Rudolph, J.W., Simon, R., Dufresne, R.L., Raemer, D.B. (2006). There's no such thing as "nonjudgmental" debriefing: a theory and method for debriefing with good judgment. Simul Healthc1, 49-55.

101. Rudolph, J. W., Simon, R., Raemer, D. B., \& Eppich, W. J. (2008). Debriefing as formative assessment: closing performance gaps in medical education. Academic Emergency Medicine, 15(11), 1010-1016. doi:10.1111/j.1553-2712.2008.00248.x 
102. Rudolph, J. W., Simon, R., Rivard, P., Dufresne, R. L., \& Raemer, D. B. (2007). Debriefing with good judgment: combining rigorous feedback with genuine inquiry. Anesthesiology clinics, 25(2), 361-376. doi:10.1016/j.anclin.2007.03.007

103. Ruesseler, M., Sterz, J., Bender, B., Hoefer, S., \& Walcher, F. (2017). The effect of videoassisted oral feedback versus oral feedback on surgical communicative competences in undergraduate training. European Journal of Trauma and Emergency Surgery, 43(4), 461466.

104. Saunders, B., Sim, J., Kingstone, T., Baker, S., Waterfield, J., Bartlam, B., . . Jinks, C. (2017). Saturation in qualitative research: Exploring its conceptualization and operationalization. Quality \& Quantity, 52(4), 1893-1907. doi:10.1007/s11135-017-0574-8

105. Sawyer, T., Eppich, W., Brett-Fleegler, M., Grant, V., \& Cheng, A. (2016). More than one way to debrief: A critical review of healthcare simulation debriefing methods. Simulation in Healthcare : Journal of the Society for Simulation in Healthcare, 11(3), 209-217. doi:10.1097/SIH.0000000000000148

106. Schunk, D. H. (2012). Learning theories an educational perspective sixth edition: Pearson.

107. Seaman, J. (2008). Experience, reflect, critique: The end of the "Learning cycles" era. Journal of Experiential Education, 31(1), 3-18. doi:10.1177/105382590803100103

108. Shuell, T. J. (1986). Cognitive Conceptions of Learning. Review of Educational Research, 56(4), 411-436. doi:10.3102/00346543056004411

109. Siedlecki, S. L. (2018). Research intervention fidelity: Tips to improve internal validity of your intervention studies. Clinical Nurse Specialist, 32(1), 12-14. doi:10.1097/NUR.0000000000000342

110. Sim, J., \& Lewis, M. (2012). The size of a pilot study for a clinical trial should be calculated in relation to considerations of precision and efficiency. Journal of clinical epidemiology, 65(3), 301-308.

111. Simon, R., Raemer, D., \& Rudolph, J. (2010). Debriefing Assessment for Simulation in Healthcare (DASH)@ - Student Version, Long Form. Center for Medical Simulation, Boston, Massachusetts.

112. Simon, R., Raemer, D., \& Rudolph, J. (2012). Debriefing Assessment for Simulation in Healthcare (DASH)@- instructor version, Long Form. Center for Medical Simulation, Boston, Massachusetts.

113. Soucisse, M. L., Boulva, K., Sideris, L., Drolet, P., Morin, M., \& Dubé, P. (2017). Video coaching as an efficient teaching method for surgical residents - a randomized controlled trial. Journal of Surgical Education, 74(2), 365-371.

doi:https://doi.org/10.1016/j.jsurg.2016.09.002

114. Stroben, F., Schröder, T., Dannenberg, K. A., Thomas, A., Exadaktylos, A., \& Hautz, W. E. (2016). A simulated night shift in the emergency room increases students' self-efficacy independent of role taking over during simulation. BMC Medical Education, 16(1), 177. doi:10.1186/s12909-016-0699-9

115. Takase, M., \& Teraoka, S. (2011). Development of the Holistic Nursing Competence Scale. Nursing \& Health Sciences, 13(4), 396-403. doi:10.1111/j.1442-2018.2011.00631.x

116. Tan, K. K., Palham, S., Ignacio, J., Dawood, R., Mackey, S., Lim, F. P., \& Liaw, S. Y. (2016). The evaluation of nursing competency in a simulation-based assessment: tool development and students' experiences. Asian Journal of the Scholarship of Teaching and Learning, 222-245.

117. Thidemann, I.-J., \& Söderhamn, O. (2013). High-fidelity simulation among bachelor students in simulation groups and use of different roles. Nurse Education Today, 33(12), 1599-1604. doi:10.1016/j.nedt.2012.12.004

118. Tong, A., Sainsbury, P., \& Craig, J. (2007). Consolidated criteria for reporting qualitative research (COREQ): a 32-item checklist for interviews and focus groups. International journal for quality in health care, 19(6), 349-357. doi:10.1093/intqhc/mzm042 
119. Tongco, M. D. C. (2007). Purposive sampling as a tool for informant selection. Ethnobotany Research and applications, 5, 147-158.

120. Turner, K., \& McCarthy, V. L. (2017). Stress and anxiety among nursing students: A review of intervention strategies in literature between 2009 and 2015. Nurse Education in Practice, 22, 21-29. doi:10.1016/j.nepr.2016.11.002

121. Vaismoradi, M., Jones, J., Turunen, H., \& Snelgrove, S. (2016). Theme development in qualitative content analysis and thematic analysis. doi: 10.5430/jnep.v6n5p100

122. Vaismoradi, M., \& Snelgrove, S. (2019). Theme in qualitative content analysis and thematic analysis. Forum, Qualitative Social Research, 20(3) doi:10.17169/fqs-20.3.3376

123. Waznonis, A. R. (2015). Simulation Debriefing Practices in Traditional Baccalaureate Nursing Programs: National Survey Results. Clinical Simulation in Nursing, 11(2), 110-119. doi:10.1016/j.ecns.2014.10.002

124. Waznonis, A. R. (2016). Faculty Descriptions of Simulation Debriefing in Traditional Baccalaureate Nursing Programs. Nursing education perspectives, 37(5), 262-268. doi:10.1097/01.NEP.0000000000000065

125. Winn, W. (1990). Some implications of cognitive theory for instructional design. Instructional Science, 19(1), 53-69. doi:10.1007/BF00377985

126. Yap, S. (2013). The story of kiasu: Expressions of identity and status via conspicuous consumption: An ethnographic study of singaporean young women in a newly adopted culture (Order No. 10308826). Available from ProQuest Dissertations \& Theses Global. (1918642373). Retrieved from http://libproxy1.nus.edu.sg/login?url=https://searchproquest-com.libproxy1.nus.edu.sg/docview/1918642373 ?accountid $=13876$

127. Yeun, E. J., Chon, M. Y., \& An, J. H. (2019). Perceptions of video-facilitated debriefing in simulation education among nursing students: Findings from a Q-methodology study. Journal of professional nursing. doi:10.1016/j.profnurs.2019.08.009

128. Zhao, B. (2011). Learning from errors: The role of context, emotion, and personality. Journal of Organizational Behavior, 32(3), 435-463. doi:10.1002/job.696

129. Zigmont, J. J., Kappus, L. J., \& Sudikoff, S. N. (2011). Theoretical foundations of learning through simulation. Seminars in Perinatology, 35(2), 47-51. doi:10.1053/j.semperi.2011.01.002 


\section{APPENDIX 1}

Sample Lesson structure for Module NUR3113 (Modular Credits: 4)

\begin{tabular}{|c|c|c|c|}
\hline Wk & e-Lecturer (1 hr) & Tutorial (1-2 hrs) & Laboratory practice (2 hrs) \\
\hline 1 & $\begin{array}{l}\text { Nursing care of clients with neurologic } \\
\text { disorders I: } \\
\text { - Headaches \& migraines } \\
\text { - Parkinson's Disease } \\
\text { - Multiple sclerosis } \\
\text { - Guillain-Barré syndrome }\end{array}$ & $\begin{array}{l}\text { Neurological case study } \\
\text { - Introduction to Tutorial } \\
\text { - } \quad \text { Briefing on CBL presentation } \\
\text { and selection of groups and } \\
\text { topics } \\
\text { - } \quad \text { Case Discussion }\end{array}$ & $\begin{array}{l}\text { Neurological Nursing Skills } \\
1.1 \text { Neurological assessment (Conscious } \\
\text { level assessment-CLC / Glasgow } \\
\text { Coma Score) } \\
\text { 1.2 Positioning and turning patient with } \\
\text { CVA and Spinal Injury }\end{array}$ \\
\hline 3 & $\begin{array}{l}\text { Emergency care nursing I: } \\
\text { - Concepts in Emergency Nursing } \\
\text { - Triage and Disaster Management } \\
\text { - Trauma Assessment and Management }\end{array}$ & $\begin{array}{l}\text { Neurological case study } \\
\text { - Tutor Consultation with each } \\
\text { sub-group for CBL presentation }\end{array}$ & $\begin{array}{l}\text { Emergency Nursing Skills } \\
\text { (Checking the E-Trolley) } \\
2.1 \text { Checking of manual resuscitator / } \\
\text { function test } \\
2.2 \text { System checks of the defibrillator } \\
2.3 \text { Checking of emergency trolley }\end{array}$ \\
\hline 4 & $\begin{array}{l}\text { Emergency care nursing II: } \\
\text { - Poisoning } \\
\text { - } \text { Burns } \\
\text { - Near Drowning }\end{array}$ & $\begin{array}{l}\text { Neurological case study } \\
\text { - Case Presentation }\end{array}$ & 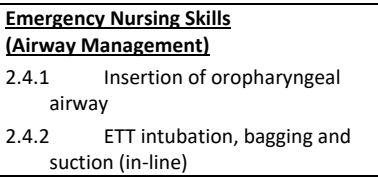 \\
\hline 5 & $\begin{array}{l}\text { Critical care nursing I: } \\
\text { - Interpretation and management of } \\
\text { - } \text { acid-base imbalances } \\
\text { - } \quad \text { Adute respiratory failure } \\
\text { - } \\
\text { Nursing patients with artificial airways } \\
\text { - ETT, Tracheostomy } \\
\text { Patients on mechanical ventilation }\end{array}$ & $\begin{array}{l}\text { Emergency and Critical care case } \\
\text { study } \\
\text { - Case Discussion }\end{array}$ & $\begin{array}{l}\text { Emergency Nursing Skills } \\
\text { (Cardiac Management) } \\
\text { 2.5 Basic Continuous Cardiac Monitoring } \\
\text { using 3-Lead ECG } \\
\text { 2.6 Safe and effective defibrillation using } \\
\text { the AED } \\
\text { 2.7 Administration of Emergency Drugs }\end{array}$ \\
\hline 6 & $\begin{array}{l}\text { Critical care nursing II: } \\
\text { - } \quad \text { Management of Shock } \\
\text { - } \quad \text { Principles of hemodynamic monitoring }\end{array}$ & $\begin{array}{l}\text { Emergency and Critical care case } \\
\text { study } \\
\text { - Tutor Consultation for CBL } \\
\text { presentation }\end{array}$ & $\begin{array}{l}\text { Code Blue Management } \\
\text { 2.8 Code Blue Management } \\
2.9 \text { Mechanical Ventilation Devices }\end{array}$ \\
\hline 7 & $\begin{array}{l}\text { Critical care Nursing III: } \\
\text { Pneumothorax / Haemothorax } \\
\text { - Nursing patients with chest drainage }\end{array}$ & $\begin{array}{l}\text { Emergency and Critical care case } \\
\text { study } \\
\text { - Case Presentation }\end{array}$ & $\begin{array}{l}\text { Critical Care Nursing Skills } \\
\text { 2.10Care of patient with chest tube } \\
\text { 2.11Care of patient with tracheostomy }\end{array}$ \\
\hline 8 & $\begin{array}{l}\text { Nursing care of clients with oncological } \\
\text { disorders I: } \\
\text { - Principles of oncology treatment } \\
\text { - Cancer symptom management } \\
\text { - Oncology emergencies }\end{array}$ & $\begin{array}{l}\text { Oncological Emergency case } \\
\text { study: } \\
\text { Case Discussion }\end{array}$ & $\begin{array}{l}\text { Simulation program (2 hr) } \\
\text { Code Blue Management }\end{array}$ \\
\hline 9 & $\begin{array}{l}\text { Nursing care of clients with Oncological } \\
\text { disorders II (1 hour) } \\
\text { - Care of patients with Central venous } \\
\text { catheter/TPN/PICC }\end{array}$ & $\begin{array}{l}\text { Oncological Emergency case study } \\
\text { (1 hour) } \\
\text { - Tutor Consultation for CBL } \\
\text { presentation }\end{array}$ & $\begin{array}{l}\text { Simulation program (2 hr) } \\
\text { Code Blue Management }\end{array}$ \\
\hline & \multicolumn{3}{|c|}{$\begin{array}{l}\text { Skill assessment (40\%): 30-min summative assessment } \\
\text { Final MCQ-exam (60\%) }\end{array}$} \\
\hline
\end{tabular}




\section{APPENDIX 2}

\section{Simulation-based Assessment Tool (adapted from Tan et al., 2016)}

Communication: Ability to effectively give and receive information using verbal and non-verbal cues with the goal of engaging, empathizing or providing education to patients and their families or care-givers

\begin{tabular}{|l|l|l|l|l|l|l|l|l|}
\hline 9 & 8 & 7 & 6 & 5 & 4 & 3 & 2 & 1 \\
\hline \multicolumn{2}{|l|}{ Exceed Expectation } \\
\hline
\end{tabular}

Professionalism: Demonstration of attributes and qualities that promote nursing professionalism in the course of providing safe and quality care to patient

\begin{tabular}{|l|l|l|l|l|l|l|l|l|}
\hline 9 & 8 & 7 & 6 & 5 & 4 & 3 & 2 & 1 \\
\hline \multicolumn{7}{|l|}{ Exceed Expectation } & \multicolumn{5}{|l|}{ Need Expectation } \\
\hline
\end{tabular}

Patient management: Ability to organize patient care activities in a systematic and coordinated manner, providing holistic and safe patient management

\begin{tabular}{|l|l|l|l|l|l|l|l|l|}
\hline 9 & 8 & 7 & 6 & 5 & 4 & 3 & 2 & 1 \\
\hline \multicolumn{7}{|l|}{ Exceed Expectation } & \multicolumn{5}{|l|}{ Neet Expectation improvement } \\
\hline
\end{tabular}

Technique skills: Ability to perform procedures with required dexterity, effectiveness, and consideration for safety and patients' response

\begin{tabular}{|l|l|l|l|l|l|l|l|l|}
\hline 9 & 8 & 7 & 6 & 5 & 4 & 3 & 2 & 1 \\
\hline \multicolumn{2}{|l|}{ Exceed Expectation } & \multicolumn{4}{|l|}{ Neet Expectation } \\
\hline
\end{tabular}

Safe Practice: Ability to deliver care utilizing patient safety standards

\begin{tabular}{|l|l|l|l|l|l|l|l|l|}
\hline 9 & 8 & 7 & 6 & 5 & 4 & 3 & 2 & 1 \\
\hline \multicolumn{7}{|l|}{ Exceed Expectation } & \multicolumn{5}{|l|}{ Need Expectation improvement } \\
\hline
\end{tabular}

Critical thinking: Ability to integrate current knowledge, scientific advances, and the human/social dimensions of patient care and direct appropriate clinical reasoning and clinical judgement that assure the highest quality of care for each patient

\begin{tabular}{|l|l|l|l|l|l|l|l|l|}
\hline 9 & 8 & 7 & 6 & 5 & 4 & 3 & 2 & 1 \\
\hline Exceed Expectation & \multicolumn{2}{|l|}{ Meet Expectation } & \multicolumn{2}{|l|}{ Need improvement } \\
\hline
\end{tabular}

Total Score: /54 


\section{APPENDIX 3}

DASH Instructor Version (adapted from Simon et al., 2012)

\begin{tabular}{|c|c|}
\hline Element 1: I set the stage for an engaging learning experience & Score \\
\hline \multicolumn{2}{|l|}{$\begin{array}{l}\text { I explained the strengths and weaknesses of the simulation and what the participants could do to get the } \\
\text { most out of simulated clinical experiences }\end{array}$} \\
\hline \multicolumn{2}{|l|}{ I attended to logistical details as necessary such as toilet location, food availability and schedule } \\
\hline \multicolumn{2}{|l|}{ Rating Element 1} \\
\hline Element 2: I maintained an engaging context for learning & Score \\
\hline \multicolumn{2}{|l|}{$\begin{array}{l}\text { I clarified the purpose of the debriefing, what was expected of the participants, and my role (as the } \\
\text { instructor) in the debriefing }\end{array}$} \\
\hline \multicolumn{2}{|l|}{ I ensured the focus was on learning and not on making people feel bad about making mistakes } \\
\hline \multicolumn{2}{|l|}{ I empowered participants to share thoughts and emotions without fear of being shamed or humiliated } \\
\hline \multicolumn{2}{|l|}{ Rating Element 2} \\
\hline Element 3: I structured the debriefing in an organized way & Score \\
\hline \multicolumn{2}{|l|}{ I guided the conversation such that it progressed logically rather than jumping around from point to point. } \\
\hline \multicolumn{2}{|l|}{$\begin{array}{l}\text { Near the beginning of the debriefing, I encouraged participants to share their genuine reactions to the } \\
\text { case(s) and I took their remarks seriously }\end{array}$} \\
\hline \multicolumn{2}{|l|}{ In the middle, I helped the participants analyze actions and thought processes as we reviewed the case(s) } \\
\hline \multicolumn{2}{|l|}{$\begin{array}{l}\text { At the end of the debriefing, there was a summary phase where I helped tie observations together and } \\
\text { relate the case(s) to ways the participants could improve their future clinical practice }\end{array}$} \\
\hline \multicolumn{2}{|l|}{$\begin{array}{l}\text { I listened and made people feel heard by trying to include everyone, paraphrasing, and using non-verbal } \\
\text { actions like eye contact and nodding etc }\end{array}$} \\
\hline \multicolumn{2}{|l|}{ I used video or recorded data to support analysis and learning } \\
\hline \multicolumn{2}{|l|}{$\begin{array}{l}\text { If someone got upset during the debriefing, I was respectful and constructive in trying to help them deal } \\
\text { with it }\end{array}$} \\
\hline \multicolumn{2}{|l|}{ Rating Element 4} \\
\hline Element 5: I identified what they did well or poorly - and why & Score \\
\hline \multicolumn{2}{|l|}{$\begin{array}{l}\text { I provided concrete feedback to participants on their performance or that of the team based on accurate } \\
\text { statements of fact and my honest point of view }\end{array}$} \\
\hline \multicolumn{2}{|l|}{ I helped explore what participants were thinking or trying to accomplish at key moments } \\
\hline \multicolumn{2}{|l|}{ Rating Element 5} \\
\hline Element 6: I helped them see how to improve or how to sustain good performance & Score \\
\hline \multicolumn{2}{|l|}{ I helped participants learn how to improve weak areas or how to repeat good performance } \\
\hline \multicolumn{2}{|l|}{ I was knowledgeable and used that knowledge to help participants see how to perform well in the future } \\
\hline \multicolumn{2}{|l|}{ I made sure we covered the most important topics } \\
\hline Rating Element 6 & \\
\hline
\end{tabular}




\section{APPENDIX 4}

\section{Comparing DES between intervention and control clusters (Study IV)}

\begin{tabular}{|c|c|c|c|c|c|c|}
\hline \multirow[t]{2}{*}{ Statements } & \multirow[t]{2}{*}{ Response } & \multicolumn{2}{|c|}{$\begin{array}{l}\text { Intervention cluster } \\
\qquad(\mathrm{n}=72)\end{array}$} & \multicolumn{2}{|c|}{$\begin{array}{l}\text { Control cluster } \\
(n=73)\end{array}$} & \multirow[t]{2}{*}{$p$} \\
\hline & & $\mathrm{n}$ & $\%$ & $\mathrm{n}$ & $\%$ & \\
\hline \multirow{2}{*}{$\begin{array}{l}\text { 1. Debriefing helped me to analyze my } \\
\text { thoughts }\end{array}$} & 4 & 53 & 73.6 & 56 & 76.7 & \\
\hline & 5 & 17 & 23.6 & 14 & 19.2 & \\
\hline \multirow{3}{*}{$\begin{array}{l}\text { 2. The facilitator reinforced aspects of the } \\
\text { health care team's behavior }\end{array}$} & 2 & 0 & 0 & 1 & 1.4 & $.619^{a}$ \\
\hline & 4 & 52 & 72.2 & 57 & 78.1 & \\
\hline & 5 & 18 & 25.0 & 13 & 17.8 & \\
\hline \multirow{3}{*}{$\begin{array}{l}\text { 3. The debriefing environment was } \\
\text { physically comfortable }\end{array}$} & 3 & 5 & 6.9 & 6 & 8.2 & .959 \\
\hline & 4 & 51 & 70.8 & 51 & 69.9 & \\
\hline & 5 & 16 & 22.2 & 16 & 21.9 & \\
\hline $\begin{array}{l}\text { 4. Unsettled feelings from the simulation } \\
\text { were resolved by debriefing }\end{array}$ & 2 & 2 & 2.8 & 2 & 2.7 & $.047^{* a}$ \\
\hline \multirow{3}{*}{$\begin{array}{l}\text { 5. Debriefing helped me to make } \\
\text { connections in my learning }\end{array}$} & 3 & 2 & 2.8 & 1 & 1.4 & $.426^{a}$ \\
\hline & 4 & 45 & 62.5 & 53 & 72.6 & \\
\hline & 5 & 25 & 34.7 & 19 & 26.0 & \\
\hline \multirow{3}{*}{$\begin{array}{l}\text { 6. Debriefing was helpful in processing the } \\
\text { simulation experience }\end{array}$} & 3 & 1 & 1.4 & 3 & 4.1 & $.024^{* a}$ \\
\hline & 4 & 38 & 52.8 & 51 & 69.9 & \\
\hline & 5 & 33 & 45.8 & 19 & 26.0 & \\
\hline \multirow{4}{*}{$\begin{array}{l}\text { 7. Debriefing provided me with a learning } \\
\text { opportunity }\end{array}$} & 2 & 1 & 1.4 & 0 & 0 & $.011^{* a}$ \\
\hline & 3 & 1 & 1.4 & 4 & 5.5 & \\
\hline & 4 & 36 & 50.0 & 50 & 68.5 & \\
\hline & 5 & 34 & 47.2 & 19 & 26.0 & \\
\hline $\begin{array}{l}\text { 8. Debriefing helped me to find meaning in } \\
\text { the simulation }\end{array}$ & 1 & 1 & 1.4 & 0 & 0 & $.098^{a}$ \\
\hline \multirow{4}{*}{$\begin{array}{l}\text { 10. I became more aware of myself during } \\
\text { the debriefing session }\end{array}$} & 2 & 1 & 1.4 & 2 & 2.7 & $<.001^{* a}$ \\
\hline & 3 & 4 & 5.6 & 11 & 15.1 & \\
\hline & 4 & 35 & 48.6 & 53 & 72.6 & \\
\hline & 5 & 32 & 44.4 & 7 & 9.6 & \\
\hline \multirow[t]{3}{*}{ 11. Debriefing helped me to clarify problems } & 3 & 2 & 2.8 & 2 & 2.7 & $.009^{* a}$ \\
\hline & 4 & 38 & 52.8 & 55 & 75.3 & \\
\hline & 5 & 32 & 44.4 & 16 & 21.9 & \\
\hline 12. Debriefing helped me to make & 2 & 1 & 1.4 & 0 & 0 & $.108^{\mathrm{a}}$ \\
\hline connections between theory and real- & 3 & 4 & 5.6 & 4 & 5.5 & \\
\hline life situations & 4 & 40 & 55.6 & 53 & 72.6 & \\
\hline & 5 & 27 & 37.5 & 16 & 21.9 & \\
\hline 13. The facilitator allowed me enough time & 3 & 8 & 11.1 & 12 & 16.4 & .151 \\
\hline to verbalize my feelings before & 4 & 48 & 66.7 & 53 & 72.6 & \\
\hline commenting & 5 & 16 & 22.2 & 8 & 11.0 & \\
\hline 14. The facilitator talked the right amount & 2 & 1 & 1.4 & 0 & 0 & $.023^{* a}$ \\
\hline during the debriefing session & 3 & 8 & 11.1 & 20 & 27.4 & \\
\hline & 4 & 48 & 66.7 & 45 & 61.6 & \\
\hline & 5 & 15 & 20.8 & 8 & 11.0 & \\
\hline 15. Debriefing provided a mean for me to & 3 & 7 & 9.7 & 0 & 0 & $<.001^{* a}$ \\
\hline reflect on my actions during the & 4 & 41 & 56.9 & 62 & 84.9 & \\
\hline
\end{tabular}




\begin{tabular}{|c|c|c|c|c|c|c|}
\hline \multirow{3}{*}{$\begin{array}{l}\text { 17. The facilitator was an expert in the } \\
\text { content area }\end{array}$} & 3 & 4 & 5.6 & 3 & 4.1 & \multirow[t]{3}{*}{$.072^{a}$} \\
\hline & 4 & 43 & 59.7 & 56 & 76.7 & \\
\hline & 5 & 25 & 34.7 & 14 & 19.2 & \\
\hline \multirow{3}{*}{$\begin{array}{l}\text { 18. The facilitator taught the right amount } \\
\text { during the debriefing session }\end{array}$} & 3 & 6 & 8.3 & 10 & 13.7 & \multirow[t]{3}{*}{$.045^{*}$} \\
\hline & 4 & 50 & 69.4 & 57 & 78.1 & \\
\hline & 5 & 16 & 22.3 & 6 & 8.2 & \\
\hline \multirow{3}{*}{$\begin{array}{l}\text { 19. The facilitator provided constructive } \\
\text { evaluation of the simulation during } \\
\text { debriefing }\end{array}$} & 3 & 1 & 1.4 & 6 & 8.2 & \multirow[t]{3}{*}{$.009^{* a}$} \\
\hline & 4 & 46 & 63.9 & 55 & 75.4 & \\
\hline & 5 & 25 & 34.7 & 12 & 16.4 & \\
\hline \multirow{3}{*}{$\begin{array}{l}\text { 20. The facilitator provided adequate } \\
\text { guidance during the debriefing }\end{array}$} & 3 & 3 & 4.2 & 8 & 11.0 & \multirow[t]{3}{*}{$.011^{* a}$} \\
\hline & 4 & 48 & 66.7 & 57 & 78.0 & \\
\hline & 5 & 21 & 29.1 & 8 & 11.0 & \\
\hline
\end{tabular}

Note: ${ }^{*}$ Chi-square test, significance at $\mathrm{p}<0.05$; 1-Strongly disagree; 2-disagree, 3-Neutral, 4-Agree, 5-Strongly Agree; ${ }^{a}$ :

Fisher's exact test was performed if the expected number of observations was less than five. 


\section{APPENDIX 5}

\section{Comparing students' GRAS before and after VAD (Study II)}

\begin{tabular}{|c|c|c|c|c|c|c|}
\hline \multirow[t]{2}{*}{ Items } & \multirow[t]{2}{*}{ Response } & \multicolumn{2}{|c|}{ Pre $(n=63)$} & \multicolumn{2}{|c|}{ Post $(n=63)$} & \multirow[b]{2}{*}{$p$} \\
\hline & & $\mathbf{n}$ & $\%$ & $\mathbf{n}$ & $\%$ & \\
\hline \multirow[t]{3}{*}{ 1. I want to know why I do what I do } & 3 & 2 & 3.2 & 0 & 0 & $0.005^{* a}$ \\
\hline & 4 & 23 & 36.5 & 26 & 41.3 & \\
\hline & 5 & 38 & 60.3 & 37 & 58.7 & \\
\hline 2. I am aware of the emotions that & 3 & 9 & 14.3 & 4 & 6.3 & $0.012 * a$ \\
\hline \multirow{2}{*}{ influence my behaviour } & 4 & 37 & 58.7 & 31 & 49.2 & \\
\hline & 5 & 17 & 27.0 & 28 & 44.4 & \\
\hline \multirow{5}{*}{$\begin{array}{l}\text { 3. I do not like to have my } \\
\text { standpoints discussed }\end{array}$} & 1 & 3 & 4.8 & 8 & 12.7 & $0.143^{a}$ \\
\hline & 2 & 34 & 54.0 & 31 & 49.2 & \\
\hline & 3 & 18 & 28.6 & 19 & 30.2 & \\
\hline & 4 & 7 & 11.1 & 5 & 7.9 & \\
\hline & 5 & 1 & 1.6 & 0 & 0 & \\
\hline \multirow{5}{*}{$\begin{array}{l}\text { 4. I do not welcome remarks about } \\
\text { my personal functioning }\end{array}$} & 1 & 9 & 14.3 & 12 & 19.0 & $0.002^{* a}$ \\
\hline & 2 & 37 & 58.7 & 37 & 58.7 & \\
\hline & 3 & 11 & 17.5 & 10 & 15.9 & \\
\hline & 4 & 5 & 7.9 & 3 & 4.8 & \\
\hline & 5 & 1 & 1.6 & 1 & 1.6 & \\
\hline \multirow{4}{*}{$\begin{array}{l}\text { 5. I take a closer look at my own } \\
\text { habits of thinking }\end{array}$} & 2 & 2 & 3.2 & 0 & 0 & $0.016^{* a}$ \\
\hline & 3 & 9 & 14.3 & 5 & 7.9 & \\
\hline & 4 & 38 & 60.3 & 36 & 57.1 & \\
\hline & 5 & 14 & 22.2 & 33 & 34.9 & \\
\hline \multirow{4}{*}{$\begin{array}{l}\text { 6. I am able to view my own } \\
\text { behaviour from a distance }\end{array}$} & 2 & 14 & 22.2 & 2 & 3.2 & $0.093^{a}$ \\
\hline & 3 & 16 & 25.4 & 9 & 14 & \\
\hline & 4 & 31 & 49.2 & 36 & 57.1 & \\
\hline & 5 & 2 & 3.2 & 16 & 25.4 & \\
\hline \multirow{4}{*}{$\begin{array}{l}\text { 7. I test my own judgments against } \\
\text { those of others }\end{array}$} & 2 & 5 & 7.9 & 1 & 1.6 & $0.148^{a}$ \\
\hline & 3 & 13 & 20.6 & 10 & 15.9 & \\
\hline & 4 & 37 & 58.7 & 38 & 60.3 & \\
\hline & 5 & 8 & 12.7 & 14 & 22.2 & \\
\hline \multirow{5}{*}{$\begin{array}{l}\text { 8. Sometimes others say that I do } \\
\text { overestimate myself }\end{array}$} & 1 & 3 & 4.8 & 1 & 1.6 & $0.009 * a$ \\
\hline & 2 & 33 & 52.4 & 33 & 52.4 & \\
\hline & 3 & 19 & 30.2 & 23 & 36.5 & \\
\hline & 4 & 5 & 7.9 & 6 & 9.5 & \\
\hline & 5 & 3 & 4.8 & 0 & 0 & \\
\hline \multirow{4}{*}{$\begin{array}{l}\text { 9. I find it important to know what } \\
\text { certain rules and guidelines are based } \\
\text { on }\end{array}$} & 2 & 1 & 1.6 & 0 & 0 & $0.481^{a}$ \\
\hline & 3 & 7 & 11.1 & 3 & 4.8 & \\
\hline & 4 & 41 & 65.1 & 36 & 57.1 & \\
\hline & 5 & 14 & 22.2 & 24 & 38.1 & \\
\hline & 2 & 1 & 1.6 & 0 & 0 & $<0.001^{* a}$ \\
\hline with a different cultural/ religious & 3 & 9 & 14.3 & 9 & 14.3 & \\
\hline background & 4 & 42 & 66.7 & 36 & 57.1 & \\
\hline & 5 & 11 & 17.5 & 18 & 28.6 & \\
\hline 11. I am accountable for what I say & 3 & 3 & 4.8 & 3 & 4.8 & $<.001^{* a}$ \\
\hline & 4 & 36 & 57.1 & 28 & 44.4 & \\
\hline & 5 & 24 & 38.1 & 32 & 50.8 & \\
\hline 12. I reject different ways of thinking & 1 & 16 & 25.4 & 14 & 22.2 & $0.001 * a$ \\
\hline & 2 & 40 & 63.5 & 42 & 66.7 & \\
\hline & 3 & 3 & 4.8 & 4 & 6.3 & \\
\hline & 4 & 4 & 6.3 & 2 & 3.2 & \\
\hline & 5 & 0 & 0 & 1 & 1.6 & \\
\hline 13. I can see an experience from & 2 & 0 & 0 & 1 & 1.6 & $0.018^{* a}$ \\
\hline different standpoints & 3 & 6 & 9.5 & 7 & 11.1 & \\
\hline & 4 & 49 & 77.8 & 39 & 61.9 & \\
\hline & 5 & 8 & 12.7 & 16 & 25.4 & \\
\hline 14. I take responsibility for what I say & 2 & 1 & 1.6 & 0 & 0 & $<.001^{* a}$ \\
\hline & 3 & 3 & 4.8 & 3 & 4.8 & \\
\hline & 4 & 36 & 57.1 & 35 & 55.6 & \\
\hline & 5 & 23 & 36.5 & 25 & 39.7 & \\
\hline 15. I am open to discussion about my & 2 & 2 & 3.2 & 0 & 0 & $0.018^{* a}$ \\
\hline opinions & 3 & 4 & 6.3 & 4 & 6.3 & \\
\hline & 4 & 38 & 60.3 & 36 & 57.1 & \\
\hline & 5 & 19 & 30.2 & 23 & 36.5 & \\
\hline
\end{tabular}




\begin{tabular}{|c|c|c|c|c|c|c|}
\hline \multirow[t]{4}{*}{ 16. I am aware of my own limitations } & 2 & 1 & 1.6 & 0 & 0 & $0.012^{* a}$ \\
\hline & 3 & 9 & 14.3 & 10 & 15.9 & \\
\hline & 4 & 40 & 63.5 & 39 & 61.9 & \\
\hline & 5 & 13 & 20.6 & 14 & 22.2 & \\
\hline \multirow{5}{*}{$\begin{array}{l}\text { 17. I sometimes find myself having } \\
\text { difficulty in illustrating an ethical } \\
\text { standpoint }\end{array}$} & 1 & 2 & 3.2 & 3 & 4.8 & $0.013^{* a}$ \\
\hline & 2 & 20 & 31.7 & 18 & 28.6 & \\
\hline & 3 & 14 & 22.2 & 13 & 20.6 & \\
\hline & 4 & 24 & 38.1 & 26 & 41.3 & \\
\hline & 5 & 3 & 4.8 & 3 & 4.8 & \\
\hline \multirow{4}{*}{$\begin{array}{l}\text { 18. I am aware of the cultural } \\
\text { influences on my opinions }\end{array}$} & 2 & 4 & 6.3 & 4 & 6.3 & $.001^{* a}$ \\
\hline & 3 & 11 & 17.5 & 8 & 12.7 & \\
\hline & 4 & 40 & 63.5 & 35 & 55.6 & \\
\hline & 5 & 8 & 12.7 & 16 & 25.4 & \\
\hline \multirow[t]{3}{*}{ 19. I want to understand myself } & 3 & 1 & 1.6 & 1 & 1.6 & $0.025^{* a}$ \\
\hline & 4 & 25 & 39.7 & 22 & 34.9 & \\
\hline & 5 & 37 & 58.7 & 40 & 63.5 & \\
\hline \multirow{3}{*}{$\begin{array}{l}\text { 20. I am aware of the possible } \\
\text { emotional impact of information on } \\
\text { others }\end{array}$} & 3 & 4 & 6.3 & 3 & 4.8 & $0.175^{a}$ \\
\hline & 4 & 44 & 69.8 & 34 & 54.0 & \\
\hline & 5. & 15 & 23.8 & 26 & 41.3 & \\
\hline \multirow{5}{*}{$\begin{array}{l}\text { 21. I sometimes find myself having } \\
\text { difficulty in thinking of alternative } \\
\text { solutions }\end{array}$} & 1 & 1 & 1.6 & 3 & 4.8 & $0.001^{* a}$ \\
\hline & 2 & 10 & 15.9 & 11 & 17.5 & \\
\hline & 3 & 14 & 22.2 & 14 & 22.2 & \\
\hline & 4 & 28 & 44.4 & 31 & 49.2 & \\
\hline & 5 & 10 & 15.9 & 4 & 6.3 & \\
\hline \multirow{3}{*}{$\begin{array}{l}\text { 22. I can empathize with someone } \\
\text { else's situation }\end{array}$} & 3 & 6 & 9.5 & 5 & 7.9 & $0.012 *$ \\
\hline & 4 & 38 & 60.3 & 37 & 58.7 & \\
\hline & 5 & 19 & 30.2 & 21 & 33.3 & \\
\hline \multirow{3}{*}{$\begin{array}{l}\text { 23. I am aware of the emotions that } \\
\text { influence my thinking }\end{array}$} & 3 & 9 & 14.3 & 8 & 12.7 & 0.079 \\
\hline & 4 & 34 & 54.0 & 31 & 49.2 & \\
\hline & 5 & 20 & 31.7 & 24 & 38.1 & \\
\hline
\end{tabular}

Note: *Significance at $\mathrm{p}<0.05$; 1-Strongly disagree; 2-disagree, 3-Neutral, 4-Agree, 5-Strongly Agree

a: Fisher's exact test was performed if the expected number of observations was less than five. 


\section{APPENDIX 6}

\section{Comparing DASH-SV between intervention and control clusters (Study IV)}

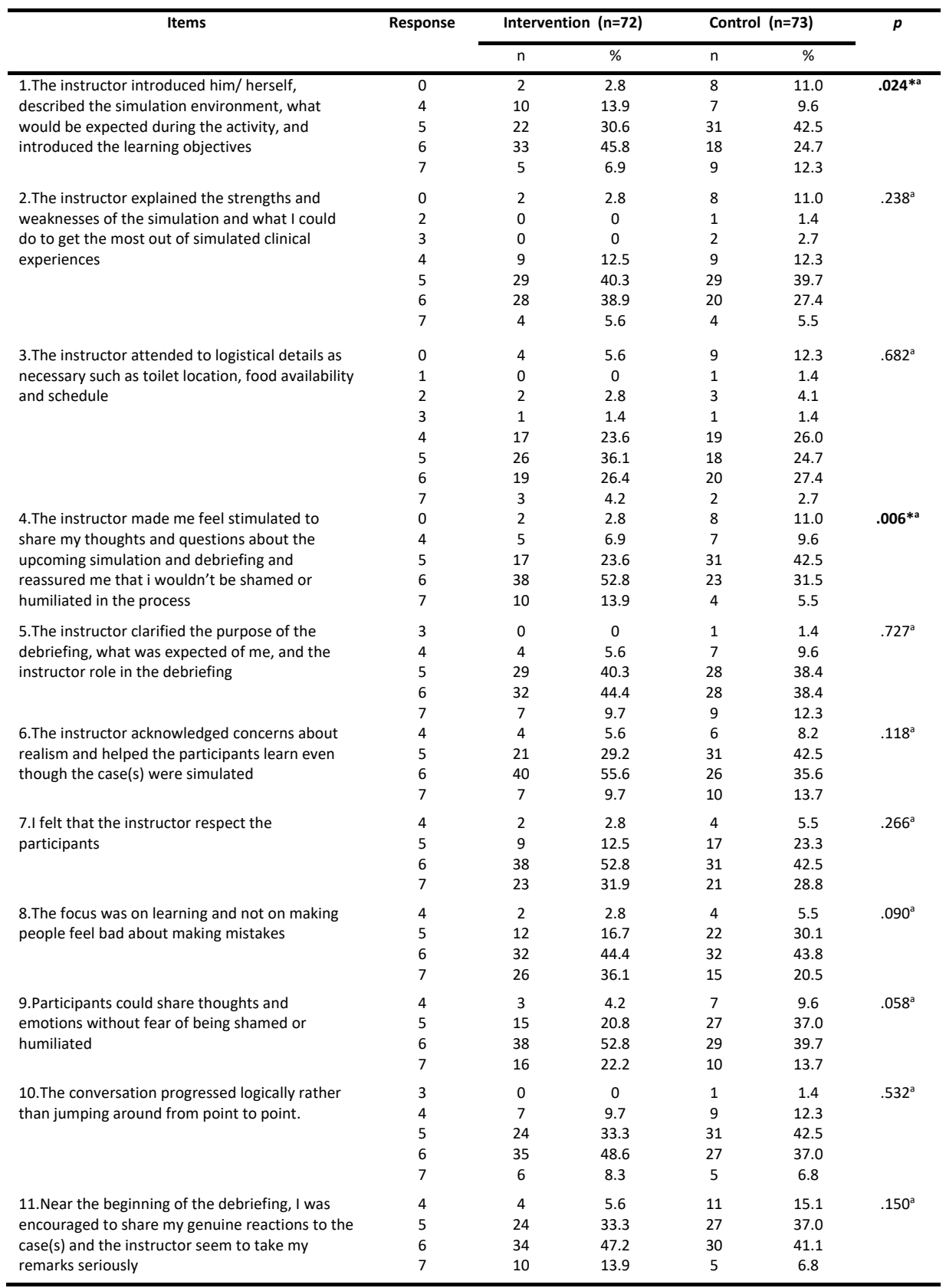




\begin{tabular}{|c|c|c|c|c|c|c|}
\hline \multirow{5}{*}{$\begin{array}{l}\text { 12.In the middle, the instructor helped me } \\
\text { analyze actions and thought processes as we } \\
\text { reviewed the case(s) }\end{array}$} & 3 & 0 & 0 & 1 & 1.4 & \multirow[t]{5}{*}{$.039^{* a}$} \\
\hline & 4 & 6 & 8.3 & 9 & 12.3 & \\
\hline & 5 & 17 & 23.6 & 31 & 42.5 & \\
\hline & 6 & 37 & 51.4 & 25 & 34.2 & \\
\hline & 7 & 12 & 16.7 & 7 & 9.6 & \\
\hline \multirow{5}{*}{$\begin{array}{l}\text { 13.At the end of the debriefing, there was a } \\
\text { summary phase where the instructor helped tie } \\
\text { observations together and relate the case(s) to } \\
\text { ways i can improve my future clinical practice }\end{array}$} & 3 & 1 & 1.4 & 0 & 0 & \multirow[t]{5}{*}{$.373^{\mathrm{a}}$} \\
\hline & 4 & 4 & 5.6 & 4 & 5.5 & \\
\hline & 5 & 18 & 25.0 & 26 & 35.6 & \\
\hline & 6 & 35 & 48.6 & 35 & 47.9 & \\
\hline & 7 & 14 & 19.4 & 8 & 11.0 & \\
\hline \multirow{4}{*}{$\begin{array}{l}\text { 14. The instructor used concrete examples-not } \\
\text { just abstract or generalized comments - to get } \\
\text { me to think about my performance }\end{array}$} & 4 & 7 & 9.7 & 8 & 11.0 & \multirow[t]{4}{*}{$.042 *$} \\
\hline & 5 & 20 & 27.8 & 36 & 49.3 & \\
\hline & 6 & 36 & 50.0 & 23 & 31.5 & \\
\hline & 7 & 9 & 12.5 & 6 & 8.2 & \\
\hline \multirow{5}{*}{$\begin{array}{l}\text { 15.The instructor's point of view was clear; I } \\
\text { didn't have to guess what the instructor was } \\
\text { thinking }\end{array}$} & 3 & 0 & 0 & 1 & 1.4 & \multirow[t]{5}{*}{$.052^{\mathrm{a}}$} \\
\hline & 4 & 5 & 6.9 & 11 & 15.1 & \\
\hline & 5 & 16 & 22.2 & 24 & 32.9 & \\
\hline & 6 & 43 & 59.7 & 27 & 37.0 & \\
\hline & 7 & 8 & 11.1 & 10 & 13.7 & \\
\hline \multirow{5}{*}{$\begin{array}{l}\text { 16. The instructor listened and made people feel } \\
\text { heard by trying to include everyone, } \\
\text { paraphrasing, and using non-verbal actions like } \\
\text { eye contact and nodding etc }\end{array}$} & 3 & 0 & 0 & 1 & 1.4 & \multirow[t]{5}{*}{$.299^{\mathrm{a}}$} \\
\hline & 4 & 4 & 5.6 & 6 & 8.2 & \\
\hline & 5 & 17 & 23.6 & 26 & 35.6 & \\
\hline & 6 & 41 & 56.9 & 31 & 42.5 & \\
\hline & 7 & 10 & 13.9 & 9 & 12.3 & \\
\hline \multirow{8}{*}{$\begin{array}{l}\text { 17.The instructor used video or recorded data to } \\
\text { support analysis and learning }\end{array}$} & 0 & 0 & 0 & 28 & 40.6 & \multirow[t]{8}{*}{$<.001^{* a}$} \\
\hline & 1 & 0 & 0 & 3 & 4.3 & \\
\hline & 2 & 0 & 0 & 2 & 2.9 & \\
\hline & 3 & 3 & 4.2 & 5 & 7.2 & \\
\hline & 4 & 10 & 13.9 & 16 & 23.2 & \\
\hline & 5 & 15 & 20.8 & 7 & 10.1 & \\
\hline & 6 & 36 & 50.0 & 7 & 10.1 & \\
\hline & 7 & 8 & 11.1 & 1 & 1.4 & \\
\hline \multirow{6}{*}{$\begin{array}{l}\text { 18.If someone got upset during the debriefing, } \\
\text { the instructor was respectful and constructive in } \\
\text { trying to help them deal with it }\end{array}$} & 0 & 0 & 0 & 4 & 5.6 & \multirow[t]{6}{*}{$.007^{* a}$} \\
\hline & 3 & 0 & 0 & 2 & 2.8 & \\
\hline & 4 & 5 & 6.9 & 12 & 16.7 & \\
\hline & 5 & 19 & 26.4 & 26 & 36.1 & \\
\hline & 6 & 35 & 48.6 & 21 & 29.2 & \\
\hline & 7 & 13 & 18.1 & 7 & 9.7 & \\
\hline \multirow{4}{*}{$\begin{array}{l}19 . I \text { received concrete feedback on my } \\
\text { performance or that of my team based on the } \\
\text { instructor's honest and accurate view }\end{array}$} & 4 & 4 & 5.6 & 5 & 6.8 & \multirow[t]{4}{*}{$.038^{* a}$} \\
\hline & 5 & 14 & 19.4 & 29 & 39.7 & \\
\hline & 6 & 41 & 56.9 & 32 & 43.8 & \\
\hline & 7 & 13 & 18.1 & 7 & 9.6 & \\
\hline 20.The instructor helped explore what I was & 3 & 1 & 1.4 & 1 & 1.4 & $.041^{* a}$ \\
\hline thinking or trying to accomplish at key moments & 4 & 3 & 4.2 & 11 & 15.1 & \\
\hline & 5 & 20 & 27.8 & 24 & 32.9 & \\
\hline & 6 & 36 & 50.0 & 33 & 45.2 & \\
\hline & 7 & 12 & 16.7 & 4 & 5.5 & \\
\hline 21.The instructor helped me learn how to & 4 & 3 & 4.2 & 5 & 6.8 & $<.001^{* a}$ \\
\hline improve weak areas or how to repeat good & 5 & 6 & 8.3 & 28 & 38.4 & \\
\hline performance & 6 & 52 & 72.2 & 29 & 39.7 & \\
\hline & 7 & 11 & 15.3 & 11 & 15.1 & \\
\hline 22.The instructor was knowledgeable and used & 4 & 1 & 1.4 & 2 & 2.7 & $.051^{\mathrm{a}}$ \\
\hline that knowledge to help me see how to perform & 5 & 10 & 13.9 & 23 & 31.5 & \\
\hline well in the future & 6 & 41 & 56.9 & 31 & 42.5 & \\
\hline & 7 & 20 & 27.8 & 17 & 23.3 & \\
\hline 23.The instructor made sure we covered & 4 & 3 & 4.2 & 7 & 9.6 & $.024 * a$ \\
\hline important topics & 5 & 9 & 12.5 & 18 & 24.7 & \\
\hline & 6 & 32 & 44.4 & 34 & 46.6 & \\
\hline & 7 & 28 & 38.9 & 14 & 19.2 & \\
\hline
\end{tabular}

*Significance at p < 0.05; 0-Not Applicable, 1-Extremely Ineffective, 2-Consistently Ineffective, 3-Mostly Ineffective, 4-Somewhat Effective, 5-Mostly Effective, 6-Consistently Effective, 7- Extremely Effective

a: Fisher's exact test was performed if the expected number of observations was less than five. 


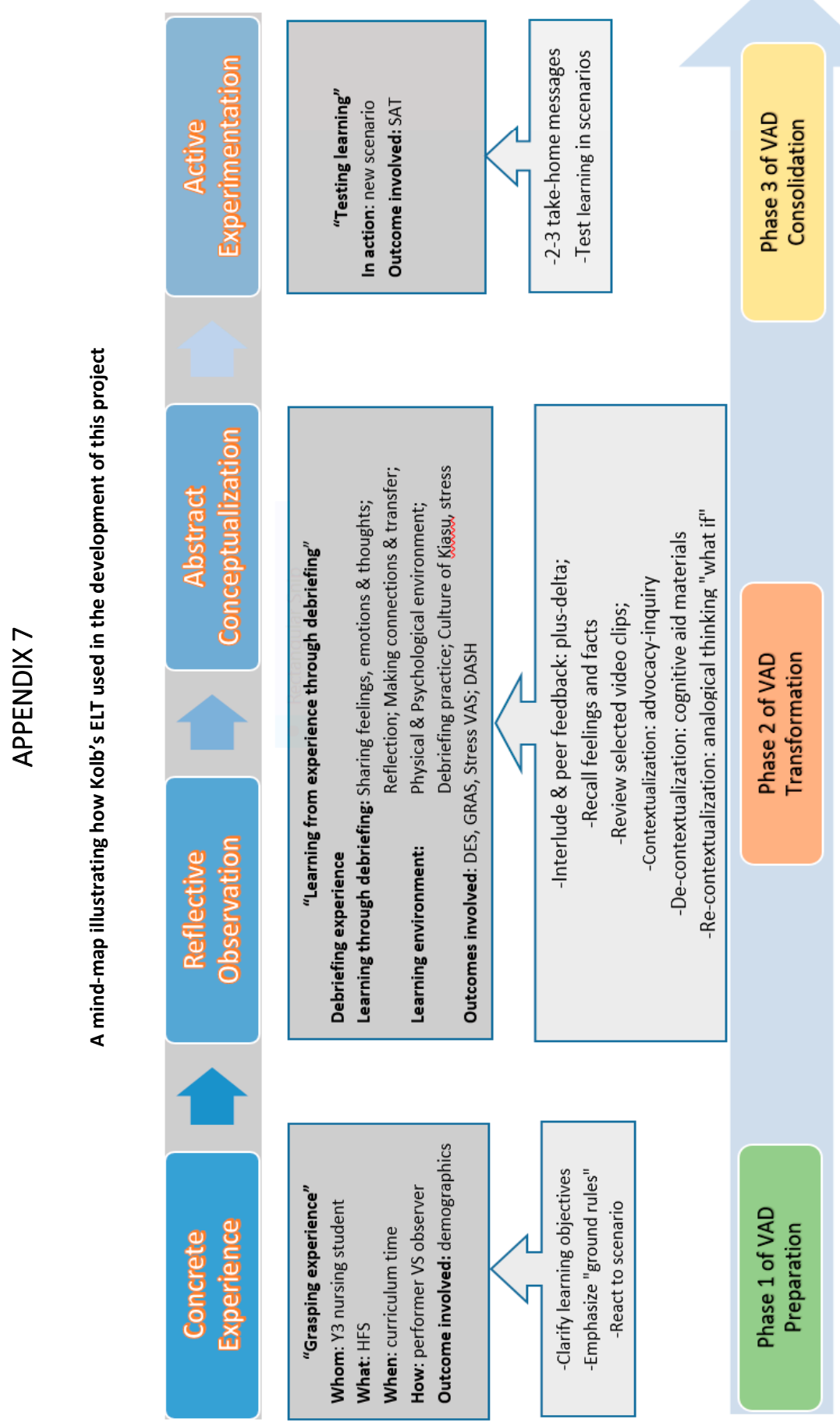




\section{Papers}

The papers associated with this thesis have been removed for copyright reasons. For more details about these see:

http://urn.kb.se/resolve?urn=urn:nbn:se:liu:diva-172784 


\section{FACULTY OF MEDICINE AND HEALTH SCIENCES}

Linköping University medical dissertations, No. 1760, 2020

Division of Nursing Sciences and Reproductive Health,

Department of Health, Medicine and Caring Sciences,

Linköping University

SE-581 83 Linköping, Sweden

www.liu.se 